\title{
Making sense of environmental responsibility: investigating environmental stewardship among retail employees and consumers
}

Citation for published version (APA):

Hensen, N. J. B. (2015). Making sense of environmental responsibility: investigating environmental stewardship among retail employees and consumers. [Doctoral Thesis, Maastricht University]. Maastricht University. https://doi.org/10.26481/dis.20150508nh

Document status and date:

Published: 01/01/2015

DOI:

10.26481/dis.20150508nh

Document Version:

Publisher's PDF, also known as Version of record

Please check the document version of this publication:

- A submitted manuscript is the version of the article upon submission and before peer-review. There can be important differences between the submitted version and the official published version of record.

People interested in the research are advised to contact the author for the final version of the publication, or visit the DOI to the publisher's website.

- The final author version and the galley proof are versions of the publication after peer review.

- The final published version features the final layout of the paper including the volume, issue and page numbers.

Link to publication

\footnotetext{
General rights rights.

- You may freely distribute the URL identifying the publication in the public portal. please follow below link for the End User Agreement:

www.umlib.nl/taverne-license

Take down policy

If you believe that this document breaches copyright please contact us at:

repository@maastrichtuniversity.nl

providing details and we will investigate your claim.
}

Copyright and moral rights for the publications made accessible in the public portal are retained by the authors and/or other copyright owners and it is a condition of accessing publications that users recognise and abide by the legal requirements associated with these

- Users may download and print one copy of any publication from the public portal for the purpose of private study or research.

- You may not further distribute the material or use it for any profit-making activity or commercial gain

If the publication is distributed under the terms of Article 25fa of the Dutch Copyright Act, indicated by the "Taverne" license above, 


\section{Making Sense of \\ Environmental Responsibility}

Investigating Environmental

Stewardship among Retail

Employees and Consumers

Niek Hensen

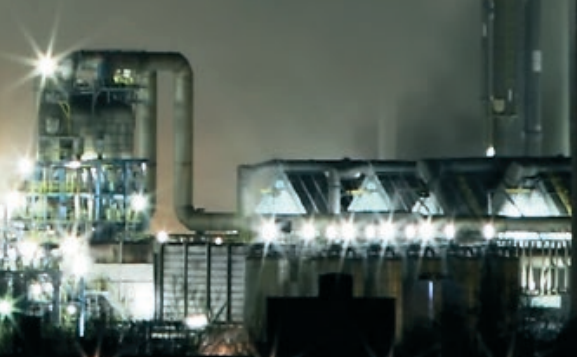

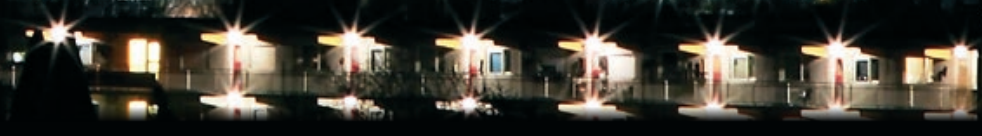
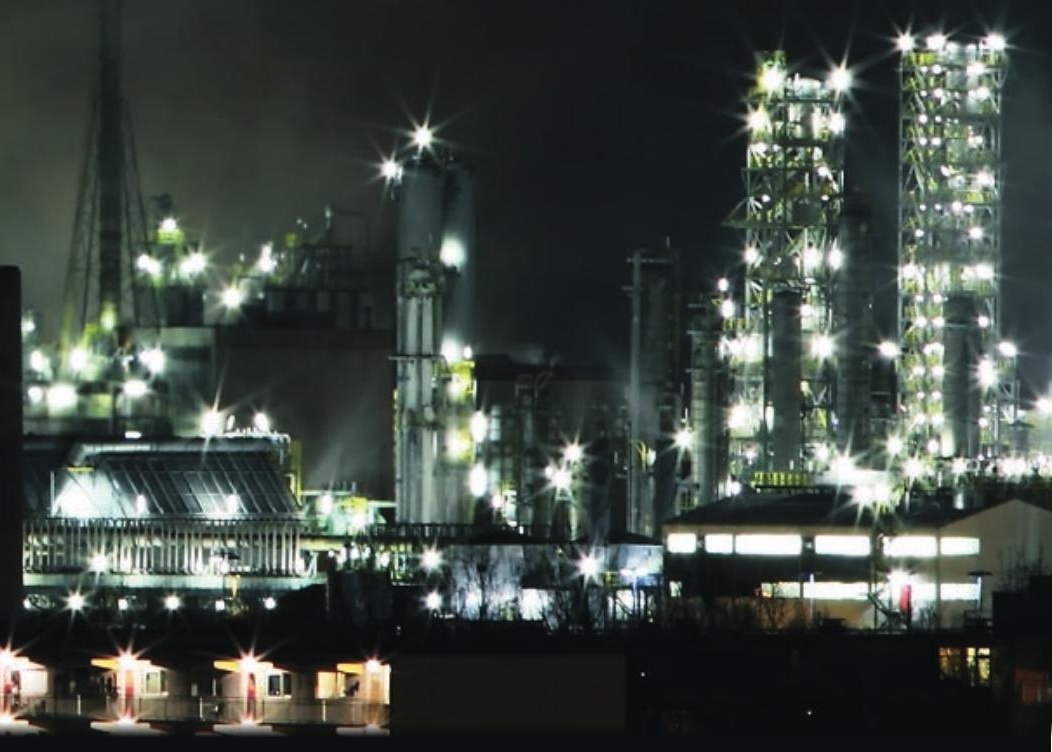
*uxthe
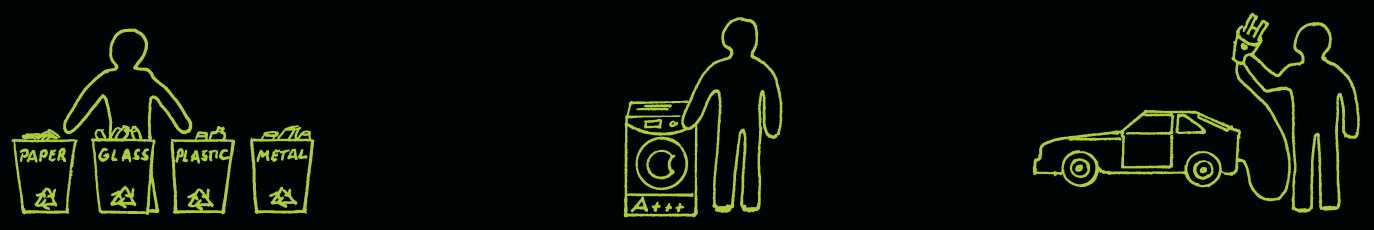
(C) Copyright Niek Hensen, Maastricht 2015

All rights reserved. No part of this publication may be reprinted or utilized in any form or by any electronic, mechanical or other means, no known, or hereafter invented, including photocopying and recording, or in any information storage or retrieval system, without written permission of the copyright owner.

ISBN 9789461594327

Photograph on cover: Roger Coenders

Drawings on cover: Enghard Diehle

Cover design: Datawyse | Universitaire Pers Maastricht

Layout and printing by: Datawyse | Universitaire Pers Maastricht 


\title{
MAKING SENSE OF ENVIRONMENTAL RESPONSIBILITY
}

\author{
Investigating Environmental Stewardship among \\ Retail Employees and Consumers
}

\begin{abstract}
PROEFSCHRIFT
ter verkrijging van de graad van doctor aan de Universiteit Maastricht, op gezag van de Rector Magnificus, Prof dr. L. L. G. Soete volgens het besluit van het College van Decanen, in het openbaar te verdedigen op vrijdag 8 mei 2015 om 12.00 uur

door

Niek Johan Bernard Hensen
\end{abstract}

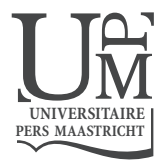




\section{Promotores}

Prof. dr. J. C. de Ruyter

Prof. dr. M. G. M. Wetzels

\section{Beoordelingscomissie}

Prof. dr. J. G. A. M. Lemmink (voorzitter)

Prof. dr. S. P. Gudergan (Newcastle Business School, Australia)

Prof. dr. P. Matthyssens (Universiteit Antwerpen, België)

Prof. dr. J. Semeijn 


\section{Table of Contents}

$\begin{array}{ll}\text { List of Figures } & 7\end{array}$

$\begin{array}{ll}\text { List of Tables } & 7\end{array}$

CHAPTER 1 Introduction 9

1.1 The Environmental Problem 11

1.2 A Marketing Research Perspective on the Environmental Problem 12

1.3 Strategies to Stimulate Pro-environmental Action 15

1.4 The Stewardship Concept 16

1.5 Dissertation objectives and contributions 19

$\begin{array}{ll}1.6 \text { Dissertation outline } & 20\end{array}$

CHAPTER 2 Walking the Green Talk: How Store Managers Lead the Way to Store Environmental Stewardship Climate (SENS-Climate) 23

Abstract $\quad 24$

2.1 Introduction $\quad 25$

2.2 Conceptual Framework $\quad 27$

2.3 Hypotheses Development 30

2.4 Empirical Study $\quad 35$

2.5 Results $\quad 45$

$\begin{array}{ll}2.6 \text { Discussion } & 47\end{array}$

CHAPTER 3 Me, Myself and Future Generations: The Role of Affinity and Efficacy in the Creation of Consumer Environmental Stewardship (CENS) $\quad 53$

Abstract $\quad 54$

3.1 Introduction $\quad 55$

3.2 Conceptualizing Consumer Environmental Stewardship (CENS) 57

3.3 Antecedents and Consequences of CENS: Hypotheses Development 59

$\begin{array}{ll}3.4 \text { Study } 1 & 61\end{array}$

3.5 Exploring Potential Interaction Effects between Affinity with Future

Generations (AFG) and Perceived Consumer Efficacy (PCE) 69

$\begin{array}{ll}3.6 \text { Study } 2 & 70\end{array}$

$\begin{array}{ll}3.7 \text { Study } 3 & 75\end{array}$

$\begin{array}{ll}3.8 \text { Discussion } & 78\end{array}$ 
CHAPTER 4 Conclusion $\quad 83$

4.1 Introduction $\quad 85$

4.2 Synopsis $\quad 85$

4.3 Discussion and future research directions $\quad 87$

4.5 Implications for practice and public policy 91

4.6 A final thought $\quad 93$

$\begin{array}{ll}\text { References } & 95\end{array}$

$\begin{array}{ll}\text { Appendix A } & 105\end{array}$

$\begin{array}{ll}\text { Appendix B } & 107\end{array}$

$\begin{array}{ll}\text { Appendix C } & 115\end{array}$

$\begin{array}{lr}\text { Valorization Addendum } & 119\end{array}$

Summary $\quad 125$

$\begin{array}{lr}\text { Samenvatting } & 129\end{array}$

Dankwoord 133

$\begin{array}{ll}\text { Curriculum Vitae } & 137\end{array}$ 


\section{List of Figures}

Figure 1.1: Two Routes for Marketing Research to Contribute to Pro-

Environmental Consumption Goals

Figure 2.1: Conceptual Framework of Antecedents and Outcomes of SENSClimate

Figure 2.2: Example Stem Scenario 1

Figure 3.1: Results Conceptual Model

Figure 3.2: Stimuli for Affinity with Future Generations (AFG)

Figure 3.3: Stimuli for Perceived Consumer Efficacy (PCE) 72

Figure 3.4: Visual Representation of Interaction between AFG and PCE for Study 2

Figure 3.5: Visual Representation of Interaction between AFG and PCE for Study 3

Figure B1: Stem Scenario 2

Figure B2: Stem Scenario 3

Figure B3: Stem Scenario 4

Figure B4: Stem Scenario 5

Figure B5: Stem Scenario 6

Figure B6: Stem Scenario 7

Figure B7: Stem Scenario 8

\section{List of Tables}

Table 1.1: Overview of Empirical Studies 21

Table 2.1: Means, Standard Deviations and Intercorrelations 44

Table 2.2: Multilevel Regression Analyses of Antecedent-SENS-Climate Relationships

Table 2.3: Results of Monte Carlo Estimation of Indirect Effects 47

Table 3.1: Items Consumer Environmental Stewardship (CENS) Scale 63

Table 3.2: Study 1: Items Pro-environmental Behavior 64

Table 3.3: Study 1: Measures and Items $\quad 66$

Table 3.4: Study 1: Intercorrelations 67

Table A1: Measures and Measurement Criteria $\quad 105$

Table C1: $\quad$ Results Exploratory Factor Analysis Pre-Study $1 \quad 116$

Table C2: $\quad$ Results Confirmatory Factor Analysis Pre-study $2 \quad 118$ 

CHAPTER 1

Introduction 

"If we have the belief that people will not take responsibility they will prove us right"

Peter Block (1993, p. 209)

\subsection{The Environmental Problem}

In the past decades environmental problems such as pollution, resource depletion and global warming have become a major concern across the globe. Environmental degradation is seen as one of the biggest threats to the achievement of sustainability (UNEP, 2011): the goal to ensure that humanity can meet "the needs of the present without compromising the ability of future generations to meet their own needs" (World Commission on Environment and Development, 1987, p. 8). Despite continuous efforts of government institutions, organizations and citizens to prevent and/or reduce environmental degradation the problem is still growing, making sustainability seem like an unachievable goal at the moment (Prothero et al., 2011). It is therefore no surprise that the prevention and reduction of environmental problems remains one of the main objectives for (inter)governmental organizations such as the United Nations, the European Union and the OECD and is a major concern among citizens across the globe (European Commission, 2008; OECD, 2011; UNEP, 2011; Urien \& Kilbourne, 2011).

One of the key causes of the current environmental problems is the fact that humanity consumes much more resources than the earth's regenerative capacity can handle (Peattie \& Peattie, 2009). This has led to the realization that consumption behaviors will have to change. As a result (inter)governmental organizations concentrate many of their environmental initiatives directly on consumers. These initiatives mainly focus on the promotion of a wide range of pro-environmental behaviors such as reducing water and energy use, stimulating recycling efforts, changing transportation choices and fostering the uptake of "green" products (e.g., products that are more environmentally friendly because they are organic or use less energy) (European Commission, 2008; OECD, 2011; UNEP, 2011). At the same time (inter)governmental organizations recognize the importance of companies, and especially retailers in the promotion of pro-environmental consumer behaviors: "Retailers are in a strong position to influence more sustainable consumption through their own operations, supply chains and consumer behavior" (European Commission, 2008, p. 8). They are in the ideal position to promote the purchase of green products and inform consumers about pro-environmental solutions (BIO Intelligence Service, 2009). However, only ten percent of European consumers thinks retailers do a lot for the environment (The Gallup Organisation, 2009), so despite the growing number of green initiatives that are instigated by retailers there still is a lot of room for improvement. 
Marketing research can thus play a valuable role in the achievement of environmental goals related to consumption by exploring effective routes to promote environmental responsibility among retailers and consumers (see Figure 1.1). In this dissertation we aim to contribute to this goal by (1) examining how retailers can stimulate their employees to take more responsibility for achieving environmental goals and how this affects sales of green products, and (2) examining how marketing communication messages that aim to increase the relevance of environmental protection can be used to stimulate consumers' sense of environmental responsibility and in turn their pro-environmental behavior.

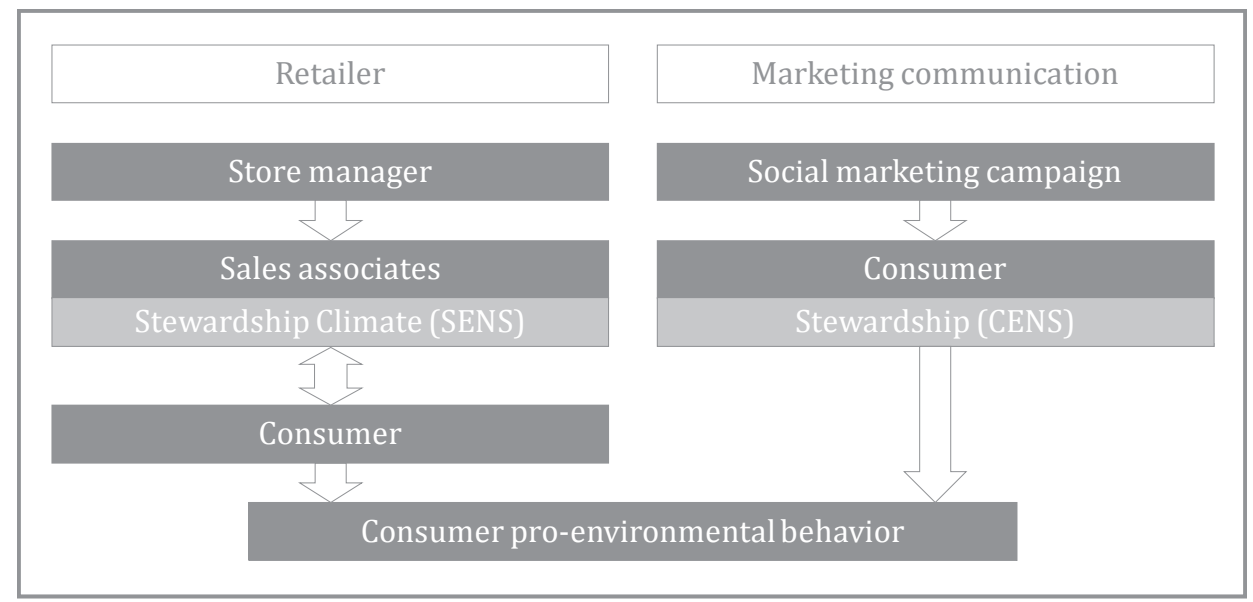

Figure 1.1: Two Routes for Marketing Research to Contribute to Pro-Environmental Consumption Goals

\subsection{A Marketing Research Perspective on the Environmental Problem}

Researchers in the fields of marketing and consumer psychology have long studied the stimulation of pro-environmental behavior, which has been defined as behavior "that harms the environment as little as possible, or even benefits the environment" (Steg \& Vlek, 2009, p. 309). Still it has proven difficult to stimulate proenvironmental behaviors on a large scale. Although recycling efforts have become common practice in many countries, other pro-environmental behaviors such as the choice for environmentally friendly transportation modes and the adoption of green products are less popular or only customary among specific consumer segments (Cleveland, Kalamas, \& Laroche, 2012; Whitmarsh \& O'Neill, 2010). One of the main barriers for consumers to perform pro-environmental behaviors more often are the associated costs. Consumers (often mistakenly) perceive proenvironmental behaviors to cost more money, more effort, or result in lower quali- 
ty solutions and worse performance (Gleim, Smith, Andrews, \& Cronin Jr, 2013; Luchs, Naylor, Irwin, \& Raghunathan, 2010; Olson, 2013). As a consequence it is often difficult for retailers to increase green sales while keeping consumer satisfaction and overall sales performance stable or even improve them. The choice for pro-environmental behavior, whether for a consumer or retailer, is thus often perceived to be a choice that benefits long-term collective interests at the cost of immediate self-interests.

This observation has led multiple marketing scholars to conclude that the environmental problem is inherently a social dilemma situation (Biel \& Thøgersen, 2007; Pieters, Bijmolt, van Raaij, \& de Kruijk, 1998). A social dilemma is a social situation defined by two features: 1 ) the situation causes each individual to receive bigger benefits for a self-serving choice than for a socially cooperative choice, regardless of the choices by other individuals; and 2) all individuals receive bigger benefits if all individuals cooperate compared to a situation where all individuals make a self-serving choice (Dawes, 1980). For example living in a town in a valley, which suffers from smaller or larger amounts of smog depending on the amount of exhaust fumes produced by its inhabitants, it might be personally beneficial to take the car when one needs to get to the other side of town because it is faster and less tiresome than biking. However, if everyone takes the car the levels of smog will increase, which is detrimental for the health of all inhabitants including the decision maker. Although it is difficult to promote cooperative choices in such situations, previous research has shown that they can be fostered by for example emphasizing the direct connection and similarities between the individual and the collective they are part of, or communicating social norms that prescribe cooperative behaviors as appropriate (Gupta \& Ogden, 2009; Thøgersen, 2008).

In the1960s and 1970s the environmental problem was often associated with "local" problems such as soil, water and local air pollution, littering, and regional water and energy shortages during a hot season (Dunlap \& Jones, 2002; Zimmer, Stafford, \& Stafford, 1994). Because of the local nature of the problems all of these situations can be regarded as social dilemma situations in the traditional sense. Later, in the 1980s and 1990s the environmental problem got associated with issues of a more global nature, such as more widespread air pollution that resulted in acid rain, problems with the ozone layer and potentially climate change (Dunlap \& Jones, 2002; Peattie, 2001). While some of the described problems have been reduced through timely government regulations and technological innovations, the most common issues associated with the environmental problem today, such as climate change, deforestation and the large scale depletion of resources such as precious metals, are more difficult to battle because they are truly global in nature. Concluding one can say that the development of issues that are associated with the environmental problem went from local and visible to more global and abstract. This has made the environmental problem more complex to understand and at the same time made it more difficult to see when the negative effects of these envi- 
ronmental problems will kick in and who will suffer from them (Dunlap \& Jones, 2002; Kollmuss \& Agyeman, 2002). This development has contributed to the view that the negative outcomes of our self-serving environmentally unfriendly behaviors today are unlikely to affect collective welfare in the short-term, even if all individuals choose to make self-serving choices instead of cooperative ones. (Kortenkamp \& Moore, 2006; Wade-Benzoni, 1999). Thus today's consumers (as well as retailers) do reap the short-term benefits of their irresponsible self-serving behaviors, but future generations are most likely to face the negative environmental consequences.

When considering these developments in views on the environmental problem it is not completely accurate to describe the environmental problem as the traditional social dilemma situation. While the first characteristic of a social dilemma situation (i.e., that each individual receives bigger benefits for a self-serving choice than for a socially cooperative choice, regardless of the choices by other individuals), is still applicable, the second characteristic of a social dilemma situation (i.e., that all individuals receive bigger benefits if all individuals cooperate compared to a situation where all individuals make a self-serving choice), might or might not apply depending on the time lag between our irresponsible actions and the resulting negative effects (e.g., global warming and resulting floods). Researchers have thus recently argued that the environmental problem can better be described as an intergenerational dilemma: that is, "decisions in which the interests of present decision makers are in conflict with those of future others" (Wade-Benzoni \& Tost, 2009 , p. 166). The intergenerational dilemma is a social situation that is defined by two features: 1) "the present generation has complete unilateral decision making power over decisions" that affect future generations; and 2) the present generation is "removed from the social exchange context over time", which means that the present generation does not suffer from the negative or benefit from the positive collective consequences of its current cooperative decisions (Wade-Benzoni \& Tost, 2009, p. 166). This intergenerational perspective on social dilemma situations emphasizes the importance of the inter-temporal factors that influence decision making as well as the interpersonal factors that are emphasized in social dilemma research. One could argue that the environmental problem is not a real intergenerational dilemma either since environmental degradation and resource depletion do have their effects in the short-term, even if they are small. It probably depends on your point of view on the environmental problem (i.e., looking from a local or global perspective) whether the social dilemma or intergenerational dilemma perspective is more appropriate to describe the environmental problem. Despite the limitations associated with both dilemma perspectives on the environmental problem, they help us to understand the trade-offs consumers (and retailers) face when deciding to act pro-environmentally or not and suggest multiple useful ways to help overcome such trade-offs. All in all these dilemma perspectives on the environmental problem show that research can benefit from consider- 
ing social influences and taking a long-term perspective when searching for ways to successfully promote pro-environmental behaviors. In this dissertation we build on this insight.

\subsection{Strategies to Stimulate Pro-environmental Action}

There are multiple strategies to increase pro-environmental consumption. The first category, called structural strategies, aims to change contextual factors that influence the attractiveness of pro-environmental actions (Steg \& Vlek, 2009). Structural strategies often rely on extrinsic forms of motivation that help to overcome the costs associated with pro-environmental behaviors. These strategies can take the shape of laws or regulations that force consumers and companies to act more pro-environmentally. Alternatively they can entail tax reductions and subsidies that reduce or eliminate the real and imagined costs associated with proenvironmental behaviors. Marketing mostly plays a limited role in the execution of such strategies, but is used to inform the public when strategies are introduced and what they entail. Structural strategies often have the desired result in terms of stimulating pro-environmental behaviors, even if the pro-environmental behaviors come at a cost (European Commission, 2008; OECD, 2011). However, they are mostly costly to implement or enforce and the positive effects of some of these strategies such as tax reductions and subsidies only last as long as the financial compensation is offered (Steg \& Vlek, 2009). Besides, tax reductions and subsidies stimulate a focus on the financial aspect of pro-environmental behaviors, which reduces feelings of personal responsibility (Prothero et al., 2011; Thøgersen \& Crompton, 2009). Additionally, financial stimuli can make people see proenvironmental behavior as personal optimization problems; which will trigger them to optimize personal gains in the absence of subsidies, hence, costly proenvironmental behaviors are avoided (Kouchaki, Smith-Crowe, Brief, \& Sousa, 2013; Tenbrunsel \& Messick, 1999)

The second category called informational strategies often relies on marketing practices and aims to change pro-environmental behavior by increasing knowledge or changing attitudes, norms and perceptions (Steg \& Vlek, 2009). Informational strategies can for example take the shape of awareness campaigns that aim to inform people of the benefits of pro-environmental behaviors or try to persuade people to take pro-environmental actions through the use of role models. One of the downsides of many information strategies such as awareness campaigns is their limited ability to help people overcome the costs that are associated with pro-environmental behaviors (Steg \& Vlek, 2009). However, there are information strategies that aim to foster people's intrinsic motivation. These strategies hold potential as stimulating an intrinsic preference for a pro-environmental behavior facilitates its adoption regardless of the associated costs (Messick, 1999). 
Previous research has shown that developing responsibility is essential for the creation of an intrinsic interest in a behavior and promotes the long-term adoption of that behavior (Tenbrunsel \& Messick, 1999). In this dissertation we build on this insight and try to contribute to marketing research on environment oriented informational strategies by examining how the stimulation of a personal sense of responsibility for the environment and its beneficiaries can be used to stimulate pro-environmental action, in a retail and a consumer context.

\subsection{The Stewardship Concept}

We take the stewardship concept as the theoretical starting point to study the promotion of pro-environmental actions as it holds the promise of helping to create a sense of personal responsibility for a larger entity that goes so far that an individual willingly subjugates his/her personal interests for the benefit of that bigger entity and the collective it serves (Block, 1993; Hernandez, 2012). In our studies we focus on the environment and its beneficiaries as the bigger entity.

\subsubsection{The History and Essence of Stewardship}

The stewardship concept has a long history and is over two thousand years old (Block, 1993; Groesbeck, 2001; Worrell \& Appleby, 2000). Stewardship is associated with situations where land-owners (e.g., a king or lord), took on a person, the steward, to manage their land in the land-owners' absence. This was especially relevant in times of war when the land-owner left his estate behind to fight wars in countries far away. Stewards were expected to manage the land in the best interest of the owner instead of their personal gain. Preferably the value of the land or the benefits derived from it would have increased by the time the owner returned (Groesbeck, 2001). The steward was left unsupervised, but held the land in trust, was expected to take responsible care of it and was held accountable for the land's development.

In present times stewardship as a concept is used in a variety of contexts although the essence of its original meaning is preserved. This is most evident in the literature on land management where stewardship is often associated with the responsible use and caretaking of forests and agricultural lands so that current generations can reap the benefits they provide while simultaneously preserving these forests and agricultural lands for future generations (Burger \& Gochfeld, 2001; Worrell \& Appleby, 2000). In health care, stewardship is often linked to programs that aim to promote more responsible prescription and use of antibiotics to ensure their effectiveness in the future (Aldeyab et al., 2014; Tamma, Holmes, \& Ashley, 2014). Furthermore, in public debt management stewardship refers to responsible management of public debt, to ensure that future generations do not 
end up paying for our current living standard (Hart \& Cornia, 1994). The governance and management literature refers to stewardship as the responsible management of organizations to make sure that shareholders, society at large and future generations of employees benefit from an organization's actions instead of being harmed by the manager's aim for profits or personal benefits (Block, 1993; Davis, Schoorman, \& Donaldson, 1997). The recurring theme across these different contexts is that stewardship as a concept refers to taking responsibility and accountability for a bigger entity, even if this comes at a personal cost, so that its value is retained for all stakeholders including those in the future. Compared to its original meaning the main development comes from the replacement of the landowner's estate by "a bigger entity", which can take the shape of an organization, future generations, society or even the environment (Block, 1993; Worrell \& Appleby, 2000).

\subsubsection{Towards Environmental Stewardship}

In our research we build on theorizing about the stewardship concept as it developed in the governance and management literature. In this literature the stewardship concept was initially introduced as an opposing view to agency theory (Donaldson \& Davis, 1991). Agency theory originates in the economics literature and is built on the assumption that people are lazy, passive and lack an intrinsic motivation to work, therefore, principals should focus on exerting control and providing extrinsic motivation to make sure that managers act in the best interest of the company instead of their self-interest (Tosi, Brownlee, Silva, \& Katz, 2003). Contrary to this view the stewardship perspective originates in the psychology literature and proposes that people are intrinsically motivated to work and have a high capacity for assuming responsibility, principals should thus arrange the work environment in such a way that intrinsic motivation is optimized (Davis et al., 1997).

At first, research on the stewardship concept mainly focused on an organizational level of analysis. Stewardship and agency were contrasted with the aim to validate which of the two perspectives was superior for improving performance (Donaldson \& Davis, 1991; Tosi et al., 2003). Later, Davis et al. (1997) proposed that the work-environment could influence whether managers would act as stewards or agents. Based on the ideas advanced by these authors the focus shifted from proving which theory was correct to examining which perspective was better able to explain organizational performance or actions under different contextual circumstances (Le Breton-Miller, Miller, \& Lester, 2011; Lee \& O'Neill, 2003; Wasserman, 2006). As more nuance entered the discussion on stewardship and agency, the two concepts were increasingly often described as two ends of a scale (Martynov, 2009). Recently some scholars stepped away from the contrast with agency theory and repositioned their focus on the development of stewardship as a 
stand-alone concept with its own psychological basis (Hernandez, 2008, 2012). Gradually, as the stewardship concept developed the focus also shifted from organizational level performance and the motivation of top management towards the motivation of employees at any level of the organization (Hernandez, 2008; Martynov, 2009).

Hernandez (2008) focused on the importance of leaders as role-models in the promotion of stewardship among followers. She defined stewardship "as the attitudes and behaviors that place the long-term best interest of a group ahead of personal goals that serve the individual's self-interest" (Hernandez, 2008, p. 122). Instead of focusing on the organization as the group (bigger entity), she went a step further by posing that stakeholder welfare is the ultimate goal of an organization and therefore also of its employees. More specifically, she posed that employees need to take personal responsibility for the effects of organizational actions on internal and external stakeholders. This expansion in the conceptualization of stewardship served as a basis for the development of environmental stewardship as a concept by de Ruyter, de Jong and Wetzels (2009). Based on the premise that stewardship entails taking responsibility for an organization's stakeholders they argued that a company's employees should also consider the environmental impact of organizational actions. Accordingly, they defined environmental stewardship for teams in a B2B service context as: "a collectively held sense of responsibility toward the environment, as reflected in the policies, procedures, and actions used during employee encounters with customers" (de Ruyter et al., 2009, p. 472).

While we build on these developments of the stewardship and environmental stewardship concept, we will additionally consider later developments as advanced by Hernandez (2012). Whereas she examined the impact of leader behaviors on stewardship development among employees in her 2008 paper, Hernandez (2012) went a step further in the theoretical development of the stewardship concept by exploring the psychological processes that drive stewardship development. In her paper, she defined stewardship as "the extent to which an individual willingly subjugates his or her personal interests to act in protection of others' long-term welfare" and argued that it can be driven through felt obligations (both relational and ideological) (Hernandez, 2012, p. 174). This means that stewardship can develop without formal written agreements or contracts. We argue that this view on stewardship makes it possible to extend the stewardship concept beyond the organizational boundaries it has previously been studied within and makes it applicable for a consumer context. All in all we pose that the stewardship concept can be of added value in the exploration of ways to stimulate pro-environmental actions through the creation of a personal sense of responsibility in both a retail and consumer setting. 


\subsection{Dissertation objectives and contributions}

Based on the insight that changing consumption levels is imperative to achieve sustainability and the conclusion that supply and demand side measures are needed to achieve this (OECD, 2011), we examine two ways in which marketing can be used to stimulate pro-environmental consumption: (1) we examine how retailers can stimulate their employees to take more responsibility for achieving environmental goals and how this affects sales of green products, and (2) we examine an approach that can be used in marketing communications and aims to increase the relevance of environmental protection to stimulate consumers' sense of environmental responsibility and in turn their pro-environmental behavior. In our examination of these topics we make use of the stewardship concept as described above.

Although stewardship has quite often been associated with environmental preservation in practice, the developments of a theoretical framework around the stewardship concept have hardly been used to explore ways to increase proenvironmental actions. To the best of the author's knowledge there is only one paper by de Ruyter et al. (2009) that did and examined environmental stewardship in a B2B service context. Since the stewardship concept holds the promise of helping people deal with trade-offs between personal and collective benefits, such as those often associated with pro-environmental actions, we aim to explore its potential in the promotion of environmental responsibility in two other contexts: (1) among retail personnel and (2) among consumers. More specifically, we aim to contribute to (marketing) research on the environmental problem and the stewardship concept by bringing these topics together and developing the concepts of Store Environmental Stewardship climate (SENS-climate) in chapter 2 and Consumer Environmental Stewardship (CENS) in chapter 3.

More specifically, chapter 2 addresses the research question: how can retailers facilitate the successful implementation of environmentally responsible strategies in stores where sales associates increasingly often face situations in which they have to balance a diversity of consumer demands and their companies', often seemingly conflicting, performance objectives (e.g., financial performance, sales targets, customer service and environmental accountability standards)? Our main contribution in this chapter stems from the introduction of SENS-climate as a mechanism that helps sales associates to strike a balance between their increasingly diverse objectives and pay more attention to environmental responsibility goals. We operationalize SENS-climate as a set of three distinct but interlinked collective beliefs and behaviors that are founded in perceived group norms that promote "green" sales and embody the interests of the retailer's 3 main stakeholders: the immediate work-unit, the retailer as a whole and the customer. Additionally we examine how a SENS-climate is shaped through the operational leader's taskoriented actions (environmental orientation and variability in this orientation) while also accounting for the leader's relationship-oriented behavior. Finally this 
chapter also explores the effects of perceived SENS-climate on sales associates' performance with regard to: (i) perceptions of whether they act "green"; (ii) traditional performance indicators, and; (iii) environmental performance indicators.

In chapter 3 we examine an approach that can be used in marketing communications aimed at promoting pro-environmental behaviors. More specifically, we address the research question; how can we encourage consumers' behavioral decisions that support environmental resource preservation through stimulation of personal responsibility, thus overcoming short-term personal costs in favor of longer term collective benefits? To address this question we develop the concept of CENS and empirically assess its impact as the responsibility mechanism through which consumers can be stimulated to act more pro-environmentally and in the service of long-term collective benefits. Our main contribution to the stewardship literature stems from our demonstration that the stewardship concept can be applied to the consumer level of responsibility despite the absence of formal contractual relationships that are present in the organizational settings where the stewardship concept has hitherto been applied. Additionally, we contribute to previous research by identifying relevant antecedents and consequences of CENS and empirically testing the conceptual framework that was developed. In this framework we focus on two antecedents. The first is aimed at increasing the relevance of taking environmental responsibility: Affinity with Future Generations (AFG), which is defined as the extent to which an individual feels empathic towards and connected with future others (Wade-Benzoni, 2008). The second is aimed at increasing beliefs of efficacy: Perceived Consumer Efficacy (PCE); the idea that one can affect the state of the environment as an individual (Do Paço, Alves, Shiel, \& Filho, 2013; Moisander, 2007; Webster Jr, 1975). Besides examining their main effects, we also assess the interaction between AFG and PCE. Finally, chapter 3 is also used to explore the consequences of CENS in the shape of a mix of pro-environmental consumer behaviors.

\subsection{Dissertation outline}

To meet the promise of our previously discussed contributions, we proceed as follows. In Chapter 2: "Walking the Green Talk: How Store Managers Lead the Way to Store Environmental Stewardship Climate (SENS-Climate)" we explore how retailers can facilitate the successful implementation of environmentally responsible strategies in stores. More specifically, we examine the influence of store managers' actions on sales associates' perceptions of the SENS-climate and their performance on margins, as well as sales of green and regular products. We test our conceptual model in the context of an electronics retailer because electronic devices have a serious impact on the environment during their whole life-time and form a large part of the environmental burden produced by consumers (Mills \& Schleich, 
2010). Additionally, sales associates can have a big influence on the consumers' product choice and their way of using the product, sales associates thus have an important share in the environmental impact of a consumers electronics purchases. We use as survey design to test our model.

In Chapter 3: Me, Myself and Future Generations: The Role of Affinity and Efficacy in the Creation of CENS (Consumer Environmental Stewardship) we explore how consumers' pro-environmental behaviors can be fostered through the stimulation of personal responsibility. More specifically, we examine how the stimulation of consumers' AFG and PCE can help to promote CENS and subsequently proenvironmental behaviors. Since we take an intergenerational view on environmental stewardship and want to limit external influences, we choose to focus on a target audience between 18 and 30 years old, commonly referred to as generation $Y$ (Burns, Reid, Toncar, Anderson, \& Wells, 2008; Kumar \& Lim, 2008). We use a survey and two experiments to test our model. Table 1.1 provides an overview of the empirical studies that are discussed in chapter 2 and chapter 3

Finally, Chapter 4 aims to come to an overall conclusion. It starts with a synopsis of findings from the two empirical studies described in chapter 2 and chapter 3. This is followed by a discussion of these findings with a focus on similarities, differences and other noteworthy links between the empirical studies, which ends with some additional suggestions for future research. Additionally, it includes a separate section with practical implications for management and public policy, before finishing with a final thought.

Table 1.1: Overview of Empirical Studies

\begin{tabular}{lll}
\hline & Chapter 2 & Chapter 3 \\
\hline Study & Walking the Green Talk: How Store & Me, Myself and Future Generations: \\
& Managers Lead the Way to Store & The Role of Affinity and Efficacy in the \\
& Environmental Stewardship Climate & Creation of CENS (Consumer \\
& (SENS-Climate) & Environmental Stewardship) \\
Objective & Explore how retailers can facilitate the & Explore how consumers' pro- \\
& successful implementation of & environmental behaviors can be \\
& environmentally responsible strategies & fostered through stimulation of \\
in stores & personal responsibility \\
Focal Concept & Store Environmental Stewardship & Consumer Environmental Stewardship \\
& Climate (SENS-Climate) & (CENS) \\
Research Context & Electronics retailer & Consumers \\
& (store managers and sales associates) & (generation Y: people aged 18-30 years \\
& & old) \\
Research Design & Qualitative and quantitative & Quantitative \\
& Interviews and survey design & Survey and experimental designs \\
& Subjective and objective data & Subjective data \\
& Confirmatory Factor Analysis & Exploratory Factor Analysis \\
Hierarchical linear regression modeling Confirmatory Factor Analysis & & Structural Equation Modeling (PLS) \\
& & ANovA \\
\hline
\end{tabular}





\section{CHAPTER 2}

Walking the Green Talk:

How Store Managers Lead the Way to Store Environmental Stewardship Climate (SENS-Climate) 


\begin{abstract}
Retailers increasingly recognize that environmental accountability is a strategic imperative. However, little research has investigated how to walk the green talk or identified factors that facilitate successful implementation of environmentally responsible strategies in stores. We propose that a store manager's ability to lead by example can support this process by fostering a climate for store environmental stewardship (SENS-climate). Thus, we examine the influence of store managers' actions on sales associates' perceptions of the SENS-climate and their performance on margins, as well as sales of green and regular products. More specifically, we demonstrate that store managers can foster a SENS-climate by prioritizing environmental responsibility in operational decisions (high environmental orientation) and adopting transformational leadership practices. These positive effects are strengthened by store manager-sales associate dyadic tenure. In contrast, when store managers display high variability in environmental orientation this hinders the development of SENS-climate perceptions by sales associates.
\end{abstract}

Keywords: environmental stewardship; store climate; transformational leadership; green products 


\section{$2.1 \quad$ Introduction}

Recent demands for environmentally responsible business practices from customers, investors and regulatory bodies have advanced environmental accountability as a strategic imperative (Leonidou, Katsikeas, \& Morgan, 2013). Talking green, such as the lip service frequently voiced in annual sustainability reports, no longer seems sufficient. Companies need to substantiate their eco-friendly pledges by embedding environmental responsibility in their day-to-day operations and interactions with customers (Porter \& Kramer, 2006). This seems particularly pertinent for retailers, whose environmental impact mainly resides in the "use phase" of products sold (Prindle, 2010). Household appliances, for instance, account for the vast majority of consumer electricity use (Mills \& Schleich, 2010). It is no surprise, therefore, that major retailers, such as WalMart, Marks \& Spencer, Best Buy, and Tesco have come to recognize that a focus on green products holds the promise of competitive advantage. As a result, they are offering an increasingly wide range of environmentally friendly alternatives to their customers (Brady, Hendry, \& Kanchwala, 2010).

While sales of compact fluorescent light bulbs and hybrid cars have flourished in the US and Europe, many green products have obtained limited market shares (Luchs et al., 2010). The success of those green products that are thriving is often based on strict government policies or tax related incentive schemes (OECD, 2008), that compensate for low quality perceptions or premium prices (Griskevicius, Tybur, \& van den Bergh, 2010; Olson, 2013). Most newly launched green appliances, for example, A++ labeled refrigerators, are sold at high price premiums, limiting interest to small, more affluent and environmentally conscious segments. Despite substantial reductions in energy use and the related usage costs, these A++ labeled refrigerators only made up 3\% of refrigerator sales in their fifth year on the European market (Nipkow, Josephy, Bush, \& Michel, 2012). For many consumers, product choice is still predominantly price-based in many markets (Euromonitor International, 2010b).

For retailers this situation presents challenges at the operational level. Sales associates face difficulties in balancing increasing diversity in consumer demands against their companies', seemingly conflicting, performance objectives (e.g., financial performance, sales targets, customer service and environmental accountability standards). When faced with such operational challenges, employees often derive guidance from their work-unit's collective appraisal of priority setting and the kind of behaviors likely to be rewarded (Zohar \& Luria, 2004). That is, employees search for a sense of "the way we do things around here". This in turn, is often based on observing their operational manager's decisions and actions, rather than formal policies (Yaffe \& Kark, 2011). Despite the emerging importance of balancing environmental prerogatives with other operational demands in those situations where they are in conflict (e.g., increasing sales of green products while meeting 
demands of cost-oriented customers), relatively little is known about how store managers can guide sales associates in striking such a balance (Lai, Cheng, \& Tang, 2010).

To address this issue, we turn to theorizing on work-unit climate. The notion of "climate" as a collective sense-making process has always been inextricably related to a specific strategic focus. As Schneider, White, and Paul (1998, p. 151) state, "a climate must be a climate for something". As the strategic focus on environmental accountability becomes an operational balancing act, stewardship theory can assist us in how this plays out on the shop floor. We argue that environmental stewardship can be the focal point (that certain "something" in the words of Schneider et al.) for work-unit climate. Support for this conceptual merging comes from de Ruyter et al. (2009) and Hernandez (2012), who stress the importance of collective processes and the role of managers in developing shared perceptions that steer employees towards behavior that takes responsibility for the sake of the welfare of multiple stakeholders.

An important contribution of this paper is, therefore, to introduce Store Environmental Stewardship climate (SENS-climate). We posit that SENS-climate becomes manifest in three distinct but interlinked collective beliefs and behaviors that are based on perceived group norms that facilitate "green" sales and reflect the interests of the 3 main stakeholders: the immediate work-unit, the company and the customer. Hence, we specify the following 3 facets of SENS-climate: (1) a sense of shared responsibility towards the environment, reflected in daily activities and actions focused on meeting personal and store level performance targets; (2) taking initiatives to improve the ways in which the store contributes to reducing the company's environmental impact, and; (3) efforts to promote environmentally responsible choices amongst a wider range of customers while trying to meet their demands.

A second contribution is in defining how SENS-climate is shaped through operational leaders' influence. The dominant emphasis in previous research has been on studying the relationship aspects of leaders in fostering stewardship (de Ruyter et al., 2009; Hernandez, 2008). However, a multi-faceted approach is needed to understand leadership influence (Casimir, 2001). More specifically, we argue that a leader's task-oriented actions are reflective of strategic choice and prioritization among available (and seemingly conflicting) alternative options and provide direction for the development for a work climate that fosters environmental responsibility. In addition, we take into account how relationship-oriented behavior aids in the creation of SENS-climate. In this study, we further contribute to the literature by theorizing and empirically examining the unique and combined effects of both types of leadership orientation.

As our third contribution, we examine the effects of perceived SENS-climate on three key outcomes: (i) sales associates' perceptions of whether they act "green"; (ii) traditional performance indicators, and; (iii) environmental performance indi- 
cators. Previous research indicates that pursuing environmental strategies results in sacrifices in financial performance at an aggregate level (e.g., de Ruyter et al., 2009). However, we argue that focusing on performance at the aggregate level might not provide a full picture. That is, by examining outcomes at a disaggregate level (i.e. differentiating between sales of green and regular products), we are able to disentangle the impact of a SENS-climate across green and regular products.

In addressing these issues, our article proceeds as follows. First, we develop our concept of SENS, in the light of the stewardship literature, and explain its potential for bridging conflicting targets in retailing. Subsequently, we develop our hypotheses regarding the antecedents and outcomes of SENS-climate. Based on data from store managers, sales associates and company records, we empirically examine the hypothesized effects of store managers' behavior on employee SENSclimate perceptions and subsequent effects on performance on reported margins, and sales of green and regular products. Finally, we discuss the theoretical and managerial implications of our findings.

\subsection{Conceptual Framework}

\subsubsection{SENS-Climate}

For the conceptual underpinnings of our study we draw on the logic of appropriateness (March, 1994; Weber, Kopelman, \& Messick, 2004). This axiom was developed as an alternative for rational models of individual behavior that assume that people are utility maximizers who act according to a logic of consequences (March, 1994). In contrast, the logic of appropriateness highlights the influence of people's social context on their decision making process. That is, people make situational assessments of their environment to derive the "appropriate" rules of conduct. Such social heuristics can instigate moral considerations that lead to collectively beneficial behavior, or alternatively, to calculative decision modes that result in self-serving utility maximization (Tenbrunsel \& Messick, 1999). Thus, social heuristics do not delineate a scripted course of action, rather they provide people with global and observable behavioral norms that serve as a guide in decision making processes and interactions with others (Deutsch Salamon \& Robinson, 2008). Crucially, perceptions of appropriateness influence perceived group norms, beliefs about other's actions in the situation at hand and perceptions about the relative importance of collective benefits and self-interest (Messick, 1999).

The relative importance attached to collective benefits compared to selfinterest is one of the defining characteristics of stewardship. Scholars now agree that stewardship entails a willingness to take responsibility for the long-term benefit of the organization, even if this means subjugating personal interests in the short-term (Block, 1993; Davis et al., 1997; Hernandez, 2012). As organizations in 
turn serve stakeholders, stewardship implies that employees also "take personal responsibility for the effects of organizational actions on stakeholder welfare" (Hernandez, 2008, p. 122). To date, most research on stewardship has focused on the managers' responsibility for maximizing long-term economic wealth of their organization, which is justified if one assumes that this will automatically result in long-term welfare for its stakeholders (Caldwell, Hayes, Bernal, \& Karri, 2008; Schepers, Falk, de Ruyter, de Jong, \& Hammerschmidt, 2012). However, recent developments, such as emerging awareness of the need to preserve the environment for the sake of long-term welfare of society (which includes a firm's stakeholders), suggest the need to adopt a more encompassing conceptual perspective on stewardship (Kotler, 2011).

De Ruyter et al. (2009, p. 472) studied environmental stewardship in boundaryspanning teams and defined it as "a collectively held sense of responsibility toward the environment, as reflected in the policies, procedures, and actions used during employee encounters with customers". However, this conceptualization does not include the role of the operational manager as a critical "go-between", that is, one who translates organizational policies and procedures to inform employee actions. Within retail chains or franchises, whilst a central level environmental policy may exist, it needs to be implemented across multiple geographically dispersed stores. This means that the policy is necessarily translated at an operational level by the store manager. Some of this policy may be "lost in translation". The implication is that the appropriate actions in implementing a central level environmental policy will be shaped by individual managers. That is, rules of appropriateness and group norms that shape a SENS-climate will form at the store level as a complement to formally prescribed policies and incentive and reward structures (Deutsch Salamon \& Robinson, 2008; March, 1994). A number of scholars (e.g., Mathieu, Heffner, Goodwin, Salas, \& Cannon-Bowers, 2000) have emphasized that work-units develop shared beliefs with regard to desirable performance behavior. These beliefs are conceptually distinct from constructs that reflect objective group attributes, such as functional diversity and size (Gully, Incalcaterra, Joshi, \& Beaubien, 2002). These aggregate-level concepts are indicative of psychosocial traits that are not reflected in individual-level concepts (Hackman, 1992). Concepts like SENS typically reflect synergistic processes within stores. Work in these units is characterized by intense interpersonal processes as sales associates work together in the same environment in which beliefs are formed that are unique to the work-unit.

Therefore, in this paper, we advance a conceptualization of environmental stewardship that adopts a process focus in alignment with the distinctive characteristics of the retail context. That is, one that takes into account that individual sales associates do not operate in isolation but within a store environment where behavioral norms as to what is appropriate based on organizational policy are driven by the store manager. Moreover, we discern the role of proximally relevant stakeholders, i.e., the store, the company and the customer. Accordingly, we define 
perceived SENS-climate within a retail context as: the extent to which sales associates perceive (i) a collective sense of responsibility toward the environment, which may at times entail subjugating their personal and collective interests, to limit the environmental impact of their company, (ii) that they contribute to and promote initiatives that help to improve their company's environmental performance; and (iii) that they promote environmentally responsible choices amongst a wider range of customers while trying to meet their demands.

\subsubsection{The Role of the Store Manager}

Starting from the logic of appropriateness, we pose that sales associates' environmental friendly behaviors will flourish most in a work environment that depicts environmental accountability as appropriate: i.e., if a SENS-climate is created. Most recently, Hernandez (2012) emphasized the important role that leaders play in developing shared perceptions to steer employees towards behavior that serves long-term collective benefits. While proponents of agency theory and the logic of consequences suggest that the provision of incentives (e.g., providing commissions on sales of green products) could help to steer sales associates towards environmentally responsible behaviors, stewardship theorists contend that such an approach hampers the consideration of long-term benefits and the development of perceived moral obligations that lie at the basis of stewardship (Davis et al., 1997). Yaffe and Kark (2011) argue that leaders can create a more effective work environment by acting as role models of prototypical behavior. In our study, we focus on managers' ability to shape a SENS-climate through two mechanisms: (1) store managers' role modeling through task-oriented actions that signal goal priority; and (2) relationship-oriented behaviors that stimulate feelings of responsibility. We posit that these mechanisms serve as a basis for translating environmental policies and procedures into actions that sales associates can use in their day-today work. In addition we acknowledge that it takes time for sales associates to make sense of their manager's behaviors (Hernandez, 2012; March, 1994) and for leader-follower relationships to develop (Caldwell \& Karri, 2005), which could influence the effectiveness of both mechanisms.

Sales associates can use store managers as role models by observing their taskoriented actions. That is, the actions managers perform to achieve the objectives that characterize their own job. Through their task-oriented actions, leaders signal the relative priority of different goals and thereby indicate which behavior is appropriate (Casimir, 2001; Zohar \& Luria, 2004). In our study, we focus on store manager task-oriented actions that indicate the relative priority of environmental accountability compared to other goals.

Stewardship scholars have argued that it is important that leaders are able to provide, both direction and clarity to followers, and we examine these two aspects of task oriented-action (de Ruyter et al., 2009; Donaldson \& Davis, 1991). First of 
all, akin to direction, we assess a leader's "environmental orientation" (cf., Zohar \& Luria, 2004), which represents the extent to which a store manager's action patterns indicate a prioritization of environmental accountability relative to competing goals (e.g., maximizing financial performance, limiting operational costs or optimizing personal gain). A store manager who makes the trade-off to sell green products in the face of lower financial returns signals higher environmental orientation than a manager who only sells green products if it does not harm financial returns (a win-win situation). Second, akin to clarity, we examine a leader's "variability in environmental orientation", which denotes the extent to which a store manager's prioritization of environmental accountability varies across similar events and situations. A store manager who instructs sales associates to sell green products regardless of financial returns in a staff meeting, but him/herself only sells green products if it does not harm financial returns, shows high variability in his/her environmental orientation.

Next to being role models who give direction and clarity regarding the relative importance of environment against other considerations, leaders are also responsible for relationship building and employee motivation (Casimir, 2001). Leaders can create a work environment that supports stewardship behaviors by building trust-based covenantal relationships through the promotion of a shared vision of an idealized future state (Caldwell et al., 2008; Hernandez, 2012). In our context, a store manager could, for example, inspire sales associates by sharing his/her belief that the most successful retailers of the future will be the ones that help customers choose more environmentally friendly alternatives. It is the building of such shared visions by managers that can promote sales associates to develop an intrinsic interest in environmental stewardship, whereas we have long known that extrinsic incentives fail to foster such a long-term perspective (Davis et al., 1997). We draw on transformational leadership as an approach to understand how a manager builds a climate of relationships based on a shared vision, trust and intrinsic motivation and posit that this facilitates the development of a SENS-climate (Bass \& Avolio, 1994; Podsakoff, MacKenzie, Moorman, \& Fetter, 1990).

\subsection{Hypotheses Development}

\subsubsection{Store Manager Task-Oriented Actions}

Sales associates use store managers as role models who provide cues about expected, supported and appropriate behavior through their own task-oriented actions (Zohar \& Luria, 2004). To get an adequate perception of appropriate behaviors, sales associates need to engage in an active sense-making process by repeatedly observing manager actions that reflect prioritization of one role facet over another (Zohar \& Luria, 2004). Continuous observation of their manager's proce- 
dures and practices will enable them to deduce a behavioral pattern that reflects the relative importance of environmental accountability compared to other competing goals, such as operational efficiency or financial performance. We term this trade-off reflecting the relative importance of various goals as the store manager's "environmental orientation". Where a store manager's actions show that (s)he repeatedly makes environmental policies contingent on operational efficiency or financial performance, in situations where these goals are at odds (termed as "low environmental orientation"), sales associates will learn that operational and financial performance have priority, regardless of their leader's voiced concern for the environment (Zohar \& Luria, 2004). However, if a store manager acts as a steward by making a trade-off in operational or financial performance for the sake of improving a store's environmental performance (termed as "high environmental orientation"), sales associates will infer that environmental responsibility is the appropriate course of action and are more likely to act as environmental stewards themselves (Block, 1993; Hernandez, 2008, 2012). A manager's environmental orientation can thus help foster a climate where environmentally responsible actions become the perceived norm. Therefore, we posit that:

H1: Store managers who display high environmental orientation have a positive effect on SENS-climate.

While sales associates can derive information about priorities and appropriate actions by observing their store managers actual choices in trade-off situations, they will also derive more implicit cues from the pattern of choices over time. We pose that variability in choice patterns can play a detrimental role and that the creation of a SENS-climate requires store managers to be consistent in their prioritization of environmental responsibility across similar situations. If store managers behave consistently (termed as "low variability in environmental orientation"), it will be easy for employees to detect their manager's action patterns and thus to deduce what kind of actions are appropriate (March, 1994; Zohar \& Luria, 2004). However, if store managers give priority to environmental responsibility in one situation, while giving priority to operational efficiency or financial performance in another, but similar situation (termed as "high variability in environmental orientation"), this can confuse sales associates and will hinder in identification of appropriate behaviors and impede the formation of shared norms within the working climate (Weber et al., 2004). Furthermore, variability in a leader's task-oriented actions might encourage sales associates to rely on other situational cues, including incentive schemes. Concluding, we hypothesize:

H2: Store managers who display high variability in their environmental orientation have a negative effect on perceived SENS-climate. 


\subsubsection{Store Manager Transformational Leadership}

Leaders can stimulate stewardship by building covenantal relationships with followers (Caldwell et al., 2008; Hernandez, 2012). Covenantal relationships are trust-based and entail a strong commitment to the company and its stakeholders, which helps to align employees' interests with those of the company. Transformational leaders use idealized influence and inspirational motivation to create such relationships (Morhart, Herzog, \& Tomczak, 2009; Podsakoff et al., 1990). In addition, transformational leaders shape work environments that are characterized by high degrees of autonomy, intrinsic motivation and self-efficacy through their use of intellectual stimulation and individual consideration (Bass \& Avolio, 1994). Although transformational leaders may not necessarily promote environmental responsibility as such, their ultimate goal is to motivate followers to take on greater responsibilities, take a long-term perspective and transcend immediate selfinterest for collective benefits (Arnold, Palmatier, Grewal, \& Sharma, 2009; Bass, 1999). Followers of transformational leaders are thus more likely to act on the rising awareness that collective long-term benefits can only be achieved if companies and customers limit their impact on the environment (Porter \& Reinhardt, 2007). Therefore, we pose that stewardship behaviors amongst sales associates are likely to blossom in work environments created by transformational leaders. Concluding, we pose that:

H3: Perceptions that a store manager uses transformational leadership practices have a positive effect on perceived SENS-climate.

Leaders are more effective when they support their task-oriented actions with efforts to build strong relationships (Casimir, 2001). Since transformational leadership helps to create strong relationships we pose that it will moderate the effects of a store manager's task-oriented actions on perceived SENS-climate. First, closer relationships allow followers to gather more information, which makes it easier to disentangle a leader's action patterns (Zohar \& Luria, 2004). Second, strong relationships allow for open communication about motives in case they are not clear (Berson \& Avolio, 2004). Third, transformational leaders have a clear understanding of the importance of different goals and know how to communicate them, which increases their ability to sense misunderstanding and create clarity among followers (Colbert, Kristof-Brown, Bradley, \& Barrick, 2008). Transformational leaders thus create the circumstances and have the ability to explain their motives, which can strengthen sales associates' understanding of their environmental orientation and limit confusion created by any variability in environmental orientation. Finally, transformational leaders are more likely to be accepted as role models, which stimulates followers to seek and accept information from them (Walumbwa, Avolio, \& Zhu, 2008). Therefore, we propose that the use of transfor- 
mational leadership practices amplifies potential positive effects of store managers' environmental orientation and reduces potential negative effects of any variability in their environmental orientation on the perceived SENS-climate. We thus posit:

H4: Perceptions that a store manager uses transformational leadership practices, will strengthen the positive effect of (a) store manager's environmental orientation on perceived SENS-climate, whereas they will diminish the negative effect of (b) variability in their environmental orientation on perceived SENS-climate.

\subsubsection{The Moderating Role of Dyadic Tenure}

Employees with a longer tenure are more likely to identify with their company and accept applicable norms that prescribe stewardship actions (Donaldson \& Davis, 1991). Since we have focused on the role of store managers' behavior in the creation of such norms, we pose that the length of the relationship between the store manager and a sales associate (dyadic tenure) can be an important moderating factor in the perceptions of SENS-climate. This is in accordance with previous research, which has shown that the characteristics of the dyadic leader-follower relationship influence information exchange and thus the follower's interpretation of their leader's behavior (Wieseke, Ahearne, Lam, \& Dick, 2009). Moreover, March (1994) has argued that rules of appropriateness develop over time and that understanding their development makes it easier to understand a decision maker's actions. This implies that it will become easier for sales associates to observe what kind of behavior is appropriate if they have a longer working relationship with their manager. Homburg, Wieseke and Bornemann (2009) have made a similar point by arguing that the accuracy of interpersonal perceptions increases with relationship length, which will improve interpretations of a manager's behavior. We therefore pose that an increase in dyadic tenure will make it easier for sales associates to identify and interpret store manager action patterns. This will amplify the potential positive effect of a store manager's environmental orientation on SENS-climate while it will diminish the potential negative effect of any variability in his/her environmental orientation.

We also argue that the effects of transformational leadership on SENS-climate will strengthen with an increase in dyadic tenure between store managers and sales associates. First, because it takes time to build covenantal relationships (Caldwell \& Karri, 2005). Second, because sales associates need time to get used to behavioral norms and the requisite development of skills to comply with those norms requires store managers to make continuous investments (Hernandez, 2012). Exposure to a transformational leadership approach over a longer period of time will facilitate these processes. Thus, we hypothesize: 
H5: When store manager-sales associate dyadic tenure is higher, the positive effects of (a) environmental orientation and (b) transformational leadership on perceived SENS-climate will be stronger, whereas the negative effect of (c) any variability in environmental orientation on perceived SENS-climate will be weaker.

\subsubsection{Outcomes of Perceived SENS-Climate}

An important question that remains is how the stimulation of SENS-climate affects sales associate performance. In a previous study de Ruyter et al. (2009) argued that when an employee has a stronger focus on the appropriateness of their actions they will demonstrate a corresponding lack of attention on financial results. Therefore, they posed that a stronger focus on environmental responsibility would have a negative impact on sales. However, their results did not show any evidence for such an effect. We argue that the effects of SENS-climate on sales might be more subtle. Shared responsibility norms that prescribe environmentally responsible actions as appropriate will increase a sales associate's attention on green products and their willingness to encourage customers to consider environmental performance in their decision making process. Since a SENS-climate involves adopting a long-term perspective, sales associates are more likely to educate customers about the long-term benefits of green products and how they outweigh any perceived disadvantages. This will make it easier for sales associates to meet customer needs while selling the "more expensive" green products, which are also usually sold at higher margins (Best Buy Co. Inc., 2010; Euromonitor International, 2010a; Prindle, 2010). This should result in an increase in sales of green products, higher margins and a higher self-perceived environmental performance by the sales associate. However, the extra attention on green products is likely to reduce attention on regular products. Sales of regular products are thus likely to go down. Overall we predict that:

H6: Perceived SENS-climate has a positive effect on (a) self-perceived performance with regard to the environment, (b) sales of green products, and (c) achieved margins, while it will have a negative effect on the (d) sales of regular products.

An overview of our hypotheses is presented in Figure 2.1, which depicts the conceptual framework of our study. 


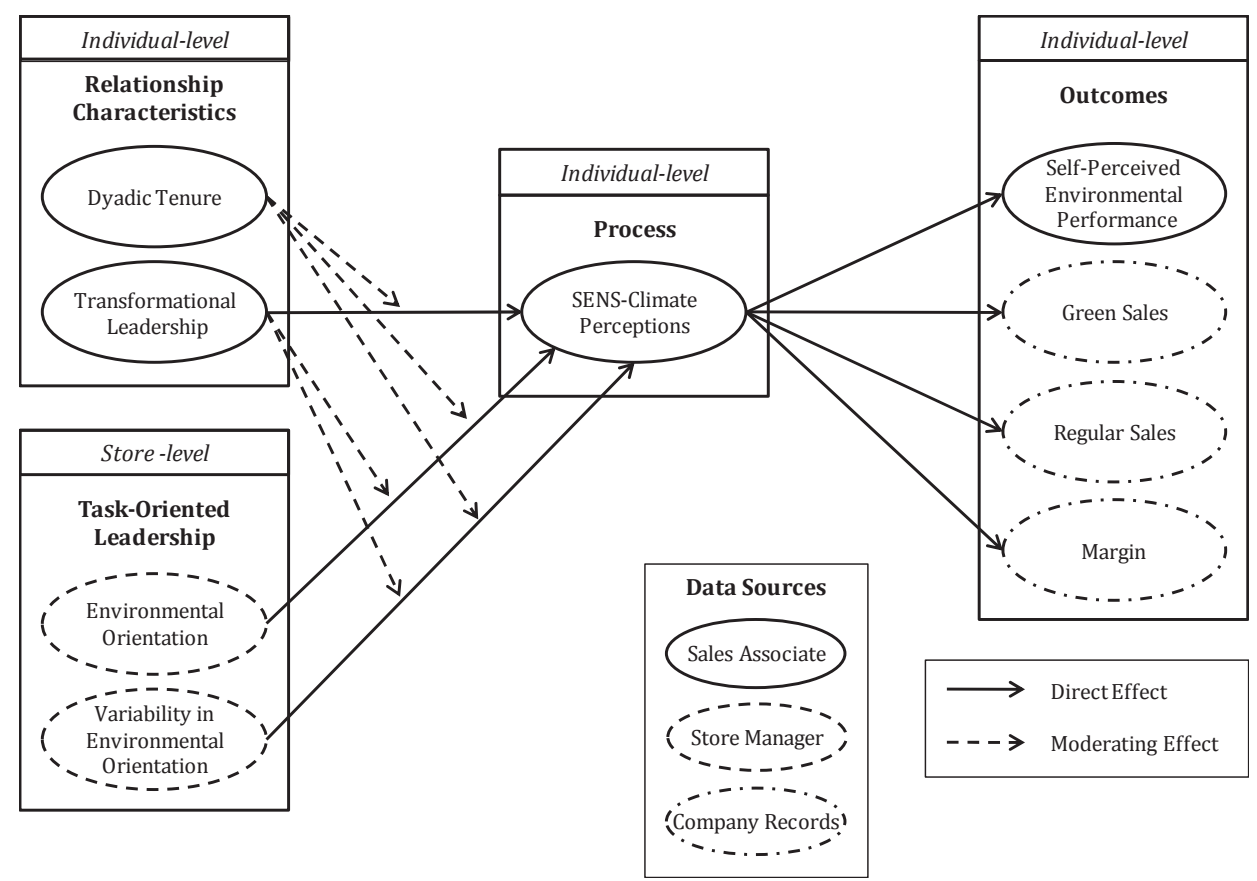

Figure 2.1: Conceptual Framework of Antecedents and Outcomes of SENS-Climate

\subsection{Empirical Study}

\subsubsection{Research Sample and Approach}

We collected data at 36 outlets of a mid-sized European electronics retailer, selling a full range of electronic appliances. Over the past years this retailer has experienced increasing consumer demand for and manufacturer supply of green products. Furthermore, multiple internet retailers have claimed a share of the market resulting in extreme price-based competition and better informed customers. This retailer is also strategically juxtaposed vis-à-vis its two biggest offline competitors; one focusing on a price leadership positioning, the other focusing almost exclusively on an environmental responsibility positioning. These market developments have increased the pressure on the focal company to compete on both fronts, both price and environmental impact. Indeed, the retailer's situation was their main motivation for participating in the study; they were talking but not "walking the green walk".

Our focal retailer employs approximately 650 people, $60 \%$ of whom work in stores as a store manager (one per store) or sales associate. Store manager and sales associate incomes are fixed through a monthly salary. They can earn small commissions on sales. The rate of commissions is uniform across stores as specified by headquarters. The retailer has no formal policy for actively promoting the 
sales of green products through commissions, which means green products sales are probably affected by store- or individual-level processes. Store managers' main tasks involve the supervision and guidance of sales associates, managing according to key performance indicators and store presentation. They spend a lot of their time on the shop floor and also deal with customers. The main responsibilities of sales associates involve customer contacts and consist of giving advice, providing service and selling products. Within stores there is a lot of contact among employees in this shared work environment and at regular staff meetings led by their store manager to discuss objectives and performance.

The data collected for our study are cross-sectional. Although we cannot exclude the possibility of common method bias entirely, we tried to limit its potential negative effects by using multiple data sources in combination with multiple measurement procedures (Podsakoff, Mackenzie, Lee, \& Podsakoff, 2003). We used company records to gather data about outcomes and control variables, an online questionnaire with stem scenarios to assess environmental orientation for store managers and a separate online survey for sales associates to measure transformational leadership and SENS-climate perceptions. The use of multiple data sources has the additional advantage of reducing hypotheses guessing and limiting potential demand effects (Shimp, Hyatt, \& Snyder, 1991).

In cooperation with the retailer's management team we approached their 43 store managers and 320 sales associates to participate in our research. To limit social desirability influences all participants received an introduction letter in which we assured that their individual data would be treated confidentially, would not be accessible to anyone but the researchers and that results would only be presented at an aggregate level. Information provided about the survey objectives was limited to avoid hypothesis guessing. Store managers were informed that their version of the online survey aimed to find out how they make decisions in dilemma situations. Sales associates answered questions about their work environment (without any reference to the trade-offs involving the environment that the store managers were asked to make) through a separate online survey. They received an individual user name and password enabling their responses to be linked to their store manager's responses and to the performance data from company records without involvement of internal retail personnel. After follow-up telephone calls to each store we received complete survey data from 36 store managers and 182 sales associates (nested within these 36 stores), which corresponds to a response rate of $84 \%$ and $57 \%$, respectively.

Among the store manager sample, 35 (97\%) are men and $23(64 \%)$ are older than forty years. Furthermore, 24 (67\%) of the store managers acted in this function for more than five years, while 22 (61\%) have managed their current store for more than three years. 147 (81\%) of the sales associate sample are male, 126 $(69 \%)$ work fulltime and $78(43 \%)$ are younger than thirty years, while $51(28 \%)$ are older than forty years. 124 (68\%) sales associates have acted in this function 
for more than five years, while 98 (54\%) have worked in their current store for more than three years.

\subsubsection{Store-Level Measures}

Assessing Environmental Orientation \& Variability: Store managers completed a set of 8 stem scenarios to evaluate their environmental orientation and the associated variability in this. Each stem scenario represents a typical store situation in which the store manager is required to make a choice between taking environmental responsibility and improving operational efficiency. We describe the development of our stem scenarios below.

Stem scenarios are a procedure developed by Zohar and Luria (2004) as a means of using scripts as a proxy of actual behavior. Scripts "provide mental representations of goal-directed behavior chains in well-known situations and serve as repositories of behavioral plans" (Zohar \& Luria, 2004, p. 326). Thus a main advantage for us is that this script-based procedure allows independent observation of leaders' actions that shape environmental stewardship and the sales associates' perceptions of a SENS-climate. Scripts encompass the multiple paths that can be used to reach a specific goal (Abelson, 1981). Situational conditions influence path selection and over time new paths are added and old paths are modified depending on their relative success (Wofford \& Goodwin, 1990). Paths become dominant over others resulting in stable contingency-based action patterns, or "if-then decision rules for each script" (Zohar \& Luria, 2004, p. 326). We capture these action patterns by recording a store manager's choices in simulated events representative of situations (s)he regularly encounters in his/her job. In our context, events are occurrences visible to sales associates that require a store manager to choose between environmental responsibility and operational efficiency. A store manager's "environmental orientation" is observed by recording his/her prioritization of environmental responsibility over efficiency, across a sample of events. "Variability" is observed by assessing differences in prioritization across events.

To develop our stem scenarios we first conducted in depth interviews with a senior manager, six store managers and five sales associates to identify typical events suited for our purposes. On the basis of these interviews ten stem scenarios were designed, which were discussed with two staff managers to ensure they were reflective of store managers' tasks. On the basis of their feedback minor adaptations were made. As a second step, the adapted versions of the ten stem scenarios were assessed by six academic researchers who were not involved in the project, but were provided with detailed information about the purpose of the scenarios. We used their feedback to make further improvements. Finally, we again consulted the staff managers, who selected the eight stem scenarios representing the most familiar and frequently occurring events. The final eight stem scenarios reflect a variety of tasks that store managers regularly face (e.g., customer contacts, advis- 
ing sales associates, assortment composition and store presentation). We included this final set of scenarios in the online survey sent to store managers.

Each stem scenario starts with describing a situation in which the store manager faces a conflict between environmental responsibility and operational efficiency. Each description is followed by four scenes that differ with regard to the environmental benefits and operational costs associated with the decision. We differentiate between low and high environmental benefits (LEB vs. HEB) and low and high operational costs (LOC vs. HOC). The four scenes correspond to the four different combinations between environmental benefits and operational costs (scene 1=HEB-LOC, scene 2=LEB-LOC, scene 3=HEB-HOC, scene 4=LEB-HOC). For each scene the store manager had to choose between "acting environmentally responsibly" (choosing the most environmentally beneficial option, but with higher operational costs) or "acting efficiently" (choosing the least environmentally beneficial option, but results in lower operational costs). After making a choice for all of the four scenes, store managers were offered the same scenes again, with a contingency added to the scene's description. The contingency depended on the first choice made. In scenes where a manager had chosen to act environmentally responsibly at first, the contingency entailed an ordinal within-scene decrease in environmental benefits or increase in operational costs (making acting environmentally responsibly less attractive). If a manager had chosen to act operationally efficiently at first, the contingency entailed an ordinal within-scene increase in environmental benefits or decrease in operational costs (making acting environmentally responsibly more attractive). Store managers were then asked to make a new choice for each scene while taking the contingency into account. Our online survey was programmed to use a manager's first choice as a filter to provide the managers with the applicable contingency for each scene. In total each store manager made eight choices for each of the eight stem scenarios (four choices in step 1 and four choices in step 2). An example stem scenario can be found in Figure 2.2 (other stem scenarios are available in Appendix B).

Scores for each store manager on "environmental orientation" and "variability in environmental orientation" were calculated using the two-step scoring procedure developed by Zohar and Luria (2004). First, scene orientation was measured on a 4-point ordinal scale based on first and second choices made in the scenarios. A score of $4=$ the highest environmental orientation and 1=the lowest environmental orientation. If a store manager chooses to act environmentally responsibly both times (s)he faces the same scene (second time, despite decreased attractiveness of acting environmentally responsibly) this shows a high priority for environmental responsibility compared to operational efficiency, which ranks as 4. An initial choice to act environmentally responsibly followed by a choice to act operationally efficiently (as a result of decreased attractiveness of acting responsibly) ranks as 3. An initial choice to act operationally efficiently followed by a choice to act environmentally responsibly (as a result of an increased attractiveness of acting re- 
sponsibly) ranks as 2 . If a store manager chooses to act operationally efficiently both times (second time, despite increased attractiveness of acting responsibly) this shows a low priority for environmental responsibility compared to operational efficiency which ranks as 1 .

\begin{abstract}
A lot of energy is used in your store and you consider taking action to reduce the energy consumption for the benefit of the environment. You know that the biggest energy consumers in your store are the televisions that are turned on all day. To limit energy consumption you could choose not to turn all televisions on. However, televisions that are turned off are harder to sell. What would you do in the following scenes?
\end{abstract}

Scene 1: You can reduce your energy use by 6\% (a lot of environmental gain) if you turn $10 \%$ of your televisions off.

Do you turn this percentage of your televisions off? (No/Yes)

Scene 2: You can reduce your energy use by 3\% (a bit of environmental gain) if you turn $10 \%$ of your televisions off.

Do you turn this percentage of your televisions off? (No/Yes)

Scene 3: You can reduce your energy use by $6 \%$ (a lot of environmental gain) if you turn $25 \%$ of your televisions off.

Do you turn this percentage of your televisions off? (No/Yes)

Scene 4: You can reduce your energy use by 3\% (a bit of environmental gain) if you turn $25 \%$ of your televisions off.

Do you turn this percentage of your televisions off? (No/Yes)

If you answered No to any of the above, how would you react if you consider this extra information:

It is summer. Turning the televisions off will lower the temperature in your store, which means you can turn the air conditioning down. This increases your energy savings by $1 \%$ compared to the scene description above.

Do you turn the televisions off?

Scene 1: (No/Yes)

Scene 2: (No/Yes)

Scene 3: (No/Yes)

Scene 4: (No/Yes)
If you answered Yes to any of the above, how would you react if you consider this extra information:

It is winter. Turning the televisions off will lower the temperature in your store, which means you need to turn the heat up. This reduces your energy savings by $1 \%$ compared to the scene description above.

Do you turn the televisions off?

Scene 1: (No/Yes)

Scene 2: (No/Yes)

Scene 3: (No/Yes)

Scene $4:$ (No/Yes)

Figure 2.2: Example Stem Scenario 1

As the second step, we incorporated the scene's context in the scoring procedure to account for the fact that it is easier to act environmentally responsibly in some scenes than in others. We assigned weights, based on a 3-point ordinal scale, to each scene reflecting the environmental benefits-operational costs trade-off. For scene 1, acting environmentally responsibly is easier as it was characterized by high environmental benefits and low operational costs (HEB-LOC). For scene 4, acting environmentally responsibly was harder as it was characterized by low environmental benefits and high operational costs (LEB-HOC). If a store manager 
acts environmentally responsibly in scene 4 (LEB-HOC), this is a stronger indication of his/her prioritization for the environment than in scene 1 (HEB-LOC). Therefore, we assigned a weight of 3 to scene 4 (LEB-HOC) and a weight of 1 to scene 1 (HEB-LOC). The other two scenes (scene 2 LEB-LOC and scene 3 HEB-HOC) represent a balance between the size of environmental benefits and operational costs; therefore, we assigned both scenes a weight of 2 .

Each store manager's environmental orientation score per stem scenario was determined by (i) multiplying a store manager's scene orientation with the scene weighting and (ii) summing the scores for all 4 scenes for each stem scenario. The mean of these scores across the eight stem scenarios represents a store manager's final environmental orientation (high mean scores indicate high environmental orientation), while the standard deviation (SD) across all stem scenarios was used to represent a manager's variability in environmental orientation (high SD indicates high variability).

Other measures: Once store managers had completed the stem-scenarios, we asked them to indicate their gender (female $=0$, male $=1$ ), age, tenure as store manager in general and tenure as manager of their current store. Age and tenure were measured in number of years. We also assessed two other store-level variables on the basis of company records. "Store size" represents the number of sales associates working in the store, while "Region" represents the area in which the store is located. We used tenure as manager of their current store, store size and regions (represented by dummy variables) as controls in our analyses.

\subsubsection{Individual-Level Measures}

Perceived SENS-climate Measurement: For our own measure of perceived SENSclimate we adapted a scale for the measurement of a collective sense of environmental stewardship from de Ruyter et al. (2009). As their scale does not reflect our multi-faceted conceptualization of environmental stewardship for the retail context, we adapted their original items to fit our conceptualization. We extended the scale based on the insights gained in 14 comprehensive interviews with company employees. The final scale for measuring SENS-climate perceptions consists of 11 items, which represent the extent to which sales associates perceive (i) a collective sense of responsibility toward the environment ( 5 items) (ii) that they contribute to and promote initiatives that help to improve their company's performance (3 items); and (iii) that they promote environmentally responsible choices amongst a wider range of customers while trying to meet their demands ( 3 items). We used a 7-point scale ranging from "strongly disagree" (1) to "strongly agree" (7). The scale is operationalized as a higher-order factor consisting of three reflective first-order constructs that represent our three facets of SENS-climate.

Transformational Leadership: For the measurement of transformational leadership we assessed individual sales associate's perceptions of their store manager's 
behavior using the original scale from Avolio and Bass' MLQ, Form 5X-short (1995). In line with previous studies (Menguc \& Auh, 2008; Walumbwa et al., 2008), transformational leadership is operationalized as a higher-order factor consisting of four reflective first-order constructs, namely idealized influence ( 6 items), inspirational motivation (3 items), intellectual stimulation (3 items), and individual consideration ( 3 items).

We assessed the measurement properties of our SENS-climate and the transformational leadership constructs simultaneously by conducting a confirmatory factor analysis (CFA). Both constructs were included as higher-order factors with three and four underlying first-order constructs, respectively. We used LISREL 8.80 (Jöreskog \& Sörbom, 2006) to obtain estimates. Our analysis reveals a good fit to the data: $\chi^{2}(293)=505.249, p<.001$, confirmatory fit index (CFI) $=.97$, incremental fit index $(\mathrm{IFI})=.97$, non-normed fit index $(\mathrm{NNFI})=.96$, root mean square error of approximation (RMSEA) $=.060$, and standardized root mean square residual $(\mathrm{SRMR})=.063$. We evaluated convergent validity of the measures by assessing whether the manifest variables load significantly and adequately in magnitude on the hypothesized latent variable (Anderson \& Gerbing, 1988). The observed standardized loadings are significant at $\alpha=.05$. We also calculated the composite reliability (CR) and average variance extracted (AVE) for both measures. Our findings show that the CRs exceed the recommended cut-off value of .7 and the AVEs exceed the recommended cut-off value of .5. For SENS-climate [CR = .92; AVE = .80] and for transformational leadership [CR = .95; AVE = .84] (Fornell \& Larcker, 1981). Finally, we assessed discriminant validity by comparing the square root of the AVE with the (attenuated) correlation between the latent variables that represent SENS-climate and transformational leadership (Fornell \& Larcker, 1981). The square root of the AVE of both latent variables exceeded the (attenuated) correlation between them, indicating discriminant validity (please see Appendix A for further details).

Other Measures: Sales associates' background information was collected; gender (female $=0$, male $=1$ ), work time (part-time $=0$, full-time $=1$ ), age, tenure as sales associate in general and tenure in their current store. We also measured store manager-sales associate dyadic tenure by asking each sales associate how long they had been working with the same store manager. Age and tenure were measured in number of years.

We examine the relationships between SENS-climate perceptions and performance at the individual-level of analysis by use of subjective and objective measures. In the survey we asked sales associates to rate their self-perceived performance with regard to the environment with the following item: "how would you rate your own performance in comparison to your colleagues if it comes to environmental performance". We used a 5-point scale ranging from "far below average" (1) to "far above average" (5) (Singh, 1993). We also used objective data from the company's records about sales associates' performance with regard to 
achieved margins and sales. Sales figures were split up in sales of green products (green sales) and sales of regular products (regular sales). This distinction was made on the basis of the EU labeling scheme (similar to the American Energy Star label) reflecting product energy efficiency. The term "green sales" relates to sales figures for more energy efficient electronic devices, while the term "regular sales" relates to figures for less energy efficient electronic devices.

\subsubsection{Analyses Approach}

To estimate the effects of the antecedent variables on perceived SENS-climate we specified hierarchical linear regression models using MLwiN 2.22 (Rasbash, Browne, Healy, Cameron, \& Charlton, 2010). We used this approach because our data is hierarchical in nature (each store manager supervised multiple sales associates). In the first step we included the control variables at the individual and store levels (Model 1). In the second step, we added the antecedent variables (Model 2). In the third step, we specified interactions among antecedent variables (Model 3) and obtained the following multilevel equation ${ }^{1}$ :

$$
\begin{aligned}
& \text { SENS }_{i j}=\gamma_{00}+\gamma_{10} \text { GENDER }_{i j}+\gamma_{20} \text { WORK }_{i j}+\gamma_{30} \text { TENE }_{i j}+\gamma_{40} \text { TENDY }_{i j} \\
& +\gamma_{50} \text { TLEAD }_{i j}+\gamma_{01} \text { STSIZE }_{j}+\gamma_{02} \text { REGD2 }_{j}+\gamma_{03} \text { REGD3 }_{j}+\gamma_{04} \text { REGD4 }_{j} \\
& \left.+\gamma_{05} \text { TENM }_{j}+\gamma_{06} \text { ENVOR }_{j}+\gamma_{07} \text { ENVVAR }_{j}+\gamma_{60} \text { TENDY }_{i j} \times \text { TLEAD }_{i j}\right)_{i j} \\
& \left.+\gamma_{70}\left(\text { TENDY }_{i j} \times \text { ENVOR }_{j}\right)_{i j}+\gamma_{80} \text { TENDY }_{i j} \times \text { ENVVAR }_{j}\right)_{i j} \\
& +\gamma_{90}\left(\text { TLEAD }_{i j} \times \text { ENVOR }_{j}\right)_{i j}+\gamma_{100}\left(\text { TLEAD }_{i j} \times \text { ENVVAR }_{j}\right)_{i j}+u_{0 j}+e_{i j} .
\end{aligned}
$$

We grand-mean-centered the first-order variables before estimating our models. These mean-centered variables also served as a basis for creating the interaction terms (Aiken \& West, 1991).

We also estimate the effects of perceived SENS-climate on performance outcomes (i.e., Hypothesis 6) through a multivariate hierarchical linear regression model, using MLwiN 2.22 (Rasbash et al., 2010). Three hierarchical levels were specified. Level 1 refers to the dependent variables indexed by $\mathrm{h}=1, \ldots, \mathrm{m}$. Level 2 reflects the individual sales associates $\mathrm{i}=1, \ldots, \mathrm{n}_{\mathrm{j}}$. Level 3 represents the stores $\mathrm{j}=$ $1, \ldots, N$. As such, each assessment of a given outcome variable for a sales associate

\footnotetext{
${ }^{1}$ Where, i=individuals; $\mathrm{j}=$ stores; SENS=sales associate's SENS-climate perception; GENDER=sales associate's gender; WORK=sales associate's work time; TENE=sales associate's tenure in store; TENDY=dyadic tenure between a sales associate and his/her store manager; TLEAD=sales associate's perception of their store manager's transformational leadership practices; STSIZE=store size in terms of the number of sales associates working in the store; REGD2, REGD3 \& REGD4=dummy variables for store regions; TENM=store manager's tenure as manager of the store; ENVOR=store manager's environmental orientation; ENVVAR=variability in the store manager's environmental orientation; $\gamma_{00}=$ the intercept; $\gamma_{10} \ldots \gamma_{100}=$ regression coefficients; $\mathrm{e}_{\mathrm{ij}}=$ =individual-level error term; $\mathrm{u}_{\mathrm{oj}}=$ unique variation of group j from the intercept $\left(\gamma_{00}\right)$, after partialing out the effects of all store-level regression coefficients $\left(\gamma_{01 \ldots}\right.$ $\gamma_{07}$.
} 
within a certain store is indicated by a specific line in the data matrix, containing the values $\mathrm{i}, \mathrm{j}, \mathrm{h}, \mathrm{Y}_{\mathrm{hij}}, \mathrm{x}_{1 \mathrm{ij}}$, and all other predictors. To formulate the multivariate regression model as a hierarchical linear model, dummy variables $d_{1}$ to $d_{m}$ are used to indicate the outcome variables (i.e., self-perceived environmental performance, green sales, regular sales, and margin). The dummy $d_{h}$ is 1 or 0 , depending on whether the data line refers to outcome variable $Y_{h}$ or to another outcome variable. This principle is expressed by Equation 2:

$$
\mathrm{d}_{\text {shij }}=\begin{array}{cc}
1 & \mathrm{~h}=\mathrm{s} \\
0 & \mathrm{~h} \neq \mathrm{s} .
\end{array}
$$

By means of these dummies, the regression equations for the m outcome variables can be integrated into one three-level hierarchical model by the next expression:

$$
Y_{\text {hij }}=\sum_{s=1}^{m} \gamma_{0 s} d_{\text {shij }}+\sum_{\mathrm{k}=1}^{\mathrm{p}} \sum_{\mathrm{s}=1}^{\mathrm{m}} \gamma_{\mathrm{ks}} \mathrm{d}_{\text {shij }} \mathrm{x}_{\mathrm{kij}}+\sum_{\mathrm{s}=1}^{\mathrm{m}} \mathrm{u}_{\mathrm{sj}} \mathrm{d}_{\text {shij }}+\sum_{\mathrm{s}=1}^{\mathrm{m}} \mathrm{e}_{\mathrm{sij}} \mathrm{d}_{\text {shij }} \text {. }
$$

All variables (including the constant) are multiplied by the dummy variables. With respect to the dummy variables, in the sums over $s=1, \ldots, m$, only the term $s=h$ renders a contribution, while all other terms are removed. We included SENSclimate as an antecedent while controlling for sales associates' gender, work time, and tenure, store manager-sales associate dyadic tenure, and for store size, region, and store manager tenure. We have also specified individual-level and store-level relationships between the dependent variables, that can be expressed as:

$\operatorname{var}\left(\mathrm{e}_{\mathrm{hij}}\right)=\sigma_{\mathrm{hh}}, \operatorname{and} \operatorname{cov}\left(\mathrm{e}_{\mathrm{hij}}, \mathrm{e}_{\mathrm{h}^{\prime} \mathrm{ij}}\right)=\mathrm{e}_{\mathrm{hh}^{\prime}}$

and

$$
\operatorname{var}\left(\mathrm{u}_{\mathrm{hj}}\right)=\tau_{\mathrm{hh}}, \text { and cov }\left(\mathrm{u}_{\mathrm{hj}}, \mathrm{u}_{\mathrm{h}^{\prime} \mathrm{j}}\right)=\tau_{\mathrm{hh}^{\prime}}
$$

respectively. The inclusion of the covariance terms allows the dependent variables to covary both at the individual and the store level.

Finally, we examine the mediating role of SENS-climate between store managers' actions and performance outcomes. Estimating mediation of SENS-climate for the effect of transformational leadership involves a 1-1-1 (e.g., independent variable level, mediating variable level and dependent variable level) model (Bauer, Preacher, \& Gil, 2006; Preacher \& Selig, 2010). In addition, the estimation of the mediating role of SENS-climate for the effects of environmental orientation and variability in environmental orientation involves 2-1-1 models (cf., Bauer et al., 2006). Based on MacKinnon, Lockwood, and Williams (2004), Bauer et al. (2006) developed a Monte Carlo mediation approach for constructing confidence intervals for hierarchical linear models, which we employed in our mediation analysis (Preacher \& Selig, 2010). 


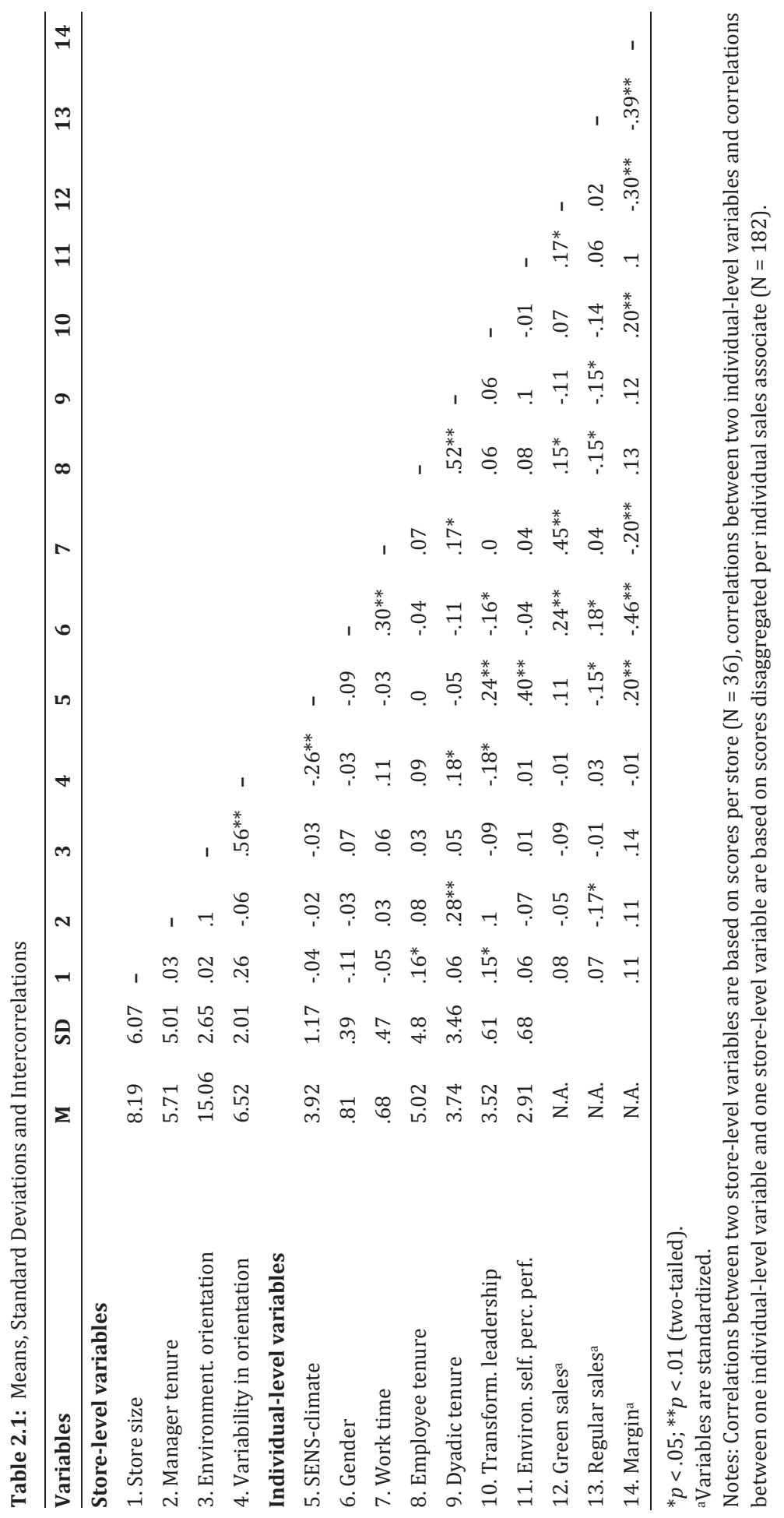




\subsection{Results}

We present the findings of our multilevel analyses in Table 2.2. The findings reveal that our antecedent model, where environmental orientation, variability in environmental orientation and transformational leadership were entered (Model 2), provides a better fit $(\chi 2(3)=25.071, p<.01)$ than our control model (Model 1). Thus adding the antecedent variables leads to significant improvement of the model. In our interaction model (Model 3), the interaction terms for transformational leadership with environmental orientation and variability in environmental orientation, and the interaction terms for dyadic tenure with transformational leadership, environmental orientation and variability in environmental orientation were entered. Model 3 yields a significantly better fit than our antecedent model (Model 2) ( $\chi 2$ (5) = 16.962, $\mathrm{p}<.01)$, demonstrating that specifying the interactions substantially contributes to the prediction of a sales associate's perceptions of SENS-climate. These results provide initial support for the model specified within the context of our study.

Specifically, Model 3 reveals a positive effect of store manager environmental orientation on SENS-climate perceptions $(\beta=.300, p<.01)$, while it reveals a negative effect of a store manager's variability in environmental orientation on SENSclimate $(\beta=-.389, p<.01)$, in support of Hypotheses 1 and 2 . In addition, store manager transformational leadership has a positive effect on SENS-climate perceptions $(\beta=.266, p<.01)$, which is in line with Hypothesis 3. Contrary to our expectations, store manager transformational leadership neither moderates the positive effect of environmental orientation on SENS-climate ( $\beta=-.104$, ns), nor the negative effect of the variability in environmental orientation on SENS-climate $(\beta=-$ .022 , ns). Hence, we find no support for Hypotheses $4 \mathrm{a}$ and $4 \mathrm{~b}$. However, store manager-sales associate dyadic tenure does strengthen the effects of environmental orientation $(\beta=.257, p<.01)$, and transformational leadership $(\beta=.191, p<$ $.05)$ on SENS-climate perceptions. These results are in support of Hypotheses $5 a$ and $5 \mathrm{~b}$. Conversely, there is no evidence for moderation of store manager-sales associate dyadic tenure on the negative effect of variability in environmental orientation on SENS-climate $(\beta=-.138$, ns), which means no support exists for Hypothesis $5 c$.

Furthermore, we estimated the effects of perceived SENS-climate on performance outcomes (Hypothesis 6). The results showed positive effects of SENSclimate on self-perceived environmental performance $(\beta=.379, p<.01)$, green sales $(\beta=.129, p<.05)$, and margin $(\beta=.178, p<.01)$, while there was a significant negative effect on sales of regular products $(\beta=-.152, p<.05)$. Hence, we find support for Hypotheses 6a-6d. 
Table 2.2: Multilevel Regression Analyses of Antecedent-SENS-Climate Relationships

\begin{tabular}{|c|c|c|c|c|}
\hline \multirow[b]{2}{*}{ Variables } & Model 1 & Model 2 & Model 3 & \\
\hline & $\begin{array}{l}\text { Standardized } \\
\text { Coefficients }\end{array}$ & $\begin{array}{l}\text { Standardized } \\
\text { Coefficients }\end{array}$ & \multicolumn{2}{|c|}{$\begin{array}{l}\text { Standardized Hypothesi } \\
\text { Coefficients }\end{array}$} \\
\hline \multicolumn{5}{|l|}{ Individual-level variables: } \\
\hline Gender & -.106 & -.092 & -.066 & \\
\hline Work time & .025 & .035 & .032 & \\
\hline Employee tenure & .033 & .012 & .021 & \\
\hline Dyadic tenure & -.006 & .030 & -.006 & \\
\hline Transformational leadership & & $.249^{* *}$ & $.266^{* *}$ & H3 \\
\hline \multicolumn{5}{|l|}{ Store-level variables: } \\
\hline Store size & -.057 & .062 & .062 & \\
\hline Region dummy 2 & -.052 & .085 & .103 & \\
\hline Region dummy 3 & -.193 & -.052 & .007 & \\
\hline Region dummy 4 & -.158 & -.163 & -.130 & \\
\hline Manager tenure & .000 & -.107 & -.103 & \\
\hline Environmental orientation & & $.218^{*}$ & $.300^{* *}$ & H1 \\
\hline Variability in orientation & & $-.382^{* *}$ & $-.389 * *$ & $\mathrm{H} 2$ \\
\hline \multicolumn{5}{|l|}{ Individual-level interaction: } \\
\hline Dyadic tenure $\times$ Transformational leadership & & & $.191^{*}$ & $\mathrm{H} 5 \mathrm{~B}$ \\
\hline \multicolumn{5}{|l|}{ Cross-level interactions: } \\
\hline Dyadic tenure $\times$ Environmental orientation & & & $.257^{* *}$ & $\mathrm{H} 5 \mathrm{~A}$ \\
\hline Dyadic tenure $\times$ Variability in orientation & & & -.138 & $\mathrm{H} 5 \mathrm{C}$ \\
\hline Transformational leadership $\times$ Environmental & orientation & & -.104 & $\mathrm{H} 4 \mathrm{~A}$ \\
\hline Transformational leadership $\times$ Variability in $o$ & rientation & & -.022 & $\mathrm{H} 4 \mathrm{~B}$ \\
\hline Increase in model fit: & $\begin{array}{c}\chi^{2}(9)= \\
5.404\end{array}$ & $\begin{array}{c}\chi^{2}(3)= \\
25.071^{* *}\end{array}$ & $\begin{array}{c}\chi^{2}(5)= \\
16.962^{* *}\end{array}$ & \\
\hline
\end{tabular}

$* \mathrm{p}<.05 ;{ }^{* *} \mathrm{p}<.01$ (two-tailed).

Notes: $\mathrm{N}=182$.

Finally, we examined the mediating role of SENS-climate between store managers' task- and relationship-oriented actions and perceptual and performance outcomes. First, we extended the outcome models by adding the direct effects of the three antecedent variables (i.e., transformational leadership, environmental orientation and variability in environmental orientation) and the five interaction terms on the four dependent variables (i.e., self-perceived environmental performance, green sales, non-green sales and margin). The results of these analyses provide initial support for the mediating role of SENS-climate. When we included these antecedents and their interactions as controls to the model this did not significantly change the results. The positive direct effects of SENS-climate on self-perceived environmental performance $(\beta=.394, \mathrm{p}<.01)$, green sales $(\beta=.150, \mathrm{p}<.05)$, and margin $(\beta=.139, \mathrm{p}<.05)$ and its negative direct effect on non-green sales $(\beta$ 
$=-.194, \mathrm{p}<.05)$ remain significant, while all direct effects of the antecedent variables on the four outcome variables turned out to be non-significant, except for environmental orientation which had a significant positive direct effect on margin $(\beta=.270, \mathrm{p}<.01)$.

In addition, we directly assessed mediation by use of a Monte Carlo mediation approach for constructing confidence intervals for the indirect effects (Bauer et al., 2006; MacKinnon et al., 2004). Our results show significant indirect effects of all three antecedent variables (i.e., transformational leadership, environmental orientation, and variability in environmental orientation) on all four dependent variables (see Table 2.3). This suggests that SENS-climate mediates the antecedent effects on the outcome variables in a way that is classified as indirect-only mediation (Zhao, Lynch Jr, \& Chen, 2010). One exception is the mediating effect of SENSclimate between environmental orientation and margin, which is categorized as complementary mediation since environmental orientation also had a significantly positive direct effect on margin (Zhao et al., 2010). Overall our results provide strong support for the mediating role of SENS-climate.

Table 2.3: Results of Monte Carlo Estimation of Indirect Effects

\begin{tabular}{|c|c|c|c|c|}
\hline & $\begin{array}{c}\text { Self-Perceived } \\
\text { Environmental } \\
\text { Performance }\end{array}$ & Green Sales & Regular Sales & Margin \\
\hline Independent variables & $\begin{array}{c}\text { (standardized }{ }^{2} \\
\text { effect sizes) }\end{array}$ & $\begin{array}{l}\text { (standardized } \\
\text { effect sizes) }\end{array}$ & $\begin{array}{l}\text { (standardized } \\
\text { effect sizes) }\end{array}$ & $\begin{array}{c}\text { (standardized } \\
\text { effect sizes) }\end{array}$ \\
\hline \multicolumn{5}{|c|}{ Independent variables (individual level): } \\
\hline Transformational leadership & $.11^{* *}$ & $.04^{*}$ & $-.05^{*}$ & $.04^{*}$ \\
\hline \multicolumn{5}{|c|}{ Independent variables (store level): } \\
\hline Environmental orientation & $.27^{* *}$ & $.10^{*}$ & $-.13^{*}$ & $.09 *$ \\
\hline Variability in orientation & $-.26^{* *}$ & $-.10^{*}$ & $.13^{* *}$ & $-.09 *$ \\
\hline
\end{tabular}

${ }^{*} p<.05 ;{ }^{* *} p<.01$ (two-tailed).

Confidence intervals are based on Monte Carlo simulations (cf., Preacher \& Selig, 2010).

Notes: $\mathrm{N}=182$.

\subsection{Discussion}

In this paper, we contribute to the marketing research literature by developing and empirically assessing a model that features SENS-climate as a central concept. SENS is based on a set of store-based shared beliefs by sales associates on how they can behave in an environmentally responsible way, while serving the interests of their store, their company and their customers. In addition, we zoom in on the role of store managers in shaping a SENS-climate. Previous research has em-

\footnotetext{
${ }^{2}$ Standardization of the indirect effects is based on Preacher and Hayes (2008)
} 
phasized the importance of transformational leadership in the retail context and we extend this by identifying transformational leadership as a significant driver of SENS-climate. Importantly, our findings provide further support for the recent claim that relationships based on social exchange support the development of a climate for stewardship (Hernandez, 2012).

Beyond the effect of transformational leadership, we demonstrate that managers' task-oriented actions are identified as an important predictor of a SENSclimate. More specifically, we find that store managers' enacted environmental orientation is conducive to creating an enabling work environment that supports environmentally responsible actions in sales associates' day-to-day operations. This affirms recent theorizing on stewardship (Hernandez, 2008) that posits that leaders function as role models and that their enacted stewardship convictions contribute to developing collectively-held convictions among sales associates about the importance of assuming responsibility for the environment, while serving the interests of various stakeholders. In addition, we demonstrate that variability in a store manager's environmental orientation has a negative effect on SENSclimate perceptions. This supports previous contentions that the formation of shared norms at the work-unit level may be hindered by inconsistencies in situational cues (Weber et al., 2004). More specifically, it aligns with previous theorizing on the concept of stewardship that claims that clarity and consistency in role expectations are paramount (Davis et al., 1997).

Additionally, and beyond aforementioned main effects, we present evidence of the moderating role of dyadic tenure. We demonstrate that dyadic tenure strengthens the relationship between a leader's environmental orientation and SENS-climate perceptions. This lends support to March's (1994) much earlier contention that it takes time for rules of appropriateness to develop. In addition, dyadic tenure also boosts the positive influence of transformational leadership practices on SENS-climate perceptions. Apparently store managers' transformational leadership practices become more effective through continued investments over time. If managers keep on stimulating and educating their sales associates this results in better returns on investment (Hernandez, 2012). On the other hand, dyadic tenure did not affect the negative relationship between variability in environmental orientation and SENS-climate. Longer relationships, thus, do not seem to act as a remedy for a store manager's lack of consistency, but neither do they seem to provide additional harm through continued exposure to confusing messages.

Further, and by no means of any less interest is our finding that there is no joint effect of transformational leadership on the impact of a store manager's environmental orientation (and the variability thereof) on SENS-climate perceptions by sales associates. One possible explanation for the lack of an interaction effect with environmental orientation could be that transformational leaders also strengthen feelings of autonomy and self-efficacy, which decrease sales associates' depend- 
ence on the store manager as a role model (Menguc \& Auh, 2008). The fact that transformational leadership does not form a buffer against variability in environmental orientation may be explained by the presence of a causal relationship. Transformational leaders are more aware of the importance of different goals and how to communicate them to their followers (Berson \& Avolio, 2004). It could be that transformational leaders show less variability in their environmental orientation because they realize it can create confusion, which would limit the potential for a moderating influence.

Finally, our results contribute to our understanding of SENS-climate perceptions and sales associates' performance. Sales associates who perceive an enabling SENS-climate, perceive their own environmental performance as better, and show higher levels of green sales and lower levels of regular sales. These findings suggest that fostering a SENS-climate results in behavioral changes that cause a shift in the kind of products sold. This finding contradicts previous research on environmental stewardship, which showed that it has no effects on total sales at a work-unit level (de Ruyter et al., 2009). Furthermore, our results show that SENSclimate perceptions result in higher achieved margins, which indicates that environmental performance does not necessarily come at a financial cost for the company. These findings imply that there are possibilities for firms to create shared value by integrating sustainability considerations at the core of a company's business, as was suggested by Porter and Kramer (2006). While this had been shown for production firms, which can save on waste-related costs by acting environmentally friendly (King \& Lenox, 2002; Klassen \& Whybark, 1999), it is encouraging to see that it can also work for retailers that integrate environmental accountability at their frontline.

A formal test for mediation showed that SENS-climate perceptions mediate the effects of store managers' task- and relationship oriented actions on sales associate's performance outcomes in a way that can be categorized as indirect-only mediation. The only exception was the mediating effect of SENS-climate between environmental orientation and margin, which was a complementary mediation. The direct effect of store managers' environmental orientation on margin could be the result of one-on-one imitations of store managers' role modeling behaviors. Next to providing cues about what is appropriate, role modeling behaviors can also be copied directly. If a store manager is successful in selling green products with higher margins they give the ultimate example of how to achieve multiple goals at once. Such examples are likely to be copied directly. Thus, our results show that interventions at the store manager level can be effective to improve environmental performance at the individual sales associate level. This shows that an attitude change at the individual sales associate level, which would require substantially higher investments, is not the only approach to foster environmental performance at the frontline. 


\subsubsection{Future Research Directions}

Any study suffers from limitations and ours is no exception. These limitations, however, form a basis for developing future research avenues. Firstly, in our paper we focused on the effects of leaders' behaviors on SENS-climate perceptions. While we controlled for a number of individual level factors (e.g., tenure and working hours) we did not specifically assess individual level psychological mechanisms that could serve as a mediator or alternative explanation for the effects between transformational leadership and climate perceptions. This might have caused an upward bias in the effects we found. Therefore, we suggest that future research explores the combination of leadership behaviors and psychological level mechanisms as antecedents for the development of stewardship climates.

Second, we find that variability in store managers' environmental orientation constitutes an important barrier for the development of SENS-climate. Future research is needed that examines how store manager variability in environmental orientation can be effectively reduced and thereby remedying its detrimental effects. Pre-post-test experimental designs could examine the impact of interventions (e.g., self-awareness training, role playing) that could promote consistency in environmental orientation. In the conceptual development of these designs, researchers should take note of Hernandez's (2012) contention that individual or collective initiatives are likely to be more influential when it comes to shared stewardship beliefs than top-down, prescriptive measures. Longitudinal research designs may assist in tracking the impact of these initiatives and changes in a store manager's (consistency) in role modeling over time.

Thirdly, most research on stewardship focuses on the identification of its antecedents. However, our study shows that situational characteristics, like store manager-sales associate dyadic tenure, can influence the effectiveness of such antecedents. Future research on stewardship in retailing and other organizations should thus focus more on potential moderators (e.g., incentive structures, consensus among employees and team composition). Finally, the results of our study show that the creation of a SENS-climate does not necessarily come at a financial cost in the short-term. Future research should explore how the promotion of a SENSclimate impacts financial performance under different contextual influences, (e.g., changes in the economic situation, competitor strategies, supply considerations) and for companies that serve different customer segments (e.g., companies that focus on serving "green" segments might be more successful than others). Furthermore it would be interesting to see whether the stimulation of a SENS-climate has different effects on performance at individual, team and company levels and whether these effects change in the long-run. 


\subsubsection{Managerial Implications}

Our findings hold implications for marketing practice and especially for retailers. First, given the central role that store managers play in improving a retailer's environmental performance, we pose that it is important to emphasize their role within the retail outlet. Retailers could, for instance, assign the role of environmental champions to store managers and make them responsible for the dissemination of environmental practices among sales associates (Cronin, Smith, Gleim, Ramirez, \& Martinez, 2011). To help store managers fulfill this role, retailers should instigate environmental awareness programs that are tailored to store managers' specific needs. Since store managers serve as role models and need to walk the talk consistently, such programs should not only provide information about new environmental practices, but should additionally help them understand and change their own action patterns. For that purpose, retailers could use training modules that are based on a script-based approach along the lines that we have used and that can be found in Appendix B. Providing store managers with behavioral scripts can help them to identify discrepancies between their own behavior and desired behavior, and change inconsistencies that are detrimental to the retailer's environmental performance. Retailers could support such an approach by asking successful store managers to act as role models and show colleagues how they manage their own shop. The described education approaches for managers could also be used to transfer knowledge to channel partners and non-retail organizations that want to foster environmental responsibility in their organizations.

Second, our results show that the development of a SENS-climate might cause a switch in the range of products sales associates sell. To facilitate this process, store managers should encourage sales associates to evaluate regular and standard sales routines. As we show that a focus on environmentally accountability does not equate with "poor" sales performance it seems advisable to organize meetings and training sessions that illustrate best sales practices of selling green products. Giving employees access to useful information sources may assist in demonstrating that the long-run impact of buying green products can be beneficial. Facilitating the use of this information in associate interactions with customers would further motivate them to translate this knowledge into their practice. To help store managers be successful in fostering SENS retail companies should additionally implement the measurement and tracking of green selling performance. This enables store managers to provide sales associates with individual, transparent feedback and introduce explicit individual and store key performance indicators.

Whilst the context of our study was within the retail environment our findings hold implications that are applicable in a broader organizational context. Companies that want to foster responsibility for the environment among their employees should stimulate managers to employ transformational leadership practices. This can be achieved through a combination of group and individual training sessions. 


\section{CHAPTER 2}

Based on the importance of dyadic tenure in our study it seems advisable to focus on established relationships and draw lessons from these. Also, an implication is that stability in the manager base is conducive to the development of SENS. In sectors where it is routine to rotate those in managerial positions, other ways of maintaining this stability should be considered. This would entail pro-environmental practices being a fundamental part of overall strategy within an organization to ensure consistency of message and practice. 


\section{CHAPTER 3}

Me, Myself and Future Generations:

The Role of Affinity and Efficacy in the Creation of Consumer Environmental Stewardship (CENS) 


\begin{abstract}
Policymakers, consumer advocate groups and researchers agree that consumers need to increase their pro-environmental behaviors if we want to ensure a decent standard of living for future generations. Despite high levels of environmental concern consumers still refrain from large scale adoption of pro-environmental behaviors. Social marketers agree that a change in attitudes is not enough to stimulate the necessary behavioral change and are looking for ways to help consumers overcome the costs (e.g., price premiums, inconvenience) that are often associated with pro-environmental behaviors. Currently, consumers often see pro-environmental behavior as a trade-off between short-term personal benefits and longer term collective benefits. We try to contribute to the social marketing literature on pro-environmental behavior by introducing the concept of Consumer Environmental Stewardship (CENS), which centers on the use of intrinsic motivation to stimulate a personal sense of responsibility for the environment. Our findings, based on a survey and two experiments, show that the stimulation of consumers' Affinity with Future Generations (AFG) and Perceived Consumer Efficacy (PCE) can help to promote CENS, which in turn raises pro-environmental behaviors. However, we also find that increasing levels of AFG can backfire and result in lower levels of CENS, if consumers experience low levels of PCE.
\end{abstract}

Keywords: consumer environmental stewardship; affinity with future generations; perceived consumer efficacy; pro-environmental behavior 


\subsection{Introduction}

Policymakers, consumer advocate groups and researchers agree that we cannot continue to (ab)use the world's resources at the current pace. That is, not if we want to ensure a decent standard of living for future generations (UNEP, 2012). In an effort to change current consumption patterns, policy makers worldwide have invested in large scale social marketing campaigns over the past decades (Kollmuss \& Agyeman, 2002; Whitmarsh \& O'Neill, 2010). These campaigns have mainly focused on information provision based on the rationale that awareness about environmental problems and knowledge about environmentally friendly alternatives would drive pro-environmental actions (Steg \& Vlek, 2009). However, despite substantial efforts and higher levels of environmental awareness and concern, recent studies confirm that consumers still refrain from large scale adoption of pro-environmental behaviors (Cleveland et al., 2012; Englis \& Phillips, 2013). Whilst "assisted behaviors" (i.e., behaviors supported through policy changes), such as waste recycling, have become common practice in many countries, more "burdensome" decisions, such as choosing travel mode and in-home energy use schemes, have hardly changed (Whitmarsh \& O'Neill, 2010). The behaviors that consumers are willing to adopt, whilst necessary, are not sufficient to bring about real impact for a sustainable future (Thøgersen \& Crompton, 2009). Thus, we still face the enduring problem of how to increase pro-environmental behaviors to a scale that makes a sustainable future possible.

Social marketing campaigns aimed at information provision have limited efficacy as the promise of long-term environmental benefits alone does not help consumers to overcome immediate pervasive barriers (Steg \& Vlek, 2009). Organic foods and hybrid cars are more expensive, public transportation is less convenient than driving a car from door to door, and environmentally friendly technologies often perform worse than conventional alternatives (Luchs et al., 2010; OECD, 2008). Information oriented social marketing campaigns tend to have most impact when the pro-environmental behaviors being promoted are convenient and of little or no cost to the consumer (Steg \& Vlek, 2009). Moreover, the use of financial incentives to stimulate pro-environmental consumer behaviors, e.g., tax reductions on hybrid cars or subsidies for home insulation, have been more effective than information oriented social marketing campaigns alone (European Commission, 2008; OECD, 2011). However, this approach is costly and only provides a shortterm solution (Steg \& Vlek, 2009). Financial rewards stimulate extrinsic motivation, which actually reduces feelings of personal responsibility towards the environment resulting in less follow-up in pro-environmental behaviors (Prothero et al., 2011; Thøgersen \& Crompton, 2009). That is, consumers are stimulated to think of pro-environmental behaviors as personal optimization problems; when subsidies are absent choices are based on optimizing personal gains, hence, pro- 
environmental behaviors with a personal cost are avoided (Kouchaki et al., 2013; Tenbrunsel \& Messick, 1999).

In contrast, stimulating intrinsic forms of motivation can be a more effective alternative solution to facilitate long-term pro-environmental behaviors. Stimulating an intrinsic preference for a behavior facilitates adoption of such behavior regardless of costs (Messick, 1999). More fundamentally, developing responsibility is a prerequisite for an intrinsic interest in and the longevity of the behavior itself (Tenbrunsel \& Messick, 1999). This makes stimulation of intrinsic, as opposed to extrinsic, motivation more complex, yet, at the same time, more worthwhile. We seek to unravel some of this complexity. We ask; how can we encourage consumers' behavioral decisions that support environmental resource preservation through stimulation of personal responsibility, thus overcoming short-term personal costs in favor of longer term collective benefits?

Specifically, we make two substantive contributions. First, drawing on the stewardship literature, which generally describes stewardship as a willingness to take personal responsibility for the long-term benefit of a larger entity, beyond one's own self-interest (Davis et al., 1997; Hernandez, 2008), we develop and empirically assess the impact of the concept of consumer environmental stewardship as the responsibility mechanism through which consumers can be stimulated to adopt pro-environmental behaviors that serve long-term collective benefits. Stewardship has hitherto been applied as an organizational level concept regarding topmanagement and team-level responsibilities for company performance (i.e., a tangible collective benefit), that overrule their own self-interests (de Ruyter et al., 2009; Wasserman, 2006). In accordance with recent theorizing (Hernandez, 2012), we demonstrate that this concept can be usefully applied to the consumer level of responsibility where there are no formal contractual relationships. That is, we can stimulate consumer environmental stewardship as a means of subjugating shortterm personal benefits to serve a higher entity or "organization", (i.e., the environment), and its current and future beneficiaries, (i.e., society at large and future generations). In lieu of contractual obligations, we focus on the psychological and community links that individuals have with the wider society to foster stewardship (Hernandez, 2012). Accordingly, we develop and validate a scale to measure consumer environmental stewardship.

As a second contribution, we develop and test a conceptual framework that centers on consumer environmental stewardship and relevant antecedents and consequences we identified. In doing so we build on recent theorizing of the stewardship concept, which emphasizes the importance of stimulating an affective connection with others in fostering a willingness to subjugate personal interests for long-term collective benefits (Hernandez, 2012). Previous research has demonstrated that this can be achieved by raising people's affinity with future generations (Wade-Benzoni, 2008). Affinity with Future Generations (AFG) is defined as the extent to which an individual feels empathic towards and connected with fu- 
ture others (Wade-Benzoni, 2008), and serves as one of the main antecedents in our study. Additionally, Hernandez (2012) has emphasized the importance of selfefficacy in the creation of stewardship, since it does not only help people to believe they can make a difference, but also fosters their desire to do so. Previous research has shown that Perceived Consumer Efficacy (PCE); the idea that one can affect the state of the environment as an individual, can stimulate people to subjugate personal interests for the good of the environment (Do Paço et al., 2013; Moisander, 2007; Webster Jr, 1975). Therefore, we also include PCE as an antecedent in our framework. Importantly, social marketing studies convincingly demonstrate that an increase in relevance of responsible behavior results in more damaging behaviors under conditions of low levels of efficacy (Witte, 1992; Wolburg, 2001). Thus, we also examine the interaction between AFG (i.e., an increase in relevance) and PCE in two studies where both factors are manipulated as can be used in marketing communications. Finally, we examine the consequences of consumer environmental stewardship by examining its effect on a mix of pro-environmental behaviors that vary with regard to impact and difficulty to perform.

To fulfill the promise of these contributions, we proceed as follows. First, we develop a conceptual framework with consumer environmental stewardship as the mechanism that translates AFG and PCE into actual behavior. Second, we empirically test this framework through three studies. Finally, we discuss the theoretical and public policy implications of our study as supported by the emergent theoretical framework.

\subsection{Conceptualizing Consumer Environmental Stewardship (CENS)}

Stewardship requires a willingness to be accountable for a higher entity with an emphasis on the intergenerational aspects "our task is to insure that when we step aside, our job, or at least our organization, still exists for the next generation" (Block, 1993, p. 3). Accordingly, there needs to be a balancing between one's own goals and those of the larger entity (Hernandez, 2008). In organizational terms, achieving community benefits demands a balance between individual obligations to stakeholders inside and outside the organization whilst maintaining commitment to societal norms. Further, Hernandez (2008) hints at a moral basis for stewardship, that is, stewardship behavior might be based on normative beliefs about what is right and wrong. It is these social and moral concerns that drive the feeling of personal obligation inherent in stewardship. Within organizations, stewardship has been represented as a collectively held sense of responsibility towards various stakeholders that is reflected in policies, procedures and employee actions (de Ruyter et al., 2009; Hernandez, 2012). Organizational rules can develop into responsibility norms that serve as a primary motivational force behind stewardship (de Ruyter et al., 2009). Based on previous research we conclude that the steward- 
ship concept is multi-faceted, it has a moral basis and centers on a feeling of obligation, responsibility and accountability towards a bigger entity that is reflected in the willingness to balance one's own self- or group-interests with the long-term interests of this bigger entity even if this requires some personal sacrifice.

Pro-environmental behavior is defined as behavior "that harms the environment as little as possible, or even benefits the environment" (Steg \& Vlek, 2009, p. 309). Typically pro-environmental behaviors are perceived as unattractive, since they often come with costs such as price premiums, inconvenience or worse performance (Olson, 2013). As environmental problems, such as global warming and natural resource depletion, are the result of gradual and accumulative environmental damage over the long-term, today's consumers are unlikely to face the negative environmental consequences while future generations will be worse off (Kollmuss \& Agyeman, 2002). Pro-environmental behaviors thus often represent a choice that benefits collective interests at the cost of self-interests (Luchs et al., 2010). This observation has led social marketing scholars to frame the environmental problem as an intergenerational social dilemma (Thøgersen, 2008; WadeBenzoni, 2002). That is, "decisions in which the interests of present decision makers are in conflict with those of future others" (Wade-Benzoni \& Tost, 2009, p. 166). Individuals receive greater benefits if they make selfish choices than if they make cooperative (pro-environmental) choices; if everyone makes selfish choices the environment, a collectively shared resource will be depleted (Weber et al., 2004).

Stimulating personal responsibility for the environment thus poses challenges, especially since the current focus is mainly on global phenomena, such as climate change. Local environment problems, such as littering and water pollution, are rather tangible and have personal relevance through the consumer's own experience. In contrast, global problems are less immediate and tangible, and more complex to understand (Kollmuss \& Agyeman, 2002). It is extremely difficult for consumers to understand when benefits from their pro-environmental behavior will occur and who will benefit. Thus, when faced with a pro-environmental choice there is an imbalance in the trade-off between immediate tangible personal gains (e.g., lower costs) and long-term collective intangible gains (e.g., prolonged availability of resources).

As described above, stewardship holds the promise of helping people manage such trade-offs by fostering responsibility and accountability for a bigger entity, such as the environment and future generations, and stimulate them to balance personal interests with those of the bigger entity. So far most research on stewardship has focused on the organization as the larger entity and the alignment of top manager or team interests with those of the organization (Schepers et al., 2012; Wasserman, 2006). More recently, Hernandez (2012), whilst maintaining the organization as the focal entity, explored the psychological mechanisms that drive stewardship among individual employees at any level in the organization. She has 
defined stewardship as "the extent to which an individual willingly subjugates his or her personal interests to act in protection of others' long-term welfare" (Hernandez, 2012, p. 174). Her view of stewardship we argue provides a solid and insightful basis for the study of pro-environmental behaviors at the individual level because of three distinctive characteristics. First, stewardship can be explained in terms of felt obligations (especially relational and ideological) without formal written agreements or contracts. Second that, based on these obligations, stewardship fundamentally relates to the 'protection' of ongoing long-term social welfare. Third, that it allows for people to be temporally and personally detached from the consequences of their stewardship behaviors, that is, they do not necessarily have to be beneficiaries of the resulting collective gains. The stewardship concept is thus adaptable to the intergenerational context of environmental protection for the welfare of society and future generations and in this way suitable for a transition to a consumer context. Based on the previous discussion, we define our concept of Consumer Environmental Stewardship (CENS) as an individual's willingness to take personal responsibility for, and balance one's own short-term interests with longterm collective interests of the environment, society and future generations, even if this requires personal sacrifices in consumption decisions.

In our study of CENS, we identify some of its antecedents and consequences. Since it is difficult to see how a single person can make a difference to global problems, we focus on how to stimulate personal responsibility through (i) making long-term collective interests more relevant than, or at least equal to, short-term individual interests, and (ii) stimulating consumers' beliefs that they are influential in achieving long-term collective benefits, while controlling for social influences in the shape of perceived descriptive norms. The ultimate goal of stimulating feelings of environmental stewardship among consumers is fostering pro-environmental behaviors, we therefore also assess the relationship between CENS and a mix of pro-environmental behaviors that vary with regard to impact and difficulty to perform.

\subsection{Antecedents and Consequences of CENS: Hypotheses Development}

A strong affective connection and identification with a bigger entity is a prerequisite for stewardship (Block, 1993; Davis et al., 1997). People who value behaviors that promote the long-term welfare of others and feel an affective sense of connection with others are more likely to display stewardship (Hernandez, 2012). Whilst it is difficult to create an affective connection between consumers and the environment, one could try to create an emotional bond with the environment's main beneficiaries to increase the relevance of pro-environmental behaviors. We argue that feelings of responsibility for the long-term wellbeing of the environment 
could be stimulated by creating affinity with future generations (AFG), which "refers to a combination of empathy, perspective taking, and perceived oneness and is a function of the extent to which an individual feels empathic toward and connected with future others" (Wade-Benzoni \& Tost, 2009, p. 171). The stimulation of feelings of affinity and identification with future generations has been shown to entice people to make sacrifices in personal interest for the benefit of long-term welfare of others (Wade-Benzoni, 2008). In line with these findings we hypothesize:

$H_{1}$ : Higher affinity with future generations (AFG) leads to higher levels of consumer environmental stewardship (CENS).

Stewardship research emphasizes the importance of self-efficacy and selfdetermination (Davis et al., 1997; Hernandez, 2012). If a person does not feel that (s)he has the ability to influence a situation or does not have a choice in what to do about it, (s)he will not feel responsible for the outcomes of her/his actions. To encourage consumers to feel responsible for their environmental behaviors one should thus emphasize that they can affect the environmental situation. This feeling of efficacy with regard to the environment has been termed perceived consumer efficacy (PCE), and is defined as a person's belief that (s)he as an individual consumer can have a positive effect on the environment by altering her/his personal behavior (Do Paço et al., 2013; Roberts, 1996; Webster Jr, 1975). PCE is an important differentiator between those who do and do not display proenvironmental behaviors (Roberts, 1996). An increase in PCE should increase a consumer's feelings of responsibility for the environment and their willingness to make sacrifices for its benefit. We therefore hypothesize:

$\mathrm{H}_{2}$ : Higher perceived consumer efficacy (PCE) leads to higher levels of consumer environmental stewardship (CENS).

Finally, we examine the relationship between CENS and pro-environmental behavior. Since previous research has shown that pro-environmental behaviors entail multiple dimensions that differ with regard to impact and sacrifices needed in terms of money or time spent, and thus differ in difficulty to perform (Englis \& Phillips, 2013), we examine the relationship of CENS with multiple dimensions of pro-environmental behavior in our study. More specifically we examine conservation behaviors (related to the reduced use of energy, water and other resources), purchasing behaviors (related to the purchase of green products), recycling efforts (for four different materials), environmental activism (e.g., in voting and support for environmental pressure groups) and information seeking related to environmental issues (Bohlen, Schlegelmilch, \& Diamantopoulos, 1993; Minton \& Rose, 1997; Staats, Harland, \& Wilke, 2004). If a consumer displays a high level of CENS 
(s)he feels more responsible for the environment and has a higher willingness to balance personal interests with the interests of the environment and its beneficiaries. Previous research has shown that a sense of stewardship can lead people to make personal sacrifices for the benefit of others (Wade-Benzoni, Hernandez, Medvec, \& Messick, 2008). Additionally, previous research has shown that consumers with higher levels of responsibility for the environment display more proenvironmental behaviors (Wells, Ponting, \& Peattie, 2011). Therefore, we pose that higher levels of CENS will lead to higher levels of pro-environmental behavior, we hypothesize:

$H_{3}:$ Higher levels of Consumer environmental stewardship (CENS) lead to higher levels of consumers' pro-environmental behavior.

Recent research on stewardship behaviors emphasizes their normative basis (Hernandez, 2012). Driven by an underlying role modeling mechanism, people use information about what previous generations did for them to establish a norm for what they will do for the next generation. If the previous generation was generous to them, people are more generous towards the future generation (Wade-Benzoni, 2002). Similarly, consumers use others' behavior as a reference point to decide whether to act in pro-environmental ways (Cialdini, Reno, \& Kallgren, 1990; Goldstein, Cialdini, \& Griskevicius, 2008; Thøgersen, 2006). Recognizing the importance of norms within our context, we take into account perceived descriptive norms illustrative of consumers' beliefs about what most others actually do (the current generation) or did (the previous generation) with regard to the environment (Lapinski \& Rimal, 2005). Controlling for these norms allows us to account for the additional influence of our focus variables, AFG and PCE, on CENS.

In the first of our studies we test our underpinning conceptual model (H1 to H3) regarding the impact of AFG and PCE on CENS, and the impact of CENS on proenvironmental behaviors.

\subsection{Study 1}

\subsubsection{Research Setting}

Since this paper takes an intergenerational view on environmental stewardship, we choose to focus on a target audience within a specific age range to try to limit external influences on our examination of causes and consequences of CENS (e.g., life stage could be of influence). We believe that it is most interesting to focus on consumers whose behavior will affect the environment for a long time to come and whose consumption patterns are not so deeply rooted that they are hard to influence. Therefore, we focus on young adults that were born after the 1980s, people 
between 18 and 30 years old, commonly referred to as generation Y (Burns et al., 2008; Kumar \& Lim, 2008). They represent a group that has recently transitioned into the age for becoming young parents, are at the start of their career and have increasing budgets for consumption.

\subsubsection{Pre-test}

As we introduce a new concept, no scales are available to measure CENS, thus, we first developed our own scale. In this process we used a stepwise procedure as recommended by Netemeyer, Bearden and Sharma (2003) including scale testing by use of both exploratory and confirmatory factor analysis on two different samples. The initial generation of scale items was based on our literature review and definition of CENS. In addition, we examined previous scales used to measure the stewardship construct in different contexts and with different reference points (e.g. Barbuto \& Wheeler, 2006; de Ruyter et al., 2009; Groesbeck, 2001; Hernandez, 2007). Initially, fifteen items were generated. The items reflected the core characteristics of CENS in terms of felt obligation, accountability, balance and sacrifice. These items were scrutinized by two researchers experienced in the field but unfamiliar with the research at hand. As a result four items were deleted due to lack of content validity.

The scale's dimensionality was assessed through principal axis factoring (SPSS 21) on data from a sample of 213 undergraduate students. These students were asked to indicate to what extent they agreed with the CENS items on a 7-point scale (from 1 = "strongly disagree" to 7 = "strongly agree"). Based on the analysis one more item was deleted because of its statistical properties and lack of fit with other items in the scale (removing the item does not affect the breadth of our scale as the remaining items covered the facets of CENS satisfactorily). Further analysis showed that the remaining 10-item scale was, as expected, best represented by a one-factor solution. The single factor accounted for $61.84 \%$ of the variance and showed good reliability (Cronbach's Alpha $=.93$ ). We then assessed the construct validity of our newly developed scale by use of a confirmatory factor analysis (CFA). For this assessment we used a different sample ( $\mathrm{N}=225$ undergraduate students) to test our 10 -item scale in combination with two constructs previously used to explain pro-environmental consumer behaviors: 1) PCE; and 2) environmental concern (EC). PCE was measured by use of a 4-item scale adapted from Roberts (1996). To measure EC we adopted 4 items that were previously used by Kim and Choi (2005) and represent a short version of the often used NEP scale (Dunlap \& Van Liere, 1978; Dunlap, Van Liere, Mertig, \& Emmet Jones, 2000). For all scales respondents were asked to indicate to what extent they agreed with each item on a 7-point scale ranging (from 1 = "strongly disagree" to 7 = "strongly agree"). Our 10-item CENS scale showed a Composite Reliability of .91, exceeding the recommended cut-off value of .7, and an AVE of .51, exceeding the recommend- 
ed cut-off value of .5 (Fornell \& Larcker, 1981). As expected our new scale correlated significantly with both the PCE and EC scale, but CFA results showed that it is a distinct separate construct, providing evidence of discriminant validity. The 10 items of the final CENS scale can be found in Table 3.1 and a more elaborate overview of the scale development process is available in Appendix C.

Table 3.1: Items Consumer Environmental Stewardship (CENS) Scale

1 I feel a personal sense of responsibility for the environment.

2 I feel accountable for the environmental impact of my purchases.

3 I think it is inappropriate, for me as a single person, to buy products without considering the environmental impact of them.

4 When searching for a product I should seek a balance between its costs and its impact on the environment.

5 I am willing to make personal sacrifices for the good of the environment.

6 I carry responsibility for the environmental impact of my purchases on society.

7 I need to help maintaining a green environment for society.

8 In my service to society I should balance short-term personal goals with long-term environmental goals.

9 I feel responsible for the environmental impact of my purchases on future generations.

10 I need to help maintaining a green environment for future generations.

\subsubsection{Sample and Procedure}

We adopted a survey methodology to empirically test our hypotheses (H1-H3) while controlling for the influence of descriptive norms. For this study we used a sample of 589 undergraduate students since they fit the profile of generation Y. The students participated in a lab session for partial course credit. 344 participants were women (58\%), and the average age of participants was 22.07 (SD = 2.28). In the lab session respondents were asked to complete an online questionnaire. Confidentially and anonymity were assured. The questionnaire consisted of measures for AFG, PCE, CENS, a battery of items to measure pro-environmental behaviors, norms among the current generation (NCG), norms among the previous generation (NPG), and some demographics.

\subsubsection{Measures}

CENS was measured by use of the 10 -item scale we developed in our pre-test. To measure AFG we used a 4-item scale adapted from Wade-Benzoni (2008). PCE was measured by use of the same 4-item scale that was also used in the pre-test. For CENS, AFG and PCE respondents indicated the extent of their agreement to items on a 7 -point scale (from 1 = "strongly disagree" to 7 = "strongly agree"). NCG and NPG were measured by use of two 4-item scales based on a scale for measuring descriptive normative beliefs about energy conservation (Nolan, Schultz, Cialdini, 
Goldstein, \& Griskevicius, 2008). We adapted the scale to represent multiple proenvironmental behaviors. For the NCG items respondents rated the behaviors of residents currently living in their home region. For the NPG items respondents rated the behaviors of a previous generation of residents who lived in their home region a few decades ago. Responses to the questions regarding NCG and NPG were both based on a 7-point scale (ranging from 1 = "never" to 7 = "almost always").

Finally, we assessed consumers' pro-environmental behaviors by use of a battery of items representing the different dimensions of relevant behaviors identified in the literature review. To assess conservation behaviors we used ten items from a scale by Staats et al. (2004). These items were chosen on the basis of their applicability to the population under study. Pro-environmental purchasing and recycling behaviors and environmental activism were assessed by use of scales developed by Bohlen et al. (1993). The scale for environmental activism is based on their political action scale and was slightly adapted to fit our context. We used three items to measure respondents' information seeking behavior related to environmental issues (Minton \& Rose, 1997). For all behavioral items, we used a 7point scale (ranging from 1 = "never" to 7 = "always").

Consumers are rather inconsistent in their pro-environmental behaviors, in the sense that one person might recycle a lot, but conserves little energy, while another consumer acts the other way around (Steg \& Vlek, 2009). This is most likely due to variations in consumers' abilities, opportunities and motivation to perform different environmental behaviors (Thøgersen \& Ölander, 2002). Different consumers are thus likely to take different actions whilst striving to reach the same goal of environmental protection. On the basis of this observation it is more appropriate to operationalize pro-environmental behavior as a formative rather than a reflective construct (Thøgersen \& Ölander, 2002). Accordingly, we treat pro-environmental behavior as a formative construct that encompasses the 28 items from the five scales. The items on pro-environmental behavior can be found in Table 3.2, while the items for the other scales can be found in Table 3.3.

Table 3.2: Study 1: Items Pro-environmental Behavior

\begin{tabular}{|c|c|c|}
\hline Items & $\begin{array}{l}\text { Low CENS Group } \\
\text { Mean score }\end{array}$ & $\begin{array}{l}\text { High CENS Group } \\
\text { Mean score }\end{array}$ \\
\hline \multicolumn{3}{|l|}{ Conservation } \\
\hline Do you have lights burning in non-occupied rooms?a & 4.94 & 5.54 \\
\hline Is your television set on "off" instead of on "standby"? & 4.37 & 4.98 \\
\hline $\begin{array}{l}\text { Do you save dirty laundry until you can load your washing } \\
\text { machine fully? }\end{array}$ & 5.79 & 6.12 \\
\hline Do you close the faucet while brushing your teeth? & 5.93 & 6.31 \\
\hline $\begin{array}{l}\text { Do you use alternatives for the car (or motorbike) to travel } \\
\text { distances less than } 5 \mathrm{~km} \text { ? }\end{array}$ & 5.11 & 5.44 \\
\hline Do you eat a dinner without meat? & 3.48 & 4.08 \\
\hline
\end{tabular}




\begin{tabular}{lcc} 
& Mean score & Mean score \\
\hline Do you eat organically grown food? & 3.31 & 4.13
\end{tabular}

Do you bring your own shopping bag from home, when you go

shopping for groceries?

Do you refuse plastic bags or wrappings of shopkeepers for

environmental reasons?

Are you inclined to repair products or have them repaired instead

4.65 of buying them new?

\section{Purchasing}

Do you choose the environmentally friendly alternative if one of the same price is available?

Do you choose the environmentally friendly alternative regardless of price?

Do you try to discover the environmental effects of products prior to purchase?

Do you buy environmentally friendly detergents?

Do you buy products not tested on animals?

Do you buy recycled paper products?

4.82

Do you buy organically grown fruit and vegetables?

3.83

4.40

\section{Recycling}

Do you recycle paper?

3.66

Do you recycle glass?

Do you recycle plastics?

5.61

Do you recycle metals?

4.97

\section{Environmental activism}

Do you support environmental pressure groups?

Do you consider green issues in your voting behavior?

Do you write about green issues in newspapers or on internet fora/blogs?

Do you boycott companies that are not environmentally responsible?

\section{Information Seeking}

Do you compare package label information about the environmental safety of the product and/or package while you are in the grocery store?

Do you actually pay attention to advertisements about environmentally friendly products? friendly products or activities?

\footnotetext{
a Item was reversely scored before analyses because it is negatively framed, mean scores shown are after recode.
} 
We employed Smart PLS 2.0 (Ringle, Wende, \& Will, 2005) to assess the measurement properties of CENS, AFG, PCE, NCG, and NPG. Since the validity and reliability of formative constructs cannot be assessed by conventional statistical techniques (P. Cohen, Cohen, Teresi, Marchi, \& Velez, 1990), our construct for proenvironmental behavior is excluded from this analysis. The reliability of our constructs is evaluated by means of composite reliability (CR) and average variance extracted (AVE) (Chin, 1998; Fornell \& Larcker, 1981). For all measures the CR exceeds the recommended cut-off value of .7 and AVE exceeds the recommended cut-off value of .5 (CENS [CR = .94; AVE = .60], APG [CR = .85; AVE = .59], PCE [CR = .87; AVE = .62], NCG [CR = .87; AVE = .64], NPG [CR = .88; AVE = .65] (Fornell \& Larcker, 1981). Furthermore, we assessed convergent validity by inspecting if the manifest variables load adequately in magnitude on the hypothesized latent variables (Anderson \& Gerbing, 1988) and found that all but two manifest variables exhibit standardized loadings above 7 (Hulland, 1999). One item of the CENS construct and one item of the AFG construct showed loadings of .68. These loadings are very close to .7, hence, as both constructs showed good levels of reliability and both items were theoretically important, these items were retained. A detailed overview of item loadings can be found in Table 3.3. Finally, we assessed discriminant validity by comparing the square root of the AVE with the (attenuated) correlation between the latent variables of CENS, PCE, AFG, NCG, and NPG (Fornell \& Larcker, 1981). The square root of the AVE of the latent variables exceeded the (attenuated) correlation between all latent variable pairs, details can be found in Table 3.4. Additionally, we checked for cross-loadings and found that no manifest variable loaded higher on another construct than its associated construct. All in all these findings indicate discriminant validity.

Table 3.3: Study 1: Measures and Items

\begin{tabular}{|c|c|c|c|}
\hline Item & SL & $\mathrm{CR}$ & AVE \\
\hline Consumer Environmental Stewardship (CENS) & & .94 & .60 \\
\hline I feel a personal sense of responsibility for the environment. & .81 & & \\
\hline I feel accountable for the environmental impact of my purchases. & .77 & & \\
\hline $\begin{array}{l}\text { I think it is inappropriate, for me as a single person, to buy products without } \\
\text { considering the environmental impact of them. }\end{array}$ & .68 & & \\
\hline $\begin{array}{l}\text { When searching for a product I should seek a balance between its costs and its } \\
\text { impact on the environment. }\end{array}$ & .75 & & \\
\hline I am willing to make personal sacrifices for the good of the environment. & .77 & & \\
\hline I carry responsibility for the environmental impact of my purchases on society. & .71 & & \\
\hline I need to help maintaining a green environment for society. & .81 & & \\
\hline $\begin{array}{l}\text { In my service to society I should balance short-term personal goals with long-term } \\
\text { environmental goals. }\end{array}$ & .77 & & \\
\hline $\begin{array}{l}\text { I feel responsible for the environmental impact of my purchases on future } \\
\text { generations. }\end{array}$ & .81 & & \\
\hline I need to help maintaining a green environment for future generations. & .82 & & \\
\hline
\end{tabular}




\begin{tabular}{lccc}
\hline Item & SL & CR & AVE \\
\hline Perceived Consumer Efficacy (PCE) & & $\mathbf{. 8 7}$ & $\mathbf{. 6 2}$ \\
${\text { It is worthless for the individual consumer to do anything about pollution. }{ }^{a}}^{.76}$ & & \\
Since one person cannot have any effect upon natural resource problems it does & .84 & &
\end{tabular}
not make any difference what I do. ${ }^{\text {a }}$

$\begin{array}{ll}\text { Each consumer's behavior can have a positive effect on society by purchasing } & .74\end{array}$ products sold by socially responsible companies.

Even as a single person one can have an effect on pollution.

$\begin{array}{ll}\text { I feel empathic toward future generations that will be living in my home region. } & .71\end{array}$

I am able to imagine future generations that will be living in my home region. $\quad .68$

I feel an affinity toward future generations that will be living in my home region. $\quad .85$

I can identify with future generations that will be living in my home region. $\quad .81$

Norms among the Current Generation (NCG)

How often do you think that the current residents of your home region...

...try to conserve valuable resources for the sake of the environment?

...try to recycle their garbage?

...try to choose the environmentally friendly alternative if available?

...try to discover the environmental effects of products prior to purchase?

How often do you think that the residents that lived in your home region a few decades ago...

...tried to conserve valuable resources for the sake of the environment?

...tried to recycle their garbage?

...tried to choose the environmentally friendly alternative if available?

...tried to discover the environmental effects of products prior to purchase?

.83

a Items were reversely scored before analyses because they are negatively framed.

Note: SL = Standardized Loading; $\mathrm{CR}=$ Composite Reliability; AVE = Average Variance Extracted.

Table 3.4: Study 1: Intercorrelations

\begin{tabular}{lllllll}
\hline Construct & 1. & 2. & 3. & 4. & 5. & 6. \\
\hline 1. Pro-environmental behavior & - & & & & & \\
2. Consumer Environmental Stewardship (CENS) & .76 & .77 & & & & \\
3. Perceived Consumer Efficacy (PCE) & .39 & .52 & .79 & & & \\
4. Affinity with Future Generations (AFG) & .19 & .29 & .14 & .77 & & \\
5. Norms among the Current Generation (NCG) & .14 & .19 & .05 & .17 & $\mathbf{. 8 0}$ & \\
6. Norms among the Previous Generation (NPG) & .18 & .16 & .07 & .09 & .19 & $\mathbf{. 8 1}$ \\
\hline
\end{tabular}

Notes: $\mathrm{N}=589$, Square root of average variance extracted (AVE) on the diagonal where applicable. 


\subsubsection{Hypotheses Testing}

We use a partial least squares (PLS) approach to test the hypotheses in our structural model (using a bootstrapping procedure with 200 re-samples) since it allows for latent constructs to be measured formatively (Chin, 1998). This is essential since we operationalized pro-environmental behavior as a formative construct. We assessed the model fit by examining the $\mathrm{R}^{2}$ values of the endogenous constructs, which are .34 for CENS and .57 for pro-environmental behavior. Both $\mathrm{R}^{2}$ values can be categorized as large effect sizes Cohen (1988). Furthermore, we obtained a GoF value of .53, which can be classified as a large effect size (Wetzels, OdekerkenSchröder, \& van Oppen, 2009).

The results confirmed all of our hypotheses. Both, AFG $(\beta=.19, p<.05)$ and PCE $(\beta=.48, p<.01)$ have a significant positive effect on CENS, supporting hypotheses 1 and 2. That is, higher levels of AFG and higher levels of PCE lead to higher levels of CENS. With regard to our control variables, neither NCG $(\beta=.12$, n.s.) nor NPG $(\beta=.08$, n.s.) have a significant influence on CENS. Supporting H3, CENS did have a significant effect on pro-environmental behavior $(\beta=.76, p<.01)$. That is, higher levels of CENS lead to more pro-environmental behaviors. The inclusion of direct effects from the antecedents and control variables on pro-environmental behavior did not result in any additional significant effects, nor did it affect our results for hypotheses 1-3, indicating that our results are robust. We also used the model with direct effects to test for mediation by use of a Sobel-test (Zhao et al., 2010). The indirect effects of AFG $(\mathrm{z}=2.19 ; p<.05)$, and PCE $(\mathrm{z}=3.86 ; p<.01)$ through CENS on pro-environmental behavior were significant. Since the direct effects of AFG and PCE on pro-environmental behavior were not significant our results can be classified as indirect-only mediation (Zhao et al., 2010). Results are summarized in Figure 3.1.

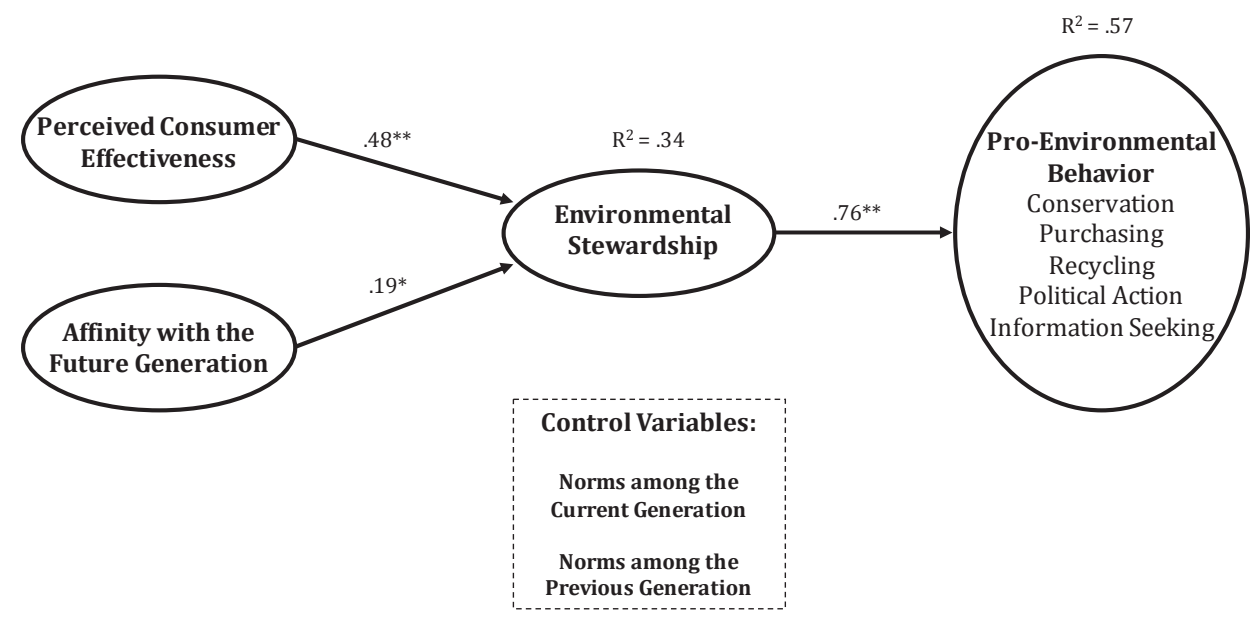

Figure 3.1: Results Conceptual Model ${ }^{*} p<.05 ;{ }^{* *} p<.01$ (two-tailed) 
We explored in further detail the effects of CENS on pro-environmental behaviors that require different amounts of effort. Based on a median split of the sample (defined by average CENS score where high CENS: $\mu_{\text {hcens }}=5.50$ and low CENS: $\mu_{\text {lcens }}$ $=3.92$ ) we used independent-samples t-tests to compare groups on their specific pro-environmental behaviors. The results are presented in Table 2.2. As expected, respondents in the high CENS group reported significantly higher levels of each of the pro-environmental behaviors compared to people in the low CENS group ( $p<$ $.05)$. Across the behavior categories, the differences between the two groups are smaller in terms of recycling and conservation behaviors, with the low CENS group also reporting recycling behaviors albeit at a lower rate. The largest differences are in recycling metal ( $\mu_{\mathrm{hcens}}=4.87$ vs. $\mu_{\mathrm{lcens}}=3.91, p<.01$ ) and refusing plastic bags ( $\mu_{\text {hcens }}=4.07$ vs. $\left.\mu_{\text {ccens }}=2.67, p<.01\right)$. We observe much larger differences between the two groups in reported purchasing, information seeking and environmental activism behaviors. Those in the higher CENS group tending to buy more environmentally friendly products (e.g., environmentally friendly detergents, $\mu_{\text {heens }}=4.31$ vs. $\left.\mu_{\text {cens }}=3.06, p<.01\right)$. However, price is still an important factor for both groups in their purchase decisions (e.g., buying environmentally important products regardless of price, $\mu_{\mathrm{hcens}}=3.67 \mathrm{vs}$. $\mu_{\mathrm{ccens}}=2.58, p<.01$ ). The high CENS group are most likely to pay attention to advertisements about pro-environmental products $\left(\mu_{\text {hcens }}=5.13\right.$ vs. $\left.\mu_{\text {lcens }}=3.73, p<.01\right)$ and consider green issues in their voting behaviors ( $\mu_{\text {hcens }}=4.77$ vs. $\left.\mu_{\text {lcens }}=3.23, p<.01\right)$.

\subsection{Exploring Potential Interaction Effects between Affinity with Future Generations (AFG) and Perceived Consumer Efficacy (PCE)}

Our first study confirms that AFG and PCE are two important predictors of CENS. Extant research in the domain of pro-environmental behavior has paid limited attention to AFG (Wade-Benzoni, 2008), while ample studies on PCE predominantly focus on consumers' general beliefs that they can personally influence the state of the environment. Many of those studies test new scales or different sets of contextual antecedents when examining the direct effects of PCE on proenvironmental behavior (Cleveland, Kalamas, \& Laroche, 2005; Cleveland et al., 2012; Kim \& Choi, 2005; Kinnear, Taylor, \& Ahmed, 1974; Roberts, 1996). In this study, we will go a step further by exploring the interaction between AFG and PCE.

Research on social dilemmas has shown that both self-efficacy and public good remedies (measures that increase the relevance of cooperative outcomes) can stimulate cooperative actions (Kerr, 1996). AFG is a stewardship antecedent that fits the characteristics of a public good remedy, while PCE is a measure of efficacy with regard to the environment. Public good remedies and efficacy are expected to interact such that public good remedies are less influential when people believe 
that they cannot personally impact the collective outcomes (low efficacy) and more effective when people believe that they can have an impact on the collective outcomes (high efficacy) (Kerr, 1996). If marketing communications increase the relevance of taking responsible action through an increase in AFG, while feelings of PCE are high, consumers have both a reason for and the ability to act proenvironmentally, making it more likely that they perform pro-environmental behavior. We propose that a stimulus that increases AFG under conditions of high PCE will result in the highest levels of CENS. However, if marketing communications stimulate AFG, but the consumer does not believe that they can have any positive influence on collective outcomes then there is no reason to cooperate.

Importantly, increasing the relevance of responsible behavior can result in more responsible behavior under high efficacy, but can backfire and result in more damaging behavior under low efficacy (Rippetoe \& Rogers, 1987; White, MacDonnell, \& Ellard, 2012; Witte, 1992; Wolburg, 2001). Low efficacy can cause people to reject marketing messages and entice them to do the opposite of what is asked. The message can create a feeling of hopelessness and fatalism that causes people to increase damaging behavior. We therefore pose that an AFG stimulus can result in boomerang effects under low levels of PCE.

$H_{4}:$ There is an interaction effect between AFG and PCE such that a condition with both high AFG and high PCE results in the highest levels of CENS, while low levels of PCE can hamper the positive impact of high AFG on CENS, and can even cause high AFG to have a negative effect on CENS.

To explore the interaction between AFG and PCE, we designed two experimental studies in which respondents' AFG and PCE were both stimulated. In these we are able to demonstrate the impact of AFG and PCE and any interaction on CENS. In our experiments we devise techniques to stimulate both $\mathrm{AFG}$ and PCE, thus demonstrating how they can be manipulated through marketing communications. Study 2 serves as a first test of our interaction hypothesis and is conducted within a student population. Additionally, we conducted a third study to test the robustness of the findings of Study 2 and assess external validity by testing our hypothesis in a sample drawn from the general public, in which a proportion of people have children.

\subsection{Study 2}

\subsubsection{Stimuli and Pre-test}

People's AFG can be stimulated by making them think of their own progeny (Wade-Benzoni, 1999; Wade-Benzoni \& Tost, 2009). By thinking of your own chil- 
dren it becomes easier to envision future generations, reducing the social distance that would prevent us from acting on their behalf. We designed a stimulus to help respondents think of their own progeny in the form of a story writing task about having (grand)children of their own (high-AFG condition). Since this experiment utilizes a student sample who belong to generation $\mathrm{Y}$ but mostly do not have children, we added a text that asked respondents in the high-AFG condition to imagine how it would be to have (grand)children of their own and how they would see their relationship with them. In addition, we designed a neutral stimulus to ensure that people in the neutral-AFG condition faced similar circumstances to people in the high-AFG condition other than the intended differences between stimuli. This neutral stimulus involved a story writing task about respondents' favorite brand and their relationship with it. The AFG stimuli used are presented in Figure 3.2.

\footnotetext{
Neutral AFG Condition Study 2 \& 3:

Please think about your favorite brand. Write a short story about your favorite brand and the reasons why you like to consume this brand. Think about your relationship with the brand. (In case you have multiple favorite brands choose one to write the story about).

Please write down everything that comes to your mind. Please spend at least 5 minutes on this assignment and try to write a story of 10 sentences or more.
}

High AFG Condition Study 2 \& 3:

Please think about your own children and grandchildren. Write a short story about how they grow up and your role as a (grand)parent. Think about your relationship with them. (In case you do not have children or grandchildren imagine what it would be like).

Please write down everything that comes to your mind. Please spend at least 5 minutes on this assignment and try to write a story of 10 sentences or more

Figure 3.2: Stimuli for Affinity with Future Generations (AFG)

We pre-tested the two AFG stimuli prior to the actual experiment. 26 people without children were randomly assigned to either the neutral- or high-AFG condition (14 respondents in the neutral-AFG condition and 12 in the high-AFG condition). After the story writing task they were asked to answer questions about their AFG and PCE. We used the same scales as in study 1, except "that will be living in my home region" was removed from each AFG item in this pre-test (Cronbach's alpha: $=.92, \mathrm{PCE}=.89$ ). Respondents in the high-AFG condition showed significantly higher levels of AFG than respondents in the neutral-AFG condition ( $\mu_{\text {hafg }}=5.44 \mathrm{vs}$. $\left.\mu_{\text {nafg }}=3.71, p<.01\right)$, while there were no significant differences with regard to PCE $\left(\mu_{\text {hafg }}=6.13\right.$ vs. $\mu_{\text {nafg }}=5.88$, n.s. $)$ demonstrating that the manipulation worked well.

Additionally, we developed two stimuli to influence respondents' PCE levels. We utilized a newspaper article, since previous research shows that media coverage has a large impact on public perceptions with regard to PCE (Roberts, 1996). Furthermore, consumers often see themselves as powerless compared to large 
industrial companies (Pieters et al., 1998). We used this information to write two articles: the first was aimed at lowering respondents PCE by arguing that consumers can have relatively little effect compared to industry (low-PCE condition); while the second was aimed at raising respondent's PCE by arguing that consumers can have a relatively big effect compared to industry (high-PCE condition). The PCE stimuli used can be found in Figure 3.3.

\begin{abstract}
Low PCE Condition:
Date

From our reporter in Brussels

In a recent report, the Institute for Sustainable Consumption (ISC) proclaims that consumers play a key role in battling climate change. A reduction in $\mathrm{CO}_{2}$ emissions is needed more quickly than industry can achieve. Disagreements and diverging interests prevent companies from taking the necessary action. In contrast, consumers show a uniform willingness to reduce the burden they put on the environment. In combination with their strength in numbers, this means consumers' potential impact is big. Looking at EU emissions alone, ISC's conservative estimate shows that 75\% of energy use and $\mathrm{CO}_{2}$ emissions are caused directly or indirectly by consumers. ISC's recent analyses show that measures directed at consumers could reduce total EU emissions by over $8 \%$ in the next ten years. This amount is larger than the combined emissions from a majority of the largest-emitting EU industrial sectors. Based on these results, ISC concluded that government initiatives for lowering emissions should focus on individual consumers. Government institutions can help consumers to change their behavior voluntarily and to seek low-carbon products and services. Consumers can reduce emissions in the least expensive way and have an immediate impact that can be sustained.
\end{abstract}

\title{
High PCE Condition: \\ Date
}

From our reporter in Brussels

In a recent report, the Institute for Sustainable Industry (ISI) proclaims that industry plays a key role in battling climate change. A reduction in $\mathrm{CO}_{2}$ emissions is needed more quickly than consumers can achieve. Disagreements and diverging interests prevent consumers from taking the necessary action. Consumers lack a uniform willingness to reduce the burden they put on the environment. In contrast, industry is more organized. In combination with its strength in size, this means that industry's potential impact is big. Looking at EU emissions alone, ISI's conservative estimate shows that $75 \%$ of energy use and $\mathrm{CO}_{2}$ emissions are caused directly or indirectly by industry. ISI's recent analyses show that measures directed at industry could reduce total EU emissions by over $8 \%$ in the next ten years. This amount is larger than the combined emissions from a majority of EU consumers. Based on these results, ISI concluded that government initiatives for lowering emissions should focus on the industrial sector. Government institutions can help industrial companies to change their practices voluntarily and to seek low-carbon solutions and opportunities. Industry can reduce emissions in the least expensive way and have an immediate impact that can be sustained.

Figure 3.3: Stimuli for Perceived Consumer Efficacy (PCE)

We pre-tested the PCE stimuli on a sample of 80 people who were randomly assigned to one of the two conditions (low-PCE vs. high-PCE). 44 respondents were allocated to the low-PCE condition and 36 to the high-PCE condition. They were asked to read a short newspaper article and think of a headline to go with the article. Afterwards, they completed the PCE scale (Cronbach's alpha = .87), AFG scale 
(Cronbach's alpha $=.80$ ) and rated the credibility of the article. Credibility of the newspaper articles was assessed by respondents indicating to what extent they agreed that the newspaper article they read was credible, believable and realistic on a 7-point scale (Cronbach's alpha $=.94$ ). We tested whether groups differed with regard to age, gender and children but this was not the case. As expected respondents in the high-PCE condition showed significantly higher levels of PCE than people in the low-PCE condition ( $\mu_{\text {hpce }}=6.09$ vs. $\mu_{\mathrm{lpce}}=4.73, p<.01$ ), but there were no significant differences for AFG ( $\mu_{\text {hpce }}=5.25$ vs. $\mu_{\mathrm{lpce}}=5.16$, n.s.) or credibility ( $\mu_{\mathrm{hpce}}=5.08$ vs. $\mu_{\mathrm{lpce}}=5.30$, n.s.).

\subsubsection{Experimental Setup}

For this experiment we used a 2 (AFG: neutral, high) $\times 2$ (PCE: low, high) betweensubjects design. We collected data from 156 undergraduate students who participated in a lab session. Four participants were excluded from the study as they had not fully completed the scales and a further 5 participants did not complete one or more of the tasks appropriately (e.g., leaving the task blank). Of the remaining 147 respondents in our sample, $49.7 \%$ (73) were female participants, the mean age was 19.80 years $(\mathrm{SD}=1.12$, range $=18-27)$ and no participants had children. Confidentiality was assured. Respondents were randomly assigned to one of the 4 conditions (36 in the neutral AFG-low PCE condition, 40 in the neutral AFG-high PCE condition, 35 in the high AFG-low PCE condition and 36 in the high AFG-high PCE condition).

Respondents took at least 5 minutes to write their story (AFG stimulus) and at least 5 minutes to read the newspaper article and come up with their headline (PCE stimulus). When finished, respondents completed a questionnaire comprised of our CENS measure (Cronbach's alpha $=.89$ ) and a behavioral measure assessing whether people would act on their environmental stewardship and forgo personal benefits for the collective good. The behavioral measure consisted of a lottery assignment where participants were asked to imagine they won a lottery and were invited to indicate the percentage of lottery winnings, if any, they would be prepared to donate to support charitable initiatives to protect the environment. Participants then completed the AFG (Cronbach's alpha $=.92$ ), PCE (Cronbach's alpha $=.82$ ) and credibility (Cronbach's alpha $=.85$ ) scales described previously. Following a short filler task, participants then answered questions on demographics. Finally, feelings of reactance, measured as a co-variate, were assessed by use of three items from the "resisting influence from others" dimension of the Hong Psychological Reactance Scale (Cronbach's alpha $=.66$ ) (Hong \& Faedda, 1996).

The manipulation check results were in line with the pre-tests. Respondents in the high-AFG condition showed significantly higher levels of AFG than the neutralAFG group ( $\mu_{\text {hafg }}=4.57$ vs. $\mu_{\text {nafg }}=2.98, p<.001$ ). Respondents in the high-PCE condition showed significantly higher levels of PCE than the low-PCE condition $\left(\mu_{\mathrm{hpce}}=\right.$ 
5.32 vs. $\mu_{\text {lpce }}=4.44, p<.001$ ), whilst both groups found the article to be a credible source of information $\left(\mu_{\mathrm{lpce}}=4.50, \mu_{\mathrm{hpce}}=4.73\right.$, n.s. $)$.

\subsubsection{Hypothesis Testing}

A two-way ANOVA was conducted to assess the effects of our AFG and PCE stimuli on CENS. Contrary to hypothesis 1 , our results show no significant effect of AFG ( $F$ $(1,143)=.76$, n.s.), but in line with hypothesis 2 they do reveal a significant positive effect of PCE $\left(F(1,143)=8.89, p<0.01, \eta^{2}=0.059\right)$. However, coefficients for the individual antecedents should be interpreted with caution, since we found a significant interaction effect between AFG and PCE on CENS $(F(1,143)=9.83, p<$ $0.01, \eta^{2}=0.064$ ), which provides support for hypothesis 4 . This interaction effect is represented in Figure 3.4 .

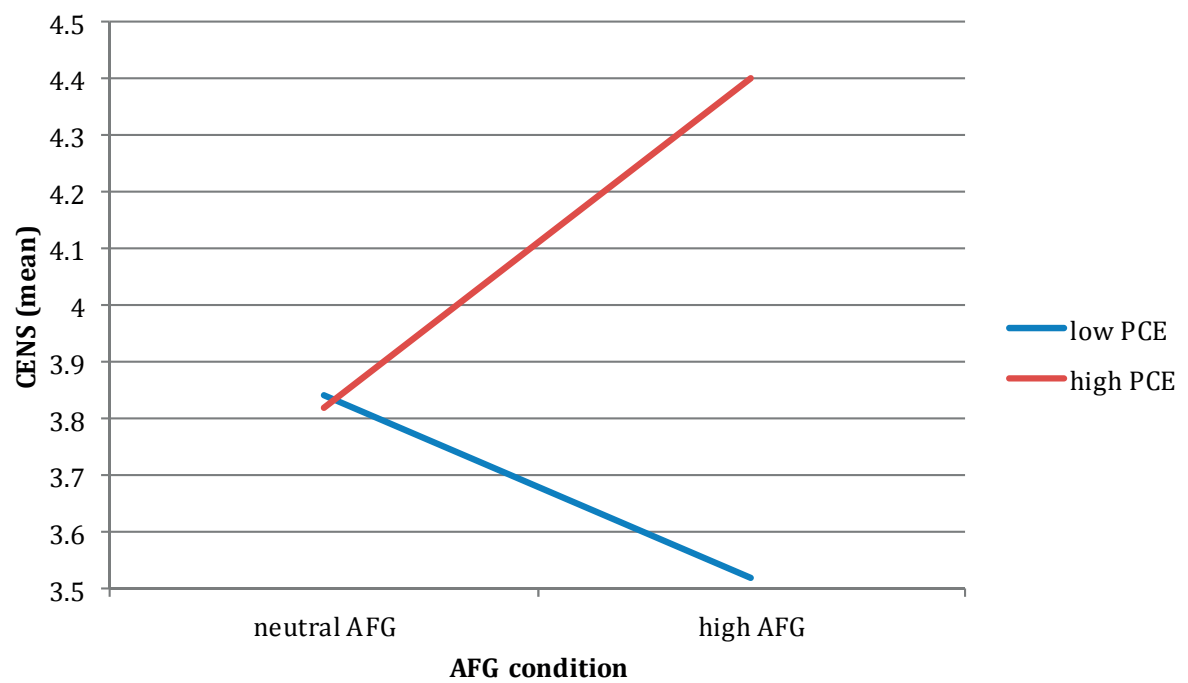

Figure 3.4: Visual Representation of Interaction between AFG and PCE for Study 2

Planned contrasts tests indicate that there is a significant difference between the high AFG-high PCE condition and the high AFG-low PCE condition ( $\mu_{\text {hafg-hpce }}=4.40$ vs. $\left.\mu_{\text {hafg-lpce }}=3.52, \mathrm{p}<.001\right)$. The high AFG-high PCE condition is also significantly different from the other two conditions ( $\mu_{\text {hafg-hpce }}=4.40$ vs. $\mu_{\text {nafg-hpce }}=3.82, \mathrm{p}<.001$; $\mu_{\text {hafg-hpce }}=4.40$ vs. $\left.\mu_{\text {nafg-lpce }}=3.84, \mathrm{p}<.001\right)$. No other significant differences were found. It is interesting that overall the group had a low mean score on CENS $\left(\mu_{2}=\right.$ 3.90 (.915)), which aids in emphasizing the positive impact of the high AFG-high PCE condition on CENS. These results provide good support for $\mathrm{H} 4$, demonstrating that stimulation of a consumer's AFG can increase levels of CENS when paired with higher PCE. It is interesting to note that, respondents in the condition in which high AFG coincided with low levels of PCE showed the lowest levels of CENS. This 
is a first indication that an increase in AFG could decrease a consumer's level of CENS if they feel that they have little individual influence on environmental change.

To test the robustness of our findings we replicated our analyses while controlling for gender and feelings of reactance. Gender was significant as a co-variate, reactance was not $\left(F_{\text {gender }}(1,141)=5.13, p<0.05, \eta^{2}=.035 ; F_{\text {reactance }}(1,141)=3.74\right.$, n.s.). Importantly, when controlling for these covariates the significant effects of our focal variables did not change.

As a final step we assessed the relationship between CENS and consumers' intentions to act in a pro-environmental way with regard to the lottery draw winnings. In line with $\mathrm{H} 3$, CENS has a significant and positive influence on the amounts of money consumers are willing to give to charity $\left(F=19.337, p<0.001\right.$, adj. $\mathrm{R}^{2}=$ $.11, \beta=.343, p<0.001$ ). Higher levels of CENS can help consumers overcome their self-interest and act in pro-environmental ways.

\section{7 $\quad$ Study 3}

Whilst the samples used previously were drawn from student groups that were representative of our target population of generation $Y$, we wanted to test the external validity of our findings by including people from the wider public within this generation who were also more likely to have children. Therefore, to test the robustness of our findings from study 2 that the stimulation of AFG has a different effect on CENS depending on the level of PCE we conducted an additional experiment, using the same method as for study 2 but with a sample drawn from the general public.

\subsubsection{Stimuli and Pre-tests}

For study 3 we used the same stimuli to manipulate PCE and AFG. Since we approached the wider public with a mix of people with and without children, we pretested the AFG stimulus once among this specific audience to make sure that the reference to people's children has the same effect in this population. In this pretest 58 people participated in an online questionnaire for a small monetary compensation (46.5\%) people indicated they had one or more children. They were randomly assigned to one of the two conditions, wrote a short story and afterwards answered questions on AFG (Cronbach's alpha $=.93$ ) and PCE (Cronbach's alpha $=.89$ ). 33 respondents were assigned to the neutral-AFG condition and 25 to the high-AFG condition (groups did not significantly differ with regard to having children). The results confirmed that people in the high-AFG condition showed significantly higher levels of AFG than people in the neutral-AFG group $\left(\mu_{\text {hafg }}=5.19\right.$ 
vs. $\left.\mu_{\text {nafg }}=3.73, p<.01\right)$, while there were no significant differences on PCE $\left(\mu_{\text {hafg }}=\right.$ 5.92 vs. $\mu_{\text {nafg }}=5.85$, n.s.).

\subsubsection{Experimental Setup}

For this second experiment we again used a 2 (AFG: neutral, high) $\times 2$ (PCE: low, high) between-subjects design. Data were collected from 139 panel members between the ages of 18 and 30 who participated in an online experiment for a small monetary compensation. Confidentiality was assured. Nine respondents were excluded from the analyses because they did not follow the instructions with regard to the story writing assignment. The mean age of participants was 24.9 years (SD = 3.60), 58\% (75) of participants were women, 32\% (42) had one or more children. Respondents were randomly assigned to one of 4 conditions (34 in the neutral AFG-low PCE condition, 33 in the neutral AFG-high PCE condition, 32 in the high AFG-low PCE condition and 31 in the high AFG-high PCE condition). Respondents were first exposed to the AFG stimulus and asked to take at least 5 minutes to write a short story. Thereafter, they were asked to read a newspaper article, that contained the PCE stimulus, and come up with their headline. Following the two tasks, they completed our measure for CENS (Cronbach's alpha $=.92$ ) and the same behavioral measure (lottery assignment) as used in study 2. As a final part of the online questionnaire respondents were asked about their AFG (Cronbach's alpha = .92), PCE (Cronbach's alpha = .78), demographics and feelings of reactance (Cronbach's alpha $=.56$ ) (Hong \& Faedda, 1996), as described for Study 2. The manipulation check results were in line with the pre-tests. Respondents in the high-AFG condition showed significantly higher levels of AFG than the neutral-AFG group $\left(\mu_{\text {hafg }}=4.85\right.$ vs. $\mu_{\text {nafg }}=4.35, p<.05$ ), while respondents in the high-PCE condition showed significantly higher levels of PCE than the low-PCE condition $\left(\mu_{\text {hpce }}=\right.$ 5.00 vs. $\mu_{\text {lpce }}=4.31, p<.01$ ).

\subsubsection{Hypothesis Testing}

Two-way ANOVA analyses were utilized to estimate the effects of our stimuli on CENS. The results were in close agreement with those found in study 2 . Contrary to hypothesis 1 there was no significant main effect of $\operatorname{AFG}(F(1,126)=1.52$, n.s.), but in line with hypothesis 2 there was a significant main effect of PCE $(F(1,126)=$ 5.91, $\left.p<.05, \eta^{2}=.05\right)$. In support of $\mathrm{H} 4$, we found a significant interaction effect between AFG and PCE on CENS $\left(F(1,126)=8.34, p<.01, \eta^{2}=.06\right)$. A visual representation of the interaction effect is presented in Figure 3.5. 


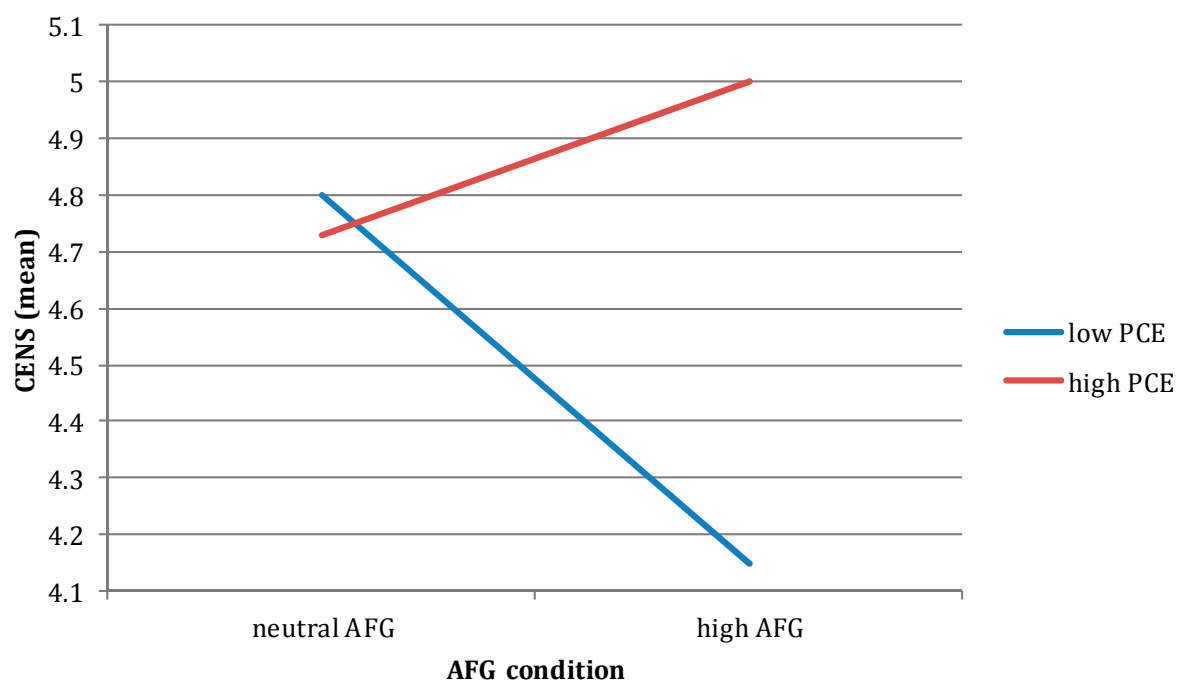

Figure 3.5: Visual Representation of Interaction between AFG and PCE for Study 3

An examination of the contrasts revealed that, as in study 2, the difference between the high AFG-high PCE condition and the high AFG-low PCE condition was significant $\left(\mu_{\text {hafg-hpce }}=5.00\right.$ vs. $\left.\mu_{\text {hafg-lpce }}=4.15, p<.01\right)$. We also found a significant difference between the other two conditions and the high-AFG-low-PCE condition $\left(\mu_{\text {lafg- }}\right.$ hpce $=4.73$ vs. $\mu_{\text {hafg-lpce }}=4.15, p<.05 ; \mu_{\text {lafg-pce }}=4.80$ vs. $\left.\mu_{\text {hafg-lpce }}=4.15, p<.01\right)$. No other significant differences were found, but the mean level of CENS was highest for the high AFG-high-PCE condition. It is worth noting that in this second sample the overall mean CENS score is higher than those for the sample in study $2\left(\mu_{3}=\right.$ 4.65 (.953) versus $\mu_{2}=3.90(.915)$ ), which aids in emphasizing the negative impact of the high AFG-low PCE interaction on lowering CENS. These results provide further support for hypothesis 4 by showing that the stimulation of consumer's AFG is only positively impactful on CENS under conditions of higher PCE. It can actually decrease levels of CENS if consumers feel that they have little personal influence on the environment. These results confirm our proposition that AFG stimuli can backfire when consumers experience low levels of PCE.

To test the robustness of our results we replicated our analyses while controlling for gender and feelings of reactance, as in study 2 , and additionally, for being a parent. None of the included control variables had a significant effect and the significant effects of our focal variables did not change $\left(F_{\text {gender }}(1,123)=1.34\right.$, n.s.; $F_{\text {reactance }}(1,123)=3.05$, n.s.; $F_{\text {parent }}(1,123)=2.12$, n.s. $)$.

Finally, we assessed the relationship between CENS and consumers' intention to exert pro-environmental behavior with regard to the lottery draw winnings. The results support hypothesis 3 and are in agreement with study 2: CENS has a significant positive influence on the amounts of money consumers are willing to give to charity $\left(F=20.97, p<.01\right.$, adj. $\left.\mathrm{R}^{2}=.13, \beta=.375, p<.01\right)$. This provides further 
evidence that higher levels of CENS can help consumers to overcome their selfinterest and act in pro-environmental ways.

\subsection{Discussion}

Despite heavy investment in information and incentive campaigns, contemporary consumers do not adopt environmentally friendly behaviors at a level necessary for future sustainability. Information-only campaigns are limited in effectiveness especially in entrenched behaviors (Whitmarsh \& O'Neill, 2010), while incentive campaigns are costly and stimulate a focus on extrinsic motivations (Prothero et al., 2011). What is needed is a fundamental shift in perceptions. We set out to establish how we could encourage consumers to adopt pro-environmental behaviors more effectively than current attempts through understanding perceived responsibility. Our first contribution is to advance the understanding of consumer responsibility for pro-environmental behaviors through the development of the concept of consumer environmental stewardship (CENS). From a theoretical perspective our conceptualization of CENS extends the notion of stewardship beyond its contemporary organizational boundaries (de Ruyter et al., 2009; Wasserman, 2006). We provide evidence to support Hernandez's (2012) claim that stewardship can be applied to a broader set of situations and at an individual consumer level. In particular, to situations where there are no formal contractual relationships to behave in certain ways, especially pertinent to the consumer context in our study. Responsibility for the environment as captured in our CENS concept is a broader concept that is not synonymous with obligation (e.g., Stern, 2000), but instead incorporates other facets. That is, in lieu of relationships based on formal contracts, consumers can adopt a stewardship perspective through not only a sense of obligation but also accountability alongside a balancing of their needs against the larger entity and making sacrifices (e.g., financial, time, convenience) if necessary.

Furthermore, we test the usefulness of CENS as the responsibility mechanism through which consumers can be stimulated to adopt behaviors with long-term collective benefits such as pro-environmental behaviors. Our second main contribution therefore stems from the exploration of the antecedents of CENS and its subsequent impact on pro-environmental behaviors. While previous research on the stewardship concept has mainly focused on laying the theoretical groundwork and identifying potential stewardship antecedents in an organizational context such as identification with a bigger entity, self-efficacy and social norms (Davis et al., 1997; Hernandez, 2008, 2012), there are, to the best of our knowledge, no studies that have operationalized or empirically tested a conceptual model centering on stewardship in a consumer context. We contribute to the literature on stewardship and pro-environmental behavior by bringing these research streams together and empirically testing our model. In this process we identified relevant anteced- 
ents of CENS by looking at factors that have previously been used in the social marketing context. We included AFG, which stems from intergenerational dilemma research (Wade-Benzoni, 2008), to increase the affective connection and identification with the bigger entity, and PCE, which is an important construct in environmental research (Roberts, 1996), to increase feelings of efficacy.

All in all, our conceptual framework, built stage wise through each of our studies, enables a better understanding of how to stimulate CENS and, crucially, how to avoid reducing CENS and the concomitant negative behavioral outcomes. The results of study 1 show that AFG and PCE both emerge as strong predictors, and therefore influencers of CENS. This is consistent with research in other areas, which has shown that PCE and AFG are strong predictors of behavior aimed to benefit a bigger entity (e.g., Roberts, 1996; Wade-Benzoni, 2008). It is these two factors that offer much promise in terms of stimulating CENS if applied appropriately. More specifically, the results of studies 2 and 3 show that increasing AFG (relevance) has a positive effect under high levels of PCE (efficacy), but can also have harmful effects under low levels of PCE. This is consistent with research in public health campaigns, which finds that increases in message relevance (e.g., through increased "threat" or "fear") can result in more damaging behavior under low levels of efficacy (Rippetoe \& Rogers, 1987; Wolburg, 2001). It has been argued that this happens because people resort to defensive mechanisms, such as denial, to cope with the "hopeless" situation (Krisjanous, Ashill, Eccarius, \& Carruthers, 2013; Witte, 1992).

Furthermore, all three studies show that there is a clear indication that stimulating CENS can foster pro-environmental behaviors. Most importantly, within our framework and throughout our three studies, CENS is shown to be a mediator of the relationships between AFG and PCE on pro-environmental behavior. Additionally, study 1 shows that people with higher levels of CENS more often perform proenvironmental behaviors than people with lower levels of CENS. Although people with higher levels of CENS can still improve, the results of study 1 show that their levels of pro-environmental behaviors are higher across all of the behavior categories tested. The differences between the two groups are smaller for conservation and recycling behaviors, which happen to be the pro-environmental behaviors that are more often performed in general. This might be a result of the large amounts of attention and spending that have been attributed to change policies and facilitate these "assisted behaviors" over recent years. People with lower levels of CENS seem to lag further behind on those pro-environmental behaviors that require higher levels of cognitive involvement such as pro-environmental purchase behaviors, environmental activism and information seeking. Previous research has shown that cognitive involvement plays an important role in the promotion of "desirable" (positive) behaviors (Krisjanous et al., 2013). The stimulation of CENS could potentially play a role in this process and foster these pro-environmental behaviors to become more commonplace. 


\subsubsection{Managerial and Practitioner Implications}

This research shows that AFG and PCE are important catalysts of CENS and indirectly pro-environmental behaviors, that can be stimulated (at least for a short while) through marketing communications. Studies 2 and 3 show that AFG can be stimulated by making people think of their own children or grandchildren. It is promising that our stimulus also worked for people who did not yet have children (study 2). Although we used a story writing task to stimulate AFG, we believe that the same effect can be reached through commercials or print ads that make people think of their own children. As such AFG could serve as a way "to instill a sense of the future in consumers" that benefits sustainability goals (Urien \& Kilbourne, 2011, p. 84). PCE can be stimulated by highlighting the importance of consumers' decisions to achieve sustainability as was shown in studies 2 and 3. Consumers feel relatively small compared to large corporations and governments, still all consumers together have a major impact. Marketing communications can be used to highlight this fact and thereby compensate for low levels of PCE.

Our findings in studies 2 and 3 are in line with the results of social marketing campaigns, especially those looking at larger scale public health issues that strongly indicate that increasing the relevance of responsible behavior to the individual can result in more damaging behaviors under conditions of low efficacy (Witte, 1992; Wolburg, 2001). Our approach demonstrates how current communication approaches could be enhanced. We show that marketing communications that stimulate AFG can promote CENS if combined with feedback signaling high PCE. $\mathrm{AFG}$ as a stimulus is significantly more effective in fostering CENS among people in the context of higher levels of PCE. However, this comes with a warning caveat. A message that stimulates AFG can backfire reducing CENS if levels of PCE are perceived as low by the individual. This finding holds several implications for commercial, governmental and non-profit organizations that use (e.g., the WWF uses communications that refer to future generations) or want to use AFG oriented communications to further the environmental cause or promote green products. First, it is better not to use AFG oriented marketing communications to target consumer groups that are known to show lower levels of PCE. Second, it is best to only use AFG oriented marketing communications in surroundings where they are unlikely to be accompanied by messages that stimulate low levels of PCE (e.g., channels that report news about environmental issues in business). All in all, it might be best to integrate a PCE stimulus in marketing communications that aim to stimulate AFG. The scale that we developed can be used to test the effectiveness of designed communications. Overall, the strong evidence of construct validity across our studies plus scale parsimony (ten-item construct) present this scale as a very usable tool for researchers and practitioners alike. 


\subsubsection{Limitations and Future Research Directions}

The findings of our studies introduce several opportunities for future research. In terms of conceptual development, establishing the nature and extent of the CENS concept across different cultures, e.g., where collectivism predominates, would provide important insights into the concept of stewardship as it applies to environmental and individual behaviors. Furthermore, our research only focuses on Generation Y, while this provides advantages with regard to internal validity, it presents a disadvantage with regard to external validity. Future research should assess to what extent the promotion of CENS helps to further pro-environmental behaviors among older generations as well. Furthermore, there are opportunities for scale development. In particular, assessing the CENS scale's validity among people outside of Generation Y would be beneficial.

Although our stimuli to manipulate AFG and PCE proved effective in the short run it would be interesting to explore their effects on CENS in the long run. It would be especially interesting to examine how repetitive exposure to such stimuli affects the development of CENS, longitudinal research designs could help to examine these effects. While our stimuli proved to be effective among people from generation $Y$, future research should examine if the effect is similar among older audiences. Previous research has shown that older people generally become more altruistic (Mathur, 1996), additionally it has been argued that older people become more concerned about the legacy they leave as a consequence of increased mortality salience (Fox, Tost, \& Wade-Benzoni, 2010; Grant \& Wade-Benzoni, 2009). These findings hint at a potentially higher effectiveness of the AFG stimuli under older age groups, but future research will have to establish if this is the case. Furthermore, our stimuli focused on children and grandchildren. These are people of the future generations that are very close to us and easily identifiable, there is limited social distance (Wade-Benzoni, 2008). Additionally, thinking of your children or grandchildren can instill a sense of future while simultaneously increasing message relevance and positive emotions, aspects that are argued to increase message acceptance and a willingness to strive for sustainability (Krisjanous et al., 2013; Urien \& Kilbourne, 2011). Future research should be used to identify the effectiveness of using different future others (in terms of distance) as there could be a threshold after which AFG stimuli become ineffective.

Finally, while testing our conceptual model in study 1 we controlled for the social normative influence, which is argued to be relevant for stewardship stimulation, by use of NCG and NPG. Contrary to expectations, consumers' perceptions of NCG and NPG did not have a significant effect on CENS. Previous findings by WadeBenzoni (2002) showed that descriptive norms that are signaled through role modeling behaviors from both the current and the previous generation can stimulate people to overcome self-interest and serve the benefit of future others. Whilst the difference with her findings may be due to the more immediate role that AFG 
and PCE have, we cannot rule out that this could be a result of the difference in approach. While Wade-Benzoni (2002) used experimental stimuli in which benefits to future others were made very salient, we used a survey design asking about perceptions of descriptive norms where benefits to others were not explicitly mentioned. Previous research on social norms has shown that such differences can have a large effect on outcomes (Lapinski \& Rimal, 2005). Therefore, future research that contrasts these different approaches could be instigated to provide more conclusive insights about the role of descriptive norms in the stimulation of CENS. Additionally, it might be interesting to examine the role of injunctive norms (Cialdini et al., 1990), especially in older generations with a heightened awareness of their legacy (Fox et al., 2010). 
CHAPTER 4

Conclusion 



\subsection{Introduction}

The objective of this dissertation was to examine how marketing can play an effective role in the achievement of environmental goals through the promotion of environmental responsibility among retailers and consumers. This final chapter concludes this dissertation by showing how this objective was achieved and starts with a brief synopsis of the findings of our empirical studies on the facilitating role of environmental stewardship in the retail and consumer contexts. Additionally, it includes a discussion of the findings of the two empirical studies with a focus on similarities, differences and other noteworthy links between the two studies without a repetition of everything that has been said in the discussions of both studies in their individual chapters. Our discussion also entails some additional suggestions for future research. Finally, this chapter provides some additional practical implications for management and public policy, before it ends with a final thought.

\subsection{Synopsis}

In this dissertation we aim to contribute to marketing research on the achievement of consumption related environmental goals by (1) examining how retailers can stimulate their employees to take more responsibility for achieving environmental goals and how this affects sales of green products, and (2) examining how marketing communication messages that aim to increase the relevance of environmental protection can be used to stimulate consumers' sense of environmental responsibility and in turn their pro-environmental behavior. We address the first aspect in chapter 2 and the second in chapter 3 .

More specifically, chapter 2 addresses the research question: how can retailers facilitate the successful implementation of environmentally responsible strategies in stores where sales associates increasingly often face situations in which they have to balance a diversity of consumer demands and their companies', often seemingly conflicting, performance objectives (e.g., financial performance, sales targets, customer service and environmental accountability standards)? To answer this question we focus on the role of store managers in the promotion of a Store Environmental Stewardship climate (SENS-climate) among sales associates. As a first contribution of this chapter we introduce the concept of SENS-climate within a retail context, which is defined as the extent to which sales associates perceive (i) a collective sense of responsibility toward the environment, which may at times entail subjugating their personal and collective interests, to limit the environmental impact of their company, (ii) that they contribute to and promote initiatives that help to improve their company's environmental performance; and (iii) that they promote environmentally responsible choices amongst a wider range of customers while trying to meet their demands. As a second contribution, we examine 
how the store managers' task-oriented actions that are reflective of strategic choice and his/her relationship-oriented actions that are aimed at relationship building and employee motivation affect the formation of a SENS-climate. With regard to task-oriented actions, our findings show that a store manager's environmental orientation, which represents the extent to which his/her action patterns indicate a prioritization of environmental accountability relative to competing goals, has a positive effect on the formation of a SENS-climate, while the store manager's variability in environmental orientation, which represents the extent to which his/her prioritization of environmental accountability varies across similar events and situations, has a negative effect on the formation of a SENS-climate. Additionally, we find that relationship-oriented actions in the shape of transformational leadership practices have a positive effect on the creation of a SENS-climate. Finally, our results show that the positive effects of a store manager's environmental orientation and transformational leadership practices on the formation of a SENS-climate are stronger for employees that have a longer working relationship with their store manager (higher dyadic tenure). As a third contribution, we examine the effects of perceived SENS-climate on three important work outcomes. The results show that SENS-climate perceptions lead to higher levels of self-perceived environmental performance, green sales and achieved margins, while such perceptions lead to lower sales of regular products.

Concluding chapter 2, we can say that facilitating the successful implementation of environmentally responsible strategies in stores starts with a focus on the store manager, since (s)he plays a key role in the promotion of environmental goals among sales associates and in turn the improvement of environmental performance at the shop floor. SENS-climate is shown to play a mediating role between a store-manager's task-oriented and relationship-oriented actions on the one hand and the sales-associate's environmental and financial performance on the other. Additionally, our results show that more attention to environmental goals does not necessarily come at the cost of financial performance. Overall, these findings indicate that retailers should instigate environmental initiatives aimed at operational managers who in turn inspire frontline employees to work towards environmental goals.

In chapter 3, we address the research question; how can we encourage consumers' behavioral decisions that support environmental resource preservation through stimulation of personal responsibility, thus overcoming short-term personal costs in favor of achieving longer term collective benefits? To answer this question we focus on the motivation of consumers to take more responsibility for their environmental impact through the stimulation of Consumer Environmental Stewardship (CENS). Our first contribution stems from the introduction of the CENS concept, which is defined as an individual's willingness to take personal responsibility for, and balance one's own short-term interests with long-term collective interests of the environment, society and future generations, even if this re- 
quires personal sacrifices in consumption decisions. Additionally, we assess its function as a responsibility mechanism that can help stimulate consumers to adopt pro-environmental behaviors that serve long-term collective interests. We do so through the development and testing of a conceptual framework that introduces Affinity with Future Generations (AFG) and Perceived Consumer Efficacy (PCE) as two important antecedents of CENS and pro-environmental behaviors as its main outcome. The first study of chapter 3 shows that AFG and PCE have a positive effect on the development of CENS which in turn stimulates pro-environmental behaviors. More specifically, our findings show that CENS mediates the effects of AFG and PCE on pro-environmental behavior in a way that can be classified as indirectonly mediation. Finally, we also examine the interaction between AFG and PCE in the development of CENS. This is done in two experimental studies where both factors are manipulated as can be adopted for use in marketing communications. The results confirm our hypothesis that the stimulation of AFG (an increase in relevance of pro-environmental action) works well in stimulating CENS under high levels of PCE (high levels of efficacy), but can backfire, and result in a decrease in CENS under low levels of PCE. Furthermore, our two experimental studies provide some extra evidence that an increase in CENS can help to stimulate proenvironmental behaviors.

All in all, chapter 3 shows that consumers can be stimulated to perform more pro-environmental behaviors by fostering feelings of responsibility through CENS. The stimulation of AFG can be used in marketing communications to raise levels of CENS as long as PCE is high or stimulated at the same time. Overall, chapter 3 shows that consumers' responsibility for their environmental impact can be stimulated in ways that can be used in marketing communications, but that contextual factors such as levels of efficacy should be kept in mind to achieve beneficial results.

Concluding, one can say that our empirical studies show that the stimulation of a sense of responsibility for the environment in a retail and a consumer context can help to achieve consumption related environmental goals. Furthermore our studies show that the stewardship concept can be used to study this phenomenon and the next paragraph will elaborate on its role in our studies and the potential for its use in future research.

\subsection{Discussion and future research directions}

This dissertation builds on previous theorizing about the stewardship concept as it has developed in the management and governance literature. Hitherto most of this literature has focused on stewardship as an organizational level concept regarding the motivation of top management and teams to take responsibility for the longterm (financial) benefits of their organization and its owners (Davis et al., 1997; 
Groesbeck, 2001). In this dissertation we take the stewardship concept a step further by demonstrating that the concept can be usefully applied to study the employee level of responsibility to a broader set of stakeholders within and outside a company (chapter 2) and the consumer level of responsibility where formal contractual relationships are absent to motivate them to take actions that benefit the collective in the long-term (chapter 3 ). In doing so we built on recent suggestions by Hernandez (2008), who pointed out that organizations serve multiple stakeholders, which means that stewardship should not only entail taking personal responsibility for an organization's financial performance, but instead should entail taking responsibility for the long-term welfare of the organizations stakeholders, and her suggestions that the concept can be applied at the individual level even if there are no contractual obligations (Hernandez, 2012). Our studies add value by providing scarce empirical evidence for her conceptual development of the stewardship concept.

We hope that our developments of the stewardship concept motivate marketing and other researchers to further use, develop and empirically test frameworks centering around the stewardship concept. Multiple marketing scholars have identified the need for companies to take a stakeholder perspective and take both environmental and social responsibility next to delivering economic value (Cronin et al., 2011; Kotler, 2011; Porter \& Kramer, 2006; Sheth, Sethia, \& Srinivas, 2011). Our findings suggest that the stewardship concept can be useful in studies that aim to identify ways in which companies can achieve this. While we examined in chapter 2 how the stewardship concept can be used to foster an increased environmental responsibility in a commercial setting where financial performance indicators traditionally are dominant, future research could use the stewardship concept to study social responsibility as well. Considering recent problems in the financial sector, there might be a great opportunity to make changes by using the stewardship concept for studying how employees of financial companies (e.g., banks and mortgage providers) can be stimulated to take personal responsibility for collective social welfare instead of maximizing their personal bonus at the end of the year or their company's financial performance. The findings of chapter 3 , that the stewardship concept can be usefully applied to the individual level of responsibility where contractual obligations are absent should be explored further in a consumer setting, but might also be useful in a medical setting. Our insights could for example be used as a basis to study the more responsible prescription of antibiotics at the level of individual health care professionals.

Hernandez (2012) has stated that there are structural (e.g., management practices and policies) and psychological (e.g., cognitive and affective) drivers of stewardship that require further study. In chapter 2 we focus on a couple of structural drivers of stewardship such as a leader's task-oriented and relationship-oriented actions, which are both shown to be important. In chapter 3 we focus on individual level psychological drivers of stewardship in the shape of consumer's AFG and PCE. 
Future research could benefit our understanding of the stewardship concept by simultaneously assessing structural and psychological drivers of stewardship. In chapter 2 we find that a structural driver such as transformational leadership practices can stimulate stewardship development, which could be because such practices stimulate beliefs of efficacy, a psychological driver which is shown to be important for the development of stewardship among consumers in our third chapter. Further studies are needed to test in detail which processes are taking place and if and to what extent individual level psychological processes mediate the effects of structural drivers on stewardship. This is relevant for processes at the organizational and consumer level of study. At a consumer level, culture and government policies might be interesting structural factors to study, culture is also interesting at an organizational level as are marketing strategies and HRM practices. With regard to psychological factors it would for example be interesting to study the influence of identification with the bigger entity or the presence of a long-term vs. short-term orientation among people.

Both of our studies show that stewardship can serve as a responsibility mechanism that plays a mediating role between its antecedents and behavior-based outcomes. Chapter 2 shows that leadership practices influence sales performance through their impact on the formation of a SENS-climate, while chapter 3 shows that AFG and PCE influence pro-environmental behaviors through the formation of CENS. This is in line with previous studies such as those by de Ruyter et al. (2009) on the role of environmental stewardship in a B2B context and Wade-Benzoni et al. (2008) on the role of stewardship in intergenerational beneficence. Future research could be aimed at examining the role of stewardship as a mediator in other contexts.

Most research on the stewardship concept aims to identify its antecedents, but both of our studies show that moderators play an important role in the creation of stewardship. Our first study shows that dyadic tenure can strengthen the effect of a leader's management practices and actions on the creation of a SENS-climate, while our second study shows that PCE impacts the effect of an AFG stimulus on levels of CENS in a consumer. Future research on the stewardship concept should take this into account and focus more on potential moderators. One potentially interesting direction for future research on this topic can be found at the crossroads of our two studies. While we study the retail (supply) and consumer (demand) side of environmental consumption separately, it would be interesting to examine what happens where they come together. Does the contact with a sales associate with low environmental stewardship impact the effect of an in-store marketing communication, such as an energy-label aimed at strengthening consumers' PCE, on the formation of environmental stewardship at the consumer level? Do a sales associates' repetitive contacts with consumers who do not care about the environmental impact of their purchases hamper the effects of a store 
manager's environmental orientation on the formation of a SENS-climate among his/her employees?

Next to studying these potential moderating factors in the formation of stewardship, it might be interesting to study what happens to the outcomes of environmental stewardship if consumers and retail employees with different levels of stewardship interact. While it is rather predictable what will happen if a consumer and sales associate both show high levels or both show low levels of environmental stewardship, it would be very interesting to see what will happen if they show contrasting levels of environmental stewardship. Will a consumer with high levels of environmental stewardship still engage in a pro-environmental purchase decision if a sales associate with a low level of environmental stewardship advises him or her, will the consumer buy anything at all or will (s)he walk away?

While previous research has highlighted the importance of role modeling and norms in the development of stewardship (Block, 1993; de Ruyter et al., 2009; Hernandez, 2008), our two studies show contrasting results on this topic. Chapter 2 shows that store managers serve as role-models who can stimulate the formation of a SENS-climate through their own environmental orientation in the shape of prioritizing environmental goals, which supports the view that a social normative influence plays a role in fostering stewardship. In chapter 3 we controlled for the perceived normative influence of current and previous generations of consumers in the stimulation of CENS and found that they did not influence stewardship development at an individual consumer level. While the focus in both studies was on descriptive norms (what others do), there is an important difference that can explain the different results. In chapter 2 we focused on the store manager's normative influence on sales associates. This normative influence is likely to be large as store managers have daily interactions with sales associates, have a higher status, more experience, and direct reward power (Brown, Treviño, \& Harrison, 2005; Manz \& Sims Jr, 1981). In contrast, chapter 3 refers to perceived actions of the current and previous generation of residents in a consumer's home region, groups of people that are probably rather abstract in a consumer's mind. The level of identification with the referent(s) who perform(s) the normative behavior is likely very different in the two studies, as sales associates are very close to their store manager, while consumers might feel a distance to current and previous generations of residents in their home region. This might have caused the difference in effects found (Lapinski \& Rimal, 2005), but future research should explore the role of descriptive norms in the stimulation of CENS further to be sure.

Additionally, it might be interesting to study which role-models have a strong social normative influence on consumers to stimulate stewardship among them. It might for example be interesting to see if prototypical consumers, celebrities or leaders such as a president are most influential. Furthermore, it could be relevant to examine how a government's actions influence normative beliefs that can stimulate stewardship among consumers. It has been recognized that policy measures 
can influence normative beliefs (OECD, 2008, 2011), but studies on this topic are scarce. Therefore, it could be interesting to study how public procurement influences consumers' perceptions of what is appropriate behavior. If your government does not buy environmentally friendly cars to perform its functions then why should you as a citizen? Next to descriptive norms it might be interesting to examine the impact of injunctive norms (consumers' beliefs about what they are expected to do) on stewardship development (Cialdini et al., 1990).

\subsection{Implications for practice and public policy}

There is a growing realization that additional supply and demand side measures are needed to decrease current consumption levels to the extent that they become sustainable (OECD, 2011). The results of the empirical studies presented in this dissertation provide some insights that can help in taking both types of measures. In this paragraph we will discuss some actions that can be taken by governments, and commercial and non-profit oriented organizations to increase proenvironmental behaviors and limit future consumption.

Chapter 2 provides insights that can help in the creation of supply side measures to decrease consumption levels. At the moment retailers such as Tesco, Walmart and BestBuy mostly focus on environmental initiatives that aim to limit their direct environmental impact through changes in transportation methods, store design, packaging, etc. (Lai et al., 2010). This is beneficial for the environment and can benefit the company through the creation of a greener image. However, considering that the largest part of a retailer's environmental impact resides in the products sold and their use phase (Prindle, 2010), retailers might be able to create an even bigger beneficial effect if they try to change what consumers buy from them. This is especially relevant for retailers selling durable products such as electronic appliances, cars or furniture. Of course, many of these retailers push their suppliers to produce greener products so that they can make their product assortments greener, which is essential and can stimulate pro-environmental consumption to a certain extent. Yet by themselves such initiatives are not enough as they do not help consumers overcome low levels of trust in the quality and higher prices of green products (Gleim et al., 2013; Luchs et al., 2010). We therefore examined how retailers' frontline employees can be motivated to pay more attention to environmental performance goals as this stimulates them to address environmental issues during customer encounters and can help their customers make more informed decisions and thereby increase levels of pro-environmental consumption.

Our study demonstrated that a store manager's behavior is essential in the creation of a SENS-climate among sales associates, which in turn increases green sales. A store manager who shows high levels of environmental orientation, a low 
variability in this orientation and high levels of transformational leadership practices is most likely to stimulate a sense of environmental responsibility among his/her sales associates. All in all this suggests that training programs aimed at improving store managers' leadership practices can be beneficial for the environmental performance of a retailer and can thereby contribute to limiting the burden created through their customers' consumption. While many retailers already have environmental training programs in place, most of them focus on changing the internal use of energy or water instead of customer choice (BIO Intelligence Service, 2009). In line with suggestions by other authors we suggest that retail management should change their environmental efforts to focus more on their customers (Sheth et al., 2011). Our results suggest they should do so by training their frontline employees to address environmental aspects when they try to meet their customers' needs, starting with store managers, who will in turn influence their sales associates. Governmental organizations could support such initiatives by providing subsidies or training materials. Such an approach could also support government institutions' continuous investments in labeling programs, which have limited impact on consumer decisions if used in isolation (OECD, 2011). If both labels and sales associates support the choice for pro-environmental alternatives, consumers might be more willing to buy them.

Furthermore, our findings show that an improvement in environmental performance does not necessarily come at a financial cost for the retailer. By informing store managers and sales associates that this is the case, the common belief that there is a trade-off to be made between environmental and financial performance might be changed, which can increase beliefs of environmental efficacy among frontline employees and create even better results.

The studies in chapter 3 provide some insights about ways to affect proenvironmental consumption through demand side measures. Our studies show how environmental responsibility among consumers can be fostered through the stimulation of AFG and PCE, which can in turn affect their willingness to engage in pro-environmental behaviors and purchase pro-environmental products. The results show that the stimulation of AFG by making consumers think of their own children can trigger them to feel more responsible for their environmental impact if they simultaneously have high levels of PCE, but that consumers might feel less responsible in case they display low levels of PCE. The main implication stemming from this research is that organizations using stimuli aimed at the increase of AFG should avoid targeting those consumers with low levels of PCE or should simultaneously include a stimulus that triggers consumers to feel higher levels of PCE. While we used a story writing task to stimulate AFG, this is also possible through other means that are more suitable for use in marketing communications. IKEA for example made an online commercial to promote their LED light bulbs in which they show a pregnant woman (stimulus of AFG), who describes how easy it is to have a positive impact on the environment (stimulus of PCE), because the light 
bulbs are available at IKEA and one only has to buy them once in 20 years (IKEA, 2013). Unilever, although using a somewhat more serious tone, used a similar approach to promote project sunlight, a project to stimulate sustainability initiatives (Unilever, 2013). In the Unilever commercial, people who are expecting a child are talking about the importance of taking action to preserve the environment so that their child can live a happy life. Simultaneously, Unilever is presented as a company that helps them to take action. By triggering you to think of future generations and thereby highlighting the relevance of taking pro-environmental action while integrating a message on how the company (IKEA or Unilever) provides you with the opportunity to make a difference, they have combined two ingredients for a successful pro-environmental marketing campaign. Governmental, commercial or non-profit organizations who want to use an AFG stimulus might want to look at these examples for ideas. A single minded focus on the need to preserve nature for future generations without stimuli for PCE, such as used in the Dutch slogan of WWF (Geef de aarde door), might be less successful if used in isolation, although it can be effective as part of their marketing activities showing how people help the environment by supporting WWF.

While the findings of chapter 3 might be useful in print ads and commercials, they could also be used for the improvement of in-store communications. In stores you often see indications that a consumer can make a difference for the environment. Just think of the increasing amount of product labels available indicating that a product is biologically grown, made from renewable resources or consumes less energy in use. Communications aimed at showing the relevance of making a proenvironmental choice, such as an AFG stimulus, are used less often. Introducing more in-store communications that highlight the relevance of taking environmental responsibility might support labeling programs and thereby help to stimulate pro-environmental choices.

\subsection{A final thought}

This dissertation started with the statement that there is a need to change consumption levels if we are to achieve sustainability goals and want to give future generations the opportunity to have a decent standard of living. Since fostering pro-environmental consumption behaviors requires both supply and demand side measures, we tried to provide valuable insights by devoting one chapter to research that can be used to advance supply side measures and another chapter to research that can help optimize demand side measures to foster proenvironmental behavior. Our findings show that studying the stewardship concept can be helpful in finding ways to stimulate environmental responsibility among retail personnel and consumers. While there still is a long road to go towards more sustainable levels of consumption and one could think that one dissertation, like 


\section{CHAPTER 4}

one consumer performing pro-environmental behaviors, will not make a difference, we believe that the combined effect of single (or small groups of) researchers devoting time and effort to study pro-environmental consumption, like the combined effect of individual consumers taking pro-environmental action, can bring about the necessary changes. Next to the main contributions of the studies presented in this dissertation, we hope that this dissertation helps to support the belief that people, whether in their role as citizens, consumers, researchers, managers, sales associates or any other, can be motivated to take environmental responsibility and thereby fosters future research on the topic. Because "if we have the belief that people will not take responsibility they will prove us right" (Block, 1993, p. 209). 
References 
Abelson, R. P. (1981). Psychological status of the script concept. American Psychologist, 36, 715-729.

Aiken, L. S., \& West, S. G. (1991). Multiple regression: Testing and interpreting interactions. Thousand Oaks, CA: Sage.

Aldeyab, M., Scott, M., Kearney, M., Alahmadi, Y., Magee, F., Conlon, G., et al. (2014). Impact of an enhanced antibiotic stewardship on reducing methicillin-resistant staphylococcus aureus in primary and secondary healthcare settings. Epidemiology and infection, 142, 494-500.

Anderson, J. C., \& Gerbing, D. W. (1988). Structural equation modeling in practice: A review and recommended two-step approach. Psychological Bulletin, 103, 411-423.

Arnold, T. J., Palmatier, R. W., Grewal, D., \& Sharma, A. (2009). Understanding retail managers' role in the sales of products and services. Journal of Retailing, 85, 129-144.

Avolio, B. J., \& Bass, B. M. (1995). Multifactor leadership questionnaire: Rater form (5x-short). Redwood City, CA: Mind Garden, Inc.

Barbuto, J., John E., \& Wheeler, D. W. (2006). Scale development and construct clarification of servant leadership. Group \& Organization Management, 31, 300-326.

Bass, B. M. (1999). Two decades of research and development in transformational leadership. European Journal of Work \& Organizational Psychology, 8, 9-32.

Bass, B. M., \& Avolio, B. J. (1994). Improving organizational effectiveness through transformational leadership. Thousand Oaks, CA: Sage.

Bauer, D. J., Preacher, K. J., \& Gil, K. M. (2006). Conceptualizing and testing random indirect effects and moderated mediation in multilevel models: New procedures and recommendations. Psychological Methods, 11, 142-163.

Berson, Y., \& Avolio, B. J. (2004). Transformational leadership and the dissemination of organizational goals: A case study of a telecommunication firm. Leadership Quarterly, 15, 625-646.

Best Buy Co. Inc. (2010). People, technology and power in the connected world: Annual sustainability report fiscal 2010. Retrieved June 12, 2014, from http://www.socialfunds.com/shared/reports/ 1279598903_BestBuy_2010_Sustainability_Report.pdf

Biel, A., \& Thøgersen, J. (2007). Activation of social norms in social dilemmas: A review of the evidence and reflections on the implications for environmental behaviour. Journal of Economic Psychology, 28, 93-112.

BIO Intelligence Service. (2009). Towards a greener retail sector. Retrieved May 16, 2012, from http://ec.europa.eu/environment/eussd/pdf/report_green_retail.pdf

Block, P. (1993). Stewardship: Choosing service over self-interest. San Francisco, CA: Berrett-Koehler.

Bohlen, G., Schlegelmilch, B. B., \& Diamantopoulos, A. (1993). Measuring ecological concern: A multiconstruct perspective. Journal of Marketing Management, 9, 415-430.

Brady, K., Hendry, J., \& Kanchwala, S. (2010, March). Retail: A sustainability benchmark. Retrieved June 12, 2014, from http://www.greenbiz.com/business/research/report/2010/04/23/retail-sustai nability-benchmark

Brown, M. E., Treviño, L. K., \& Harrison, D. A. (2005). Ethical leadership: A social learning perspective for construct development and testing. Organizational Behavior and Human Decision Processes, 97, 117-134.

Burger, J., \& Gochfeld, M. (2001). Stewardship and the US department of energy: Encompassing ecosystem protection. Journal of Environmental Planning \& Management, 44, 437-454.

Burns, D. J., Reid, J., Toncar, M., Anderson, C., \& Wells, C. (2008). The effect of gender on the motivation of members of Generation Y college students to volunteer. Journal of Nonprofit \& Public Sector Marketing, 19, 99-118.

Caldwell, C., Hayes, L., Bernal, P., \& Karri, R. (2008). Ethical stewardship - implications for leadership and trust. Journal of Business Ethics, 78, 153-164.

Caldwell, C., \& Karri, R. (2005). Organizational governance and ethical systems: A covenantal approach to building trust. Journal of Business Ethics, 58, 249-259.

Casimir, G. (2001). Combinative aspects of leadership style: The ordering and temporal spacing of leadership behaviors. Leadership Quarterly, 12, 245-278. 
Chin, W. W. (1998). The partial least squares approach to structural equation modeling. In G. A. Marcoulides (Ed.), Modern methods for business research (pp. 295-336). Mahwah, NJ: Lawrence Erlbaum Associates.

Cialdini, R. B., Reno, R. R., \& Kallgren, C. A. (1990). A focus theory of normative conduct: Recycling the concept of norms to reduce littering in public places. Journal of Personality and Social Psychology, 58, 1015-1026.

Cleveland, M., Kalamas, M., \& Laroche, M. (2005). Shades of green: Linking environmental locus of control and pro-environmental behaviors. Journal of Consumer Marketing, 22, 198-212.

Cleveland, M., Kalamas, M., \& Laroche, M. (2012). 'It's not easy being green': Exploring green creeds, green deeds, and internal environmental locus of control. Psychology \& Marketing, 29, 293-305.

Cohen, J. (1988). Statistical power analysis for the behavioral sciences. Hillsdale NJ: Lawrence Erlbaum Associates.

Cohen, P., Cohen, J., Teresi, J., Marchi, M. L., \& Velez, C. N. (1990). Problems in the measurement of latent variables in structural equations causal models. Applied Psychological Measurement, 14, 183-196.

Colbert, A. E., Kristof-Brown, A. L., Bradley, B. H., \& Barrick, M. R. (2008). CEO transformational leadership: The role of goal importance congruence in top management teams. Academy of Management Journal, 51, 81-96.

Cronin, J., Smith, J., Gleim, M., Ramirez, E., \& Martinez, J. (2011). Green marketing strategies: An examination of stakeholders and the opportunities they present. Journal of the Academy of Marketing Science, 39, 158-174.

Davis, J. H., Schoorman, F. D., \& Donaldson, L. (1997). Toward a stewardship theory of management. Academy of Management Review, 22, 20-47.

Dawes, R. M. (1980). Social dilemmas. Annual Review of Psychology, 31, 169-193.

de Ruyter, K., de Jong, A., \& Wetzels, M. G. M. (2009). Antecedents and consequences of environmental stewardship in boundary-spanning B2B teams. Journal of the Academy of Marketing Science, 37, 470-487.

Deutsch Salamon, S., \& Robinson, S. L. (2008). Trust that binds: The impact of collective felt trust on organizational performance. Journal of Applied Psychology, 93, 593-601.

Do Paço, A., Alves, H., Shiel, C., \& Filho, W. L. (2013). A multi-country level analysis of the environmental attitudes and behaviours among young consumers. Journal of Environmental Planning \& Management, 56, 1532-1548.

Donaldson, L., \& Davis, J. H. (1991). Stewardship theory or agency theory: CEO governance and shareholder returns. Australian Journal of Management, 16, 49-65.

Dunlap, R. E., \& Jones, R. E. (2002). Environmental concern: Conceptual and measurement issues. In R. E. Dunlap \& W. Michelson (Eds.), Handbook of environmental sociology (pp. 482-524). Westport: Greenwood Press.

Dunlap, R. E., \& Van Liere, K. D. (1978). The "new environmental paradigm": A proposed measuring instrument and and preliminary results. Journal of Environmental Education, 9, 10-19.

Dunlap, R. E., Van Liere, K. D., Mertig, A. G., \& Jones, R. E. (2000). Measuring endorsement of the new ecological paradigm: A revised NEP scale. Journal of Social Issues, 56, 425-442.

Englis, B. G., \& Phillips, D. M. (2013). Does innovativeness drive environmentally conscious consumer behavior? Psychology \& Marketing, 30, 160-172.

Euromonitor International. (2010a, February). The future's electric: Prospects for electronics and appliance specialist retailers - world. Retrieved June 12, 2014, from http://www.euromonitor .com/the-futures-electric-prospects-for-electronics-and-appliance-specialist-retailersworld/report

Euromonitor International. (2010b, October). Global discretionary goods \& services markets in 2009 and 2010: Legacy of the downturn (part 2). Retrieved June, 2014, from http://www.euromonitor. com/global-discretionary-goods-and-services-markets-in-2009-and-2010-legacy-of-thedownturn-part-2/report

European Commission. (2008). Communication from the commission to the European parliament, the council, the European economic and social committee and the committee of the regions on the sustainable consumption and production and sustainable industrial policy action plan. Retrieved June 
30, 2014, from http://eur-lex.europa.eu/LexUriServ/LexUriServ.do?uri=COM:2008:0397:FIN:EN: PDF

Fornell, C., \& Larcker, D. F. (1981). Evaluating structural equation models with unobservable variables and measurement error. Journal of Marketing Research, 18, 39-50.

Fox, M., Tost, L. P., \& Wade-Benzoni, K. A. (2010). The legacy motive: A catalyst for sustainable decision making in organizations. Business Ethics Quarterly, 20, 153-185.

Gleim, M. R., Smith, J. S., Andrews, D., \& Cronin Jr, J. J. (2013). Against the green: A multi-method examination of the barriers to green consumption. Journal of Retailing, 89, 44-61.

Goldstein, N. J., Cialdini, R. B., \& Griskevicius, V. (2008). A room with a viewpoint: Using social norms to motivate environmental conservation in hotels. Journal of Consumer Research, 35, 472-482.

Grant, A. M., \& Wade-Benzoni, K. A. (2009). The hot and cool of death awareness at work: Mortality cues, aging, and self-protective and prosocial motivations. The Academy of Management Review, 34, 600-622.

Griskevicius, V., Tybur, J. M., \& van den Bergh, B. (2010). Going green to be seen: Status, reputation, and conspicuous conservation. Journal of Personality and Social Psychology, 98, 392-404.

Groesbeck, R. L. (2001). An empirical study of group stewardship and learning: Implications for work group effectiveness. Unpublished doctoral dissertation, State University, Blacksburg VA.

Gully, S. M., Incalcaterra, K. A., Joshi, A., \& Beaubien, J. M. (2002). A meta-analysis of team-efficacy, potency, and performance: Interdependence and level of analysis as moderators of observed relationships. Journal of Applied Psychology, 87, 819.

Gupta, S., \& Ogden, D. T. (2009). To buy or not to buy? A social dilemma perspective on green buying. Journal of Consumer Marketing, 26, 376-391.

Hackman, J. R. (1992). Group influences on individuals in organizations. In M. D. Dunnette \& L. M. Hough (Eds.), Handbook of industrial and organizational psychology, vol. 3 (2nd ed.). (pp. 199-267). Palo Alto, CA: Consulting Psychologists Press.

Hair, J. F., Black, B., Babin, B., Anderson, R. E., \& Tatham, R. L. (2006). Multivariate data analysis (Sixth ed.). NJ: Prentice Hall.

Hart, D. W., \& Cornia, G. C. (1994). From intergenerational equity to intergenerational stewardship. International Journal of Public Administration, 17, 2267-2389.

Hernandez, M. (2007). Stewardship: Theoretical development and empirical test of its determinants. Unpublished doctoral dissertation, Duke University, Durham NC.

Hernandez, M. (2008). Promoting stewardship behavior in organizations: A leadership model. Journal of Business Ethics, 80, 121-128.

Hernandez, M. (2012). Toward an understanding of the psychology of stewardship. Academy of Management Review, 37, 172-193.

Homburg, C., Wieseke, J., \& Bornemann, T. (2009). Implementing the marketing concept at the employee-customer interface: The role of customer need knowledge. Journal of Marketing, 73, 64-81.

Hong, S.-M., \& Faedda, S. (1996). Refinement of the Hong psychological reactance scale. Educational \& Psychological Measurement, 56, 173.

Hulland, J. (1999). Use of partial least squares (PLS) in strategic management research: A review of four recent studies. Strategic Management Journal, 20, 195.

IKEA. (2013). Imagine not having to change a light bulb for 20 years. Retrieved October 19, 2014, from http://www.youtube.com/watch?v=rZGHhTglbvU

Jöreskog, K. G., \& Sörbom, D. (2006). Lisrel 8.80 for Windows. Lincolnwood, IL: Scientific Software International, Inc.

Kerr, N. L. (1996). "Does my contribution really matter?”: Efficacy in social dilemmas. In W. Stroebe \& M. Hewstone (Eds.), European review of social psychology (Vol. 7, pp. 209-240). Chichester UK: Wiley.

Kim, Y., \& Choi, S. M. (2005). Antecedents of green purchase behavior: An examination of collectivism, environmental concern, and PCE. Advances in Consumer Research, 32, 592-599.

King, A., \& Lenox, M. (2002). Exploring the locus of profitable pollution reduction. Management Science, 48, 289-299. 
Kinnear, T. C., Taylor, J. R., \& Ahmed, S. A. (1974). Ecologically concerned consumers: Who are they? Journal of Marketing, 38, 20-24.

Klassen, R. D., \& Whybark, D. C. (1999). The impact of environmental technologies on manufacturing performance. Academy of Management Journal, 42, 599-615.

Kollmuss, A., \& Agyeman, J. (2002). Mind the gap: Why do people act environmentally and what are the barriers to pro-environmental behavior? Environmental Education Research, 8, 239-260.

Kortenkamp, K. V., \& Moore, C. F. (2006). Time, uncertainty, and individual differences in decisions to cooperate in resource dilemmas. Personality and Social Psychology Bulletin, 32, 603-615.

Kotler, P. (2011). Reinventing marketing to manage the environmental imperative. Journal of Marketing, 75, 132-135.

Kouchaki, M., Smith-Crowe, K., Brief, A. P., \& Sousa, C. (2013). Seeing green: Mere exposure to money triggers a business decision frame and unethical outcomes. Organizational Behavior \& Human Decision Processes, 121, 53-61.

Krisjanous, J., Ashill, N. J., Eccarius, K., \& Carruthers, J. (2013). Scared stiff? The effectiveness of threat appeals in counseling services advertising to high-anxiety students. Psychology \& Marketing, 30, 874-890.

Kumar, A., \& Lim, H. (2008). Age differences in mobile service perceptions: Comparison of Generation Y and baby boomers. Journal of Services Marketing, 22, 568-577.

Lai, K.-h., Cheng, T. C. E., \& Tang, A. K. Y. (2010). Green retailing: Factors for success. California Management Review, 52, 6-31.

Lapinski, M. K., \& Rimal, R. N. (2005). An explication of social norms. Communication Theory, 15, 127147.

Le Breton-Miller, I., Miller, D., \& Lester, R. H. (2011). Stewardship or agency? A social embeddedness reconciliation of conduct and performance in public family businesses. Organization Science, 22, 704-721.

Lee, P. M., \& O’Neill, H. M. (2003). Ownership structures and R\&D investments of U.S. and Japanese firms: Agency and stewardship perspectives. Academy of Management Journal, 46, 212-225.

Leonidou, C. N., Katsikeas, C. S., \& Morgan, N. A. (2013). "Greening” the marketing mix: Do firms do it and does it pay off? Journal of the Academy of Marketing Science, 41, 151-170.

Luchs, M. G., Naylor, R. W., Irwin, J. R., \& Raghunathan, R. (2010). The sustainability liability: Potential negative effects of ethicality on product preference. Journal of Marketing, 74, 18-31.

MacKinnon, D. P., Lockwood, C. M., \& Williams, J. (2004). Confidence limits for the indirect effect. Multivariate Behavioral Research, 39, 99-128.

Manz, C. C., \& Sims Jr, H. P. (1981). Vicarious learning: The influence of modeling on organizational behavior. Academy of Management Review, 6, 105-113.

March, J. G. (1994). A primer on decision making: How decisions happen. New York, NY: The Free Press.

Martynov, A. (2009). Agents or stewards? Linking managerial behavior and moral development. Journal of Business Ethics, 90, 239-249.

Mathieu, J. E., Heffner, T. S., Goodwin, G. F., Salas, E., \& Cannon-Bowers, J. A. (2000). The influence of shared mental models on team process and performance. Journal of Applied Psychology, 85, 273.

Mathur, A. (1996). Older adults' motivations for gift giving to charitable organizations: An exchange theory perspective. Psychology \& Marketing, 13, 107-123.

Menguc, B., \& Auh, S. (2008). Conflict, leadership, and market orientation. International Journal of Research in Marketing, 25, 34-45.

Messick, D. M. (1999). Alternative logics for decision making in social settings. Journal of Economic Behavior \& Organization, 39, 11-28.

Mills, B., \& Schleich, J. (2010). What's driving energy efficient appliance label awareness and purchase propensity? Energy Policy, 38, 814-825.

Minton, A. P., \& Rose, R. L. (1997). The effects of environmental concern on environmentally friendly consumer behavior: An exploratory study. Journal of Business Research, 40, 37-48.

Moisander, J. (2007). Motivational complexity of green consumerism. International Journal of Consumer Studies, 31, 404-409. 
Morhart, F. M., Herzog, W., \& Tomczak, T. (2009). Brand-specific leadership: Turning employees into brand champions. Journal of Marketing, 73, 122-142.

Netemeyer, R. G., Bearden, W. O., \& Sharma, S. (2003). Scaling procedures: Issues and applications. Thousand Oaks, CA: Sage Publications, Inc.

Nipkow, J., Josephy, B., Bush, E., \& Michel, A. (2012). Cold appliances: Recommendations for policy design. Retrieved February 2, 2014, from http://www.topten.eu/uploads/File/Recommendations_Cold_May\%202012.pdf

Nolan, J. M., Schultz, P. W., Cialdini, R. B., Goldstein, N. J., \& Griskevicius, V. (2008). Normative social influence is underdetected. Personality and Social Psychology Bulletin, 34, 913-923.

OECD. (2008). Promoting sustainable consumption: Good practices in OECD countries. Paris: OECD Publishing.

OECD. (2011). Greening household behaviour: The role of public policy. Paris: OECD Publishing.

Olson, E. L. (2013). It's not easy being green: The effects of attribute tradeoffs on green product preference and choice. Journal of the Academy of Marketing Science, 41, 171-184.

Peattie, K. (2001). Towards sustainability: The third age of green marketing. Marketing Review, 2, 129146.

Peattie, K., \& Peattie, S. (2009). Social marketing: A pathway to consumption reduction? Journal of Business Research, 62, 260-268.

Pieters, R., Bijmolt, T., van Raaij, F., \& de Kruijk, M. (1998). Consumers' attributions of proenvironmental behavior, motivation, and ability to self and others. Journal of Public Policy \& Marketing, 17, 215 225.

Podsakoff, P. M., Mackenzie, S. B., Lee, J.-Y., \& Podsakoff, N. P. (2003). Common method biases in behavioral research: A critical review of the literature and recommended remedies. Journal of Applied Psychology, 88, 879-903.

Podsakoff, P. M., MacKenzie, S. B., Moorman, R. H., \& Fetter, R. (1990). Transformational leader behaviors and their effects on followers' trust in leader, satisfaction, and organizational citizenship behaviors. Leadership Quarterly, 1, 107-142.

Poortinga, W., Steg, L., \& Vlek, C. (2004). Values, environmental concern, and environmental behavior: A study into household energy use. Environment and Behavior, 36, 70-93.

Porter, M. E., \& Kramer, M. R. (2006). Strategy \& society: The link between competitive advantage and corporate social responsibility. Harvard Business Review, 84, 78-92.

Porter, M. E., \& Reinhardt, F. L. (2007). A strategic approach to climate. Harvard Business Review, 85, 22-26.

Preacher, K. J., \& Hayes, A. F. (2008). Contemporary approaches to assessing mediation in communication research. In A. F. Hayes, M. D. Slater \& L. B. Snyder (Eds.), The sage sourcebook of advanced data analysis methods for communication research (pp. 13-54). Thousand Oaks, CA: Sage.

Preacher, K. J., \& Selig, J. P. (2010). Monte carlo method for assessing multilevel mediation: An interactive tool for creating confidence intervals for indirect effects in 1-1-1 multilevel models. Retrieved June 1, 2014, from http://www.quantpsy.org/medmc/medmc111.htm

Prindle, W. R. (2010). From shop floor to top floor: Best business practices in energy efficiency. Retrieved June 12, 2014, from http://www.c2es.org/docUploads/PEW_EnergyEfficiency_FullReport.pdf

Prothero, A., Dobscha, S., Freund, J., Kilbourne, W. E., Luchs, M. G., Ozanne, L. K., et al. (2011). Sustainable consumption: Opportunities for consumer research and public policy. Journal of Public Policy \& Marketing, 30, 31-38.

Rasbash, J., Browne, W., Healy, M., Cameron, B., \& Charlton, C. (2010). Mlwin 2.22. Bristol, UK: University of Bristol, Centre for Multilevel Modelling.

Ringle, C. M., Wende, S., \& Will, A. (2005). Smart PLS 2.0 (beta). Hamburg, Germany.

Rippetoe, P. A., \& Rogers, R. W. (1987). Effects of components of protection-motivation theory on adaptive and maladaptive coping with a health threat. Journal of Personality and Social Psychology, 52, 596-604.

Roberts, J. A. (1996). Green consumers in the 1990s: Profile and implications for advertising. Journal of Business Research, 36, 217-231. 
Schepers, J., Falk, T., de Ruyter, K., de Jong, A., \& Hammerschmidt, M. (2012). Principles and principals: Do customer stewardship and agency control compete or complement when shaping frontline employee behavior? Journal of Marketing, 26, 1-20.

Schneider, B., White, S. S., \& Paul, M. C. (1998). Linking service climate and customer perceptions of service quality: Test of a causal model. Journal of Applied Psychology, 83, 150-163.

Sheth, J., Sethia, N., \& Srinivas, S. (2011). Mindful consumption: A customer-centric approach to sustainability. Journal of the Academy of Marketing Science, 39, 21-39.

Shimp, T. A., Hyatt, E. M., \& Snyder, D. J. (1991). A critical appraisal of demand artifacts in consumer research. Journal of Consumer Research, 18, 273-283.

Singh, J. (1993). Boundary role ambiguity: Facets, determinants, and impacts. Journal of Marketing, 57, 11-31.

Staats, H., Harland, P., \& Wilke, H. A. M. (2004). Effecting durable change: A team approach to improve environmental behavior in the household. Environment and Behavior, 36, 341-367.

Steg, L., \& Vlek, C. (2009). Encouraging pro-environmental behaviour: An integrative review and research agenda. Journal of Environmental Psychology, 29, 309-317.

Stern, P. C. (2000). Toward a coherent theory of environmentally significant behavior. Journal of Social Issues, 56, 407-424.

Tamma, P. D., Holmes, A., \& Ashley, E. D. (2014). Antimicrobial stewardship: Another focus for patient safety? Current opinion in infectious diseases, 27, 348-355.

Tenbrunsel, A. E., \& Messick, D. M. (1999). Sanctioning systems, decision frames, and cooperation. Administrative Science Quarterly, 44, 684-707.

The Gallup Organisation. (2009). Europeans' attitudes towards the issue of sustainable consumption and production: European Commission, Directorate-General for the Environment.

Thøgersen, J. (2006). Norms for environmentally responsible behaviour: An extended taxonomy. Journal of Environmental Psychology, 26, 247-261.

Thøgersen, J. (2008). Social norms and cooperation in real-life social dilemmas. Journal of Economic Psychology, 29, 458-472.

Thøgersen, J., \& Crompton, T. (2009). Simple and painless? The limitations of spillover in environmental campaigning. Journal of Consumer Policy, 32, 141-163.

Thøgersen, J., \& Ölander, F. (2002). Human values and the emergence of a sustainable consumption pattern: A panel study. Journal of Economic Psychology, 23, 605-630.

Tosi, H. L., Brownlee, A. L., Silva, P., \& Katz, J. P. (2003). An empirical exploration of decision-making under agency controls and stewardship structure. Journal of Management Studies, 40, 2053-2071.

UNEP. (2011). Visions for change: Recommendations for effective policies on sustainable lifestyles. Paris.

UNEP. (2012). Global outlook on sustainable consumption and production policies: Taking action together. Paris: United Nations Environment Programme.

Unilever. (2013). Why bring a child into this world? Retrieved October 19, 2014, from http://www.youtube.com/watch?v=NL-207QGzN0

Urien, B., \& Kilbourne, W. (2011). Generativity and self-enhancement values in eco-friendly behavioral intentions and environmentally responsible consumption behavior. Psychology \& Marketing, 28, 69-90.

Wade-Benzoni, K. A. (1999). Thinking about the future: An intergenerational perspective on the conflict and compatability between economic and environmental interests. American Behavioral Scientist, $42,1393$.

Wade-Benzoni, K. A. (2002). A golden rule over time: Reciprocity in intergenerational allocation decisions. Academy of Management Journal, 45, 1011-1028.

Wade-Benzoni, K. A. (2008). Maple trees and weeping willows: The role of time, uncertainty, and affinity in intergenerational decisions. Negotiation and Conflict Management Research, 1, 220-245.

Wade-Benzoni, K. A., Hernandez, M., Medvec, V., \& Messick, D. (2008). In fairness to future generations: The role of egocentrism, uncertainty, power, and stewardship in judgments of intergenerational allocations. Journal of Experimental Social Psychology, 44, 233-245. 
Wade-Benzoni, K. A., \& Tost, L. P. (2009). The egoism and altruism of intergenerational behavior. Personality \& Social Psychology Review, 13, 165-193.

Walumbwa, F. O., Avolio, B. J., \& Zhu, W. (2008). How transformational leadership weaves its influence on individual job performance: The role of identification and efficacy beliefs. Personnel Psychology, 61, 793-825.

Wasserman, N. (2006). Stewards, agents, and the founder discount: Executive compensation in new ventures. Academy of Management Journal, 49, 960-976.

Weber, J. M., Kopelman, S., \& Messick, D. M. (2004). A conceptual review of decision making in social dilemmas: Applying a logic of appropriateness. Personality \& Social Psychology Review, 8, 281307.

Webster Jr, F. E. (1975). Determining the characteristics of the socially conscious consumer. Journal of Consumer Research, 2, 188-196.

Wells, V. K., Ponting, C. A., \& Peattie, K. (2011). Behaviour and climate change: Consumer perceptions of responsibility. Journal of Marketing Management, 27, 808-833.

Wetzels, M., Odekerken-Schröder, G., \& van Oppen, C. (2009). Using PLS path modeling for assessing hierarchical construct models: Guidelines and empirical illustration. MIS Quarterly, 33, 177-195.

White, K., MacDonnell, R., \& Ellard, J. H. (2012). Belief in a just world: Consumer intentions and behaviors toward ethical products. Journal of Marketing, 76, 103-118.

Whitmarsh, L., \& O’Neill, S. (2010). Green identity, green living? The role of pro-environmental selfidentity in determining consistency across diverse pro-environmental behaviours. Journal of Environmental Psychology, 30, 305-314.

Wieseke, J., Ahearne, M., Lam, S. K., \& Dick, R. v. (2009). The role of leaders in internal marketing. Journal of Marketing, 73, 123-145.

Witte, K. (1992). Putting the fear back into fear appeals: The extended parallel process model. Communication Monographs, 59, 329-349.

Wofford, J. C., \& Goodwin, V. L. (1990). Effects of feedback on cognitive processing and choice of decision style. Journal of Applied Psychology, 75, 603-612.

Wolburg, J. M. (2001). The "risky business" of binge drinking among college students: Using risk models for PSAs and anti-drinking campaigns. Journal of Advertising, 30, 23-39.

World Commission on Environment and Development. (1987). Our common future. Oxford, UK: Oxford University Press.

Worrell, R., \& Appleby, M. C. (2000). Stewardship of natural resources: Definition, ethical and practical aspects. Journal of Agricultural and Environmental Ethics, 12, 263-277.

Yaffe, T., \& Kark, R. (2011). Leading by example: The case of leader OCB. Journal of Applied Psychology, 96, 806-826.

Zhao, X., Lynch Jr, J. G., \& Chen, Q. (2010). Reconsidering Baron and Kenny: Myths and truths about mediation analysis. Journal of Consumer Research, 37, 197-206.

Zimmer, M. R., Stafford, T. F., \& Stafford, M. R. (1994). Green issues: Dimensions of environmental concern. Journal of Business Research, 30, 63-74.

Zohar, D., \& Luria, G. (2004). Climate as a social-cognitive construction of supervisory safety practices: Scripts as proxy of behavior patterns. Journal of Applied Psychology, 89, 322-333. 
Appendix 



\section{Appendix A}

Table A1: Measures and Measurement Criteria

\begin{tabular}{lr}
\hline Measures & St. Loadings t-Value ${ }^{\mathrm{a}}$
\end{tabular}

SENS-Climate $[\mathrm{n}=3, \mathrm{CR}=.921, \mathrm{AVE}=.797]$

1. The sales associates in our store display a collective sense of responsibility

$.97^{b}$

.75 for the environment.

2. Sales associates in our store feel accountable for the environmental impact of our work.

3. In our store, we feel that we have to act in service of the environment when trying to achieve our sales goals.

4. Sales associates in our store seek to balance long-term environmental goals and short-term profitability goals.

5. Sales associates working in our store are willing to make sacrifices for the good of the environment.

For company initiatives

6. We come up with initiatives to make our company more environmentally friendly.

7. We believe that we need to play a leading role to make our company more sustainable.

8. If we have an idea that can help our company to improve its environmental performance we take the initiative to execute it.

For customers' choices

9. In addressing customer demands, we attempt to come up with solutions that are best for the environment.

10. We encourage customers to seek a balance between personal and environmental interests.

11. We educate customers about the environmental impact of the products in our assortment.

Transformational Leadershipc $[n=4, \mathrm{CR}=.954, \mathrm{AVE}=.837]$

Idealized influence

1. IIA1

2. IIA2

3. IIA3

4. IIB1

5. IIB2

6. IIB3

Inspirational motivation

7. IM1

8. IM2

9. IM3

Intellectual stimulation

10. IS1

11. IS2

12. IS3
N.A.

N.A.

11.76

.69

9.64

.66

.73

10.32

$.95^{b}$

9.07

.79 N.A.

$.69 \quad 9.86$

.72

10.35

$.74^{b}$

7.74

.77 N.A.

.84

11.12

.72

9.76 


\section{APPENDIX}

\begin{tabular}{lcc}
\hline Measures & \multicolumn{2}{c}{ St. Loadings t-Value ${ }^{\mathrm{a}}$} \\
\hline Individual consideration & $.88^{b}$ & 7.09 \\
13. IC1 & .72 & N.A. \\
14. IC2 & .56 & 7.13 \\
15. IC3 & .82 & 9.99 \\
\hline
\end{tabular}

aAll t-values are $p<.05$.

${ }^{b}$ These refer to the standardized loadings of the first-order constructs on the higher-order construct.

'Because of copyright restrictions item-wording of transformational leadership scale cannot be published.

Notes: $\mathrm{CR}=$ composite reliability, $\mathrm{AVE}=$ average variance extracted, N.A. = not applicable. 


\section{Appendix B}

You have the possibility to add another washing machine to your assortment with a price of $€ 800$. Which washing machine would you choose to add to your assortment in the following scenes?

Scene 1: Machine B uses $8 \%$ less electricity per wash and is therefore a lot more environmentally friendly. The margin on Machine B is 29\%, while the margin on Machine A is 30\%.

Which one would you choose? (Machine A/Machine B)

Scene 2: Machine B uses 2\% less electricity per wash and is therefore a bit more environmentally friendly. The margin on Machine B is 29\%, while the margin on Machine A is 30\%.

Which one would you choose? (Machine A/Machine B)

Scene 3: Machine B uses $8 \%$ less electricity per wash and is therefore a lot more environmentally friendly. The margin on Machine B is $25 \%$, while the margin on Machine A is $30 \%$.

Which one would you choose? (Machine A/Machine B)

Scene 4: Machine B uses $2 \%$ less electricity per wash and is therefore a bit more environmentally friendly. The margin on Machine B is $25 \%$, while the margin on Machine A is $30 \%$.

Which one would you choose? (Machine A/Machine B)

If you answered Machine A to any of the above, how would you react if you consider this extra information:

The production of Machine B costs less energy. The amount of energy saved in the production process equals the amount of energy that can be saved by using Machine B for two years. The energy saved in the production process thus adds up to the environmental gain that can be achieved by using Machine B.

Which one would you choose?

Scene 1: (Machine A/Machine B)

Scene 2: (Machine A/Machine B)

Scene 3: (Machine A/Machine B)

Scene 4: (Machine A/Machine B)
If you answered Machine B to any of the above, how would you react if you consider this extra information:

The production of Machine B costs more energy. The amount of energy lost in the production process equals the amount of energy that can be saved by using Machine B for two years. The energy lost in the production process thus offsets part of the environmental gain that can be achieved by using Machine $\mathrm{B}$.

Which one would you choose?

Scene 1: (Machine A/Machine B)

Scene 2: (Machine A/Machine B)

Scene 3: (Machine A/Machine B)

Scene 4: (Machine A/Machine B)

Figure B1: Stem Scenario 2 
It is busy in your store and you decide to help an unattended customer in the appliances section. The customer is looking for a refrigerator with a content of 200 liters and a freezing compartment for a maximum of $€ 600$. You have two options of different brands in your assortment. Brand B is more sustainable and therefore better for the environment. Which refrigerator would you promote in the following scenes?

Scene 1: The refrigerator of Brand B has a lifetime that is 3 years longer on average than the refrigerator of Brand A. Brand B is therefore a lot more sustainable. For Brand A you can earn a commission of 10 points ${ }^{a}$, while you will not get any commission for selling Brand B.

Which one would you promote? (Brand A/Brand B)

Scene 2: The refrigerator of Brand B has a lifetime that is 1 year longer on average than the refrigerator of Brand A. Brand B is therefore a bit more sustainable. For Brand A you can earn a commission of 10 pointsa, while you will not get any commission for selling Brand B.

Which one would you promote? (Brand A/Brand B)

Scene 3: The refrigerator of Brand B has a lifetime that is 3 years longer on average than the refrigerator of Brand A. Brand B is therefore a lot more sustainable. For Brand A you can earn a commission of 20 points ${ }^{\text {a }}$, while you will not get any commission for selling Brand B.

Which one would you promote? (Brand A/Brand B)

Scene 4: The refrigerator of Brand B has a lifetime that is 1 year longer on average than the refrigerator of Brand A. Brand B is therefore a bit more sustainable. For Brand A you can earn a commission of 20 pointsa, while you will not get any commission for selling Brand B.

Which one would you promote? (Brand A/Brand B)

If you answered Brand $\mathbf{A}$ to any of the above, how would you react if you consider this extra information:

Brand $\mathrm{A}$ also uses 3\% more electricity on warm days, which adds up to the environmental burden it creates through its shorter lifetime.

Which refrigerator would you promote?

Scene 1: (Brand A/Brand B)

Scene 2: (Brand A/Brand B)

Scene 3: (Brand A/Brand B)

Scene 4: (Brand A/Brand B)
If you answered Brand B to any of the above, how would you react if you consider this extra information:

Brand B uses 3\% more electricity on warm days, which offsets part of the environmental gain that is achieved by its longer lifetime.

Which refrigerator would you promote?

Scene 1: (Brand A/Brand B)

Scene 2: (Brand A/Brand B)

Scene 3: (Brand A/Brand B)

Scene 4: (Brand A/Brand B)

Figure B2: Stem Scenario 3

${ }^{a}$ The focal company uses a point system for commissions, the collected points are later transferred to money. 
You have a staff meeting with your sales associates. You only have 45 minutes before the store opens. There are a number of regular topics that need to be discussed like the sales promotions for the week, and performance targets with regard to sales and returns. Besides, your supervisor has composed a list of measures that can be taken to alleviate the environmental impact of your activities. The list includes guidelines about the efficient use of heaters, air-conditioning, and lighting. You can choose to discuss these environmental measures in 5 minutes, which will severely limit their impact. Or you can choose to take 15 minutes to explain the environmental measures, which will allow you to clarify everything and will help your sales associates to achieve the predicted energy savings. How much time would you spend on the environmental measures in the following scenes?

Scene 1: The environmental measures proposed by your supervisor can reduce your energy use by $6 \%$, which means a large environmental gain can be achieved. You would be able to fill 45 minutes with the regular items on your agenda, but you are on schedule with regard to your performance targets.

How much time would you spend on the environmental measures? (5 Minutes/15 Minutes)

Scene 2: The environmental measures proposed by your supervisor can reduce your energy use by $2 \%$, which means a small environmental gain can be achieved. You would be able to fill 45 minutes with the regular items on your agenda, but you are on schedule with regard to your performance targets.

How much time would you spend on the environmental measures? (5 Minutes/15 Minutes)

Scene 3: The environmental measures proposed by your supervisor can reduce your energy use by $6 \%$, which means a large environmental gain can be achieved. Actually, you need 45 minutes for the regular items on your agenda, since you are behind schedule with regard to your performance targets.

How much time would you spend on the environmental measures? (5 Minutes/15 Minutes)

Scene 4: The environmental measures proposed by your supervisor can reduce your energy use by $2 \%$, which means a small environmental gain can be achieved. Actually, you need 45 minutes for the regular items on your agenda, since you are behind schedule with regard to your performance targets.

How much time would you spend on the environmental measures? (5 Minutes/15 Minutes)

If you answered 5 Minutes to any of the above, how would you react if you consider this extra information:

You know that your supervisor thinks that the environmental measures are very important?

How much time would you spend on the environmental measures?

Scene 1: (5 Minutes/15 Minutes)

Scene 2: (5 Minutes/15 Minutes)

Scene 3: (5 Minutes/15 Minutes)

Scene 4: (5 Minutes/15 Minutes)
If you answered 15 Minutes to any of the above, how would you react if you consider this extra information:

You know that your supervisor thinks that the performance targets are very important?

How much time would you spend on the environmental measures?

Scene 1: (5 Minutes/15 Minutes)

Scene 2: (5 Minutes/15 Minutes)

Scene 3: (5 Minutes/15 Minutes)

Scene 4: (5 Minutes/15 Minutes)

Figure B3: Stem Scenario 4 
It is busy in your store and you decide to help an unattended customer in the television section. In a short conversation about the customer's wishes, (s)he tells you that (s)he would like to spend around $€ 500$. From your conversation you also know that there is $100 \%$ chance that (s)he would buy a Plasma TV of $€ 500$ if you recommend it. Next to the Plasma TV is a LED TV for €600, which is much more energy efficient and therefore better for the environment. You can earn a margin of $€ 120$ on both. When considering the following scenes, would you go for the certain sale of the Plasma TV or try to sell the LED TV.

Scene 1: The LED TV uses 30\% less energy than the Plasma TV and is therefore a lot more environmentally friendly. From your conversation you know that there is a 95\% chance that the customer buys the LED TV if you recommend it, and a 5\% chance (s)he buys nothing at all.

Which TV would you recommend? (Plasma/LED)

Scene 2: The LED TV uses 5\% less energy than the Plasma TV and is therefore a bit more environmentally friendly. From your conversation you know that there is a $95 \%$ chance that the customer buys the LED TV if you recommend it, and a 5\% chance (s)he buys nothing at all.

Which TV would you recommend? (Plasma/LED)

Scene 3: The LED TV uses 30\% less energy than the Plasma TV and is therefore a lot more environmentally friendly. From your conversation you know that there is a $75 \%$ chance that the customer buys the LED TV if you recommend it, and a 25\% chance (s)he buys nothing at all.

Which TV would you recommend? (Plasma/LED)

Scene 4: The LED TV uses 5\% less energy than the Plasma TV and is therefore a bit more environmentally friendly. From your conversation you know that there is a $75 \%$ chance that the customer buys the LED TV if you recommend it, and a 25\% chance (s)he buys nothing at all.

Which TV would you recommend? (Plasma/LED)

If you answered Plasma to any of the above, how would you react if you consider this extra information:

The energy savings that can be achieved with the LED TV will allow the customer to recoup the extra costs quickly, which halves the chance that the customer buys nothing at all, if you recommend the LED TV.

Which TV would you recommend?

Scene 1: (Plasma/LED)

Scene 2: (Plasma/LED)

Scene 3: (Plasma/LED)

Scene 4: (Plasma/LED)
If you answered LED to any of the above, how would you react if you consider this extra information:

The energy savings that can be achieved with the LED TV will only allow the customer to recoup the extra costs slowly, which doubles the chance that the customer buys nothing at all, if you recommend the LED TV.

Which TV would you recommend?

Scene 1: (Plasma/LED)

Scene 2: (Plasma/LED)

Scene 3: (Plasma/LED)

Scene 4: (Plasma/LED)

Figure B4: Stem Scenario 5 
There is a customer in your store who asks for washing machine "Delta". It is a specific washing machine that you do not have in your store. One of your sales associates has come to ask you about the possibilities to order it for the customer. A quick information search showed that it is available and can be ordered with the same delivery time as the washing machines that you have in your store. Furthermore you found that the Delta uses less electricity because of a new technology, which makes it more environmentally friendly than the other washing machines in your store. Its washing results are as good as the available alternatives can deliver. When considering the following scenes, would you advise your sales associate to promote an alternative with the same price to the customer, or would you order the Delta for the customer?

Scene 1: The Delta uses $10 \%$ less electricity per wash and is therefore a lot more environmentally friendly than the alternative. The margin on the Delta is $1 \%$ lower than the margin on the alternative.

What would you do? (Promote Alternative/Order Delta)

Scene 2: The Delta uses 2\% less electricity per wash and is therefore a bit more environmentally friendly than the alternative. The margin on the Delta is $1 \%$ lower than the margin on the alternative.

What would you do? (Promote Alternative/Order Delta)

Scene 3: The Delta uses 10\% less electricity per wash and is therefore a lot more environmentally friendly than the alternative. The margin on the Delta is $10 \%$ lower than the margin on the alternative.

What would you do? (Promote Alternative/Order Delta)

Scene 4: The Delta uses 2\% less electricity per wash and is therefore a bit more environmentally friendly than the alternative. The margin on the Delta is $10 \%$ lower than the margin on the alternative.

What would you do? (Promote Alternative/Order Delta)

If you answered Promote Alternative to any of the above, how would you react if you consider this extra information: The Delta also uses 5\% less water than the alternative, which adds up to the environmental gain achieved by its lower electricity use.

What would you do?

Scene 1: (Promote Alternative/Order Delta) Scene 2: (Promote Alternative/Order Delta) Scene 3: (Promote Alternative/Order Delta) Scene 4: (Promote Alternative/Order Delta)
If you answered Order Delta to any of the above, how would you react if you consider this extra information: The Delta uses 5\% more water than the alternative, which offsets part of the environmental gain achieved by its lower electricity use.

What would you do?

Scene 1: (Promote Alternative/Order Delta) Scene 2: (Promote Alternative/Order Delta) Scene 3: (Promote Alternative/Order Delta) Scene 4: (Promote Alternative/Order Delta)

Figure B5: Stem Scenario 6 
The dishwasher in your canteen has broken down. Therefore, you are looking to replace it with a new one. Dishwasher A costs $€ 500$. Which dishwasher would you acquire in the following scenes?

Scene 1: Dishwasher B uses 10\% less electricity and is therefore a lot more environmentally friendly, but is $€ 25$ more expensive than Dishwasher A.

Which dishwasher would you acquire? (Dishwasher A/Dishwasher B)

Scene 2: Dishwasher B uses 3\% less electricity and is therefore a bit more environmentally friendly, but is €25 more expensive than Dishwasher A.

Which dishwasher would you acquire? (Dishwasher A/Dishwasher B)

Scene 3: Dishwasher B uses 10\% less electricity and is therefore a lot more environmentally friendly, but is $€ 75$ more expensive than Dishwasher A.

Which dishwasher would you acquire? (Dishwasher A/Dishwasher B)

Scene 4: Dishwasher B uses 3\% less electricity and is therefore a bit more environmentally friendly, but is €75 more expensive than Dishwasher A.

Which dishwasher would you acquire? (Dishwasher A/Dishwasher B)

If you answered Dishwasher A to any of the above, how would you react if you consider this extra information: Dishwasher A has an average lifetime of 9 years, while Dishwasher B has an average lifetime of 10 years. The longer lifetime of Dishwasher B will increase the environmental gain that is achieved by using Dishwasher B .

Which dishwasher would you acquire?

Scene 1: (Dishwasher A/Dishwasher B) Scene 2: (Dishwasher A/Dishwasher B) Scene 3: (Dishwasher A/Dishwasher B) Scene 4: (Dishwasher A/Dishwasher B)
If you answered Dishwasher B to any of the above, how would you react if you consider this extra information: Dishwasher A has an average lifetime of 10 years, while Dishwasher B has an average lifetime of 9 years. The shorter lifetime of Dishwasher B will offset part of the environmental gain that is achieved by using Dishwasher B.

Which dishwasher would you acquire?

Scene 1: (Dishwasher A/Dishwasher B)

Scene 2: (Dishwasher A/Dishwasher B)

Scene 3: (Dishwasher A/Dishwasher B)

Scene 4: (Dishwasher A/Dishwasher B)

Figure B6: Stem Scenario 7 
There is a customer in your store who wants to buy a refrigerator. The customer is looking at a refrigerator (Fridge A) that costs $€ 800$, and is not very energy efficient. You have the possibility to promote a more energy efficient refrigerator (Fridge B) for the same price. Which refrigerator would you promote in the following scenes?

Scene 1: Fridge B uses 15\% less electricity than Fridge A and is therefore a lot more environmentally friendly. The margin on Fridge $B$ is $€ 10$ less than the margin on Fridge A. Which one would you promote? (Fridge A/Fridge B)

Scene 2: Fridge B uses 3\% less electricity than Fridge A and is therefore a bit more environmentally friendly. The margin on Fridge $B$ is $€ 10$ less than the margin on Fridge A. Which one would you promote? (Fridge A/Fridge B)

Scene 3: Fridge B uses 15\% less electricity than Fridge A and is therefore a lot more environmentally friendly. The margin on Fridge $B$ is $€ 50$ less than the margin on Fridge A. Which one would you promote? (Fridge A/Fridge B)

Scene 4: Fridge B uses 3\% less electricity than Fridge A and is therefore a bit more environmentally friendly. The margin on Fridge B is $€ 50$ less than the margin on Fridge A. Which one would you promote? (Fridge A/Fridge B)

If you answered Fridge A to any of the above, how would you react if you consider this extra information: The customer told you that the refrigerator's energy efficiency is very important to him/her.

Which one would you promote?

Scene 1: (Fridge A/Fridge B)

Scene 2: (Fridge A/Fridge B)

Scene 3: (Fridge A/Fridge B)

Scene 4: (Fridge A/Fridge B)
If you answered Fridge B to any of the above, how would you react if you consider this extra information: The customer told you that the refrigerator's energy efficiency is not important to him/her.

Which one would you promote?

Scene 1: (Fridge A/Fridge B)

Scene 2: (Fridge A/Fridge $B$ )

Scene 3: (Fridge A/Fridge B)

Scene 4: (Fridge A/Fridge B)

Figure B7: Stem Scenario 8 



\section{Appendix C}

\section{Scale Validation}

\section{Pre-Study 1: Developing the Initial Scale}

In our development of a scale for consumer environmental stewardship (CENS) we used a stepwise procedure as recommended by Netemeyer et al. (2003). We started with the generation of scale items on the basis of our literature review and our definition of CENS. Since there are no scales available to measure environmental stewardship among consumers, we looked at previous scales that were used to measure the stewardship construct in different contexts and with different reference points (e.g. Barbuto \& Wheeler, 2006; de Ruyter et al., 2009; Groesbeck, 2001; Hernandez, 2007). Initially, fifteen items were generated. To assess content validity, these items were presented to two researchers who are experienced in the field, but unfamiliar with the research at hand. They were asked to indicate to what extent these items were representative of our definition of CENS. On the basis of their input we decided to exclude four of the fifteen original items since they were not considered representative. We then sought to empirically assess the dimensionality of the 11-item scale to confirm the expected one-factor structure by use of exploratory factor analysis.

\section{Sample and Procedure}

The sample consisted of 213 undergraduate students who were asked to participate in a lab session in exchange for partial course credit. As a part of this session they were presented with an online questionnaire in which they were assured that their data would be treated confidentially before they were asked to read the CENS items and indicate to what extent they agreed with each item on a 7-point scale ranging from "strongly disagree" (1) to "strongly agree" (7). Fifty-one percent of the participants were women (109), and the average age of participants was 20.82 $(\mathrm{SD}=1.56)$.

\section{Results and Discussion}

In line with guidelines by Netemeyer et al. (2003) we used principal axis factoring to assess the dimensionality of our scale and multiple criteria to decide on the adequate number of factors. We used SPSS 21 for analysis. Both the MSA score (.92) and Bartlett's test for sphericity $(p<.01)$ showed that there was ample correlation among used variables to conduct exploratory factor analysis. Our initial solu- 
tion showed that a one-factor solution was most appropriate, since there was only one factor with an Eigen-value above 1 (6.56) that accounted for 59.64\% of variance extracted and the scree plot gave a plain indication that the one-factor solution was most fitting. However, our solution showed that one item ("I believe I need to be among the $10 \%$ most environmentally responsible consumers even if it costs more money") showed a rather low factor loading of .60 and a low communality of .36. Therefore we decided to drop this item and re-run the exploratory factor analysis with the ten retained items. Again we found one factor with an Eigen-value above 1 (6.18) that accounted for $61.84 \%$ of variance extracted and a scree plot that confirmed that a one factor solution was most fitting. All but one item showed factor loadings and communalities above the recommended values of .7 and .5. respectively (Hair, Black, Babin, Anderson, \& Tatham, 2006). Since the item "In my service to society I should balance short-term personal goals with long-term environmental goals" was judged to have good content validity and its factor loading of .67 and communality of .45 were close to the recommended values we decided to retain it in the scale. The 10-item scale showed good reliability with a Cronbach's Alpha of .93. Overall the results show that our new measure of consumer environmental stewardship is well represented by one factor consisting of ten items. More detailed information about individual items can be found in Table C1.

Table C1: Results Exploratory Factor Analysis Pre-Study 1

\begin{tabular}{lcc}
\hline Item & Communalities & $\begin{array}{c}\text { Factor } \\
\text { Loading }\end{array}$ \\
\hline I feel a personal sense of responsibility for the environment. & .68 \\
I feel accountable for the environmental impact of my purchases. & .77 \\
I think it is inappropriate, for me as a single person, to buy products without & .50 & .74 \\
considering the environmental impact of them. & .51 & .71 \\
When searching for a product I should seek a balance between its costs and & .76 \\
its impact on the environment. & .59 \\
$\begin{array}{l}\text { I am willing to make personal sacrifices for the good of the environment. } \\
\text { I carry responsibility for the environmental impact of my purchases on }\end{array}$ & .55 \\
society. & .74 \\
I need to help maintaining a green environment for society. & .63 \\
$\begin{array}{l}\text { In my service to society I should balance short-term personal goals with } \\
\text { long-term environmental goals. }\end{array}$ & .45 & .79 \\
I feel responsible for the environmental impact of my purchases on future & .67 \\
generations. & .63 & .79 \\
I need to help maintaining a green environment for future generations. & .64 & .80 \\
\hline
\end{tabular}

\section{Pre-Study 2: Additional Evidence of Scale Validity}

As a next step we assessed the construct validity of our newly developed construct by conducting a confirmatory factor analysis (CFA) while accounting for two con- 
structs that have previously been used to explain pro-environmental consumer behaviors: 1) perceived consumer efficacy (PCE); and 2) environmental concern (EC). PCE represents an individual's belief that (s)he can have a positive effect on the environment by altering her/his personal behavior (Do Paço et al., 2013; Moisander, 2007; Webster Jr, 1975), while EC represents a person's general belief about nature's vulnerability to human interference (Dunlap \& Jones, 2002; Poortinga, Steg, \& Vlek, 2004).

\section{Sample and Procedure}

The sample used for this second pre-study consisted of 225 undergraduate students who participated in a lab session in exchange for partial course credit. Fiftythree percent of the participants were women (120), and the average age of participants was $22.80(\mathrm{SD}=2.36)$. During the session respondents were presented with an online questionnaire in which they were assured that their data would be treated confidentially before they were asked to answer questions about the three focal constructs. CENS was measured by use of our previously developed 10-item scale, while PCE was measured by use of a 4-item scale adapted from Roberts (1996). To measure EC we adopted 4 items that were previously used by Kim and Choi (2005) and represent a short version of the often used NEP scale (Dunlap \& Van Liere, 1978; Dunlap et al., 2000). For all scales respondents were asked to indicate to what extent they agreed with each item on a 7-point scale ranging from "strongly disagree" (1) to "strongly agree" (7).

\section{Results and Discussion}

We assessed the measurement properties of the focal constructs by conducting a CFA in LISREL 8.80 (Jöreskog \& Sörbom, 2006). Our analysis reveals an adequate fit to the data: $\left(\chi^{2}(132)=291.730, p<.001\right), \mathrm{CFI}=.97, \mathrm{NNFI}=.97$, RMSEA $=.078$, and SRMR $=.060$ ). To evaluate the convergent validity of the used measures, we assessed whether the manifest variables loaded significantly and adequately in magnitude on the hypothesized latent variable (Anderson \& Gerbing, 1988). All observed standardized loadings were significant at $\alpha=.05$. Additionally, we calculated the composite reliability (CR) and average variance extracted (AVE) for all three measures. Our findings show that the CRs exceed the recommended cut-off value of .7 and the AVEs exceed the recommended cut-off value of .5 (environmental stewardship [CR = .91; AVE = .51], PCE [CR = .79; AVE = .50], EC [CR = .80; AVE $=.50]$ ) (Fornell \& Larcker, 1981). Furthermore, our analyses showed that environmental stewardship correlated significantly with both PCE $(\mathrm{r}=.70, \mathrm{p}<.01)$, and $\mathrm{EC}(\mathrm{r}=.66, \mathrm{p}<.01)$, while PCE and EC also correlated significantly $(\mathrm{r}=.56, \mathrm{p}<.01)$. All in all, these findings provide support that our measure of environmental stewardship shows convergent validity. Finally, we assessed discriminant validity by 


\section{APPENDIX}

comparing the square root of the AVE with the (attenuated) correlation between the latent variables that represent environmental stewardship, PCE, and EC (Fornell \& Larcker, 1981). The square root of the AVE of all three latent variables exceeded the (attenuated) correlation between any of them, which indicates discriminant validity. The choice to retain the item "In my service to society I should balance short-term personal goals with long-term environmental goals" in prestudy 1 seems justified as the CFA showed a factor loading that is average compared to other items of the CENS scale. Concluding, the results of our second prestudy show additional evidence for the validity of our CENS scale. More detailed information about individual items can be found in Table C2.

Table C2: Results Confirmatory Factor Analysis Pre-study 2

\begin{tabular}{|c|c|}
\hline Item & St. Loading \\
\hline \multicolumn{2}{|l|}{ Environmental Stewardship } \\
\hline I feel a personal sense of responsibility for the environment. & .72 \\
\hline I feel accountable for the environmental impact of my purchases. & .72 \\
\hline $\begin{array}{l}\text { I think it is inappropriate, for me as a single person, to buy products without } \\
\text { considering the environmental impact of them. }\end{array}$ & .63 \\
\hline $\begin{array}{l}\text { When searching for a product I should seek a balance between its costs and its } \\
\text { impact on the environment. }\end{array}$ & .67 \\
\hline I am willing to make personal sacrifices for the good of the environment. & .68 \\
\hline I carry responsibility for the environmental impact of my purchases on society. & .68 \\
\hline I need to help maintaining a green environment for society. & .77 \\
\hline $\begin{array}{l}\text { In my service to society I should balance short-term personal goals with long-term } \\
\text { environmental goals. }\end{array}$ & .69 \\
\hline $\begin{array}{l}\text { I feel responsible for the environmental impact of my purchases on future } \\
\text { generations. }\end{array}$ & .76 \\
\hline I need to help maintaining a green environment for future generations. & .77 \\
\hline \multicolumn{2}{|l|}{ Perceived Consumer Efficacy } \\
\hline It is worthless for the individual consumer to do anything about pollution. ${ }^{a}$ & .73 \\
\hline $\begin{array}{l}\text { Since one person cannot have any effect upon natural resource problems it does not } \\
\text { make any difference what I do. }\end{array}$ & .82 \\
\hline $\begin{array}{l}\text { Each consumer's behavior can have a positive effect on society by purchasing } \\
\text { products sold by socially responsible companies. }\end{array}$ & .50 \\
\hline Even as a single person one can have an effect on pollution. & .73 \\
\hline \multicolumn{2}{|l|}{ Environmental Concern } \\
\hline $\begin{array}{l}\text { I am extremely worried about the state of the world's environment and what it will } \\
\text { mean for my future. }\end{array}$ & .73 \\
\hline Mankind is severely abusing the environment. & .72 \\
\hline When humans interfere with nature it often produces disastrous consequences. & .68 \\
\hline The balance of nature is very delicate and easily upset. & .70 \\
\hline
\end{tabular}

a Items were reversely scored before analyses because they are negatively framed. 
Valorization Addendum 
In this valorization addendum we reflect on the added value of this dissertation to society and business with a focus on the opportunities to use our findings in practice. First, we discuss the societal and economic relevance of our research by describing in which ways it is innovative compared to prior research. Second, we suggest activities and processes that can be developed and implemented in practice on the basis of our findings while focusing on potential benefits to nonacademic audiences.

\section{Societal and Economic Relevance}

As mentioned at the start of this dissertation, environmental problems have become a major concern across the globe in the last couple of decades, as they are seen to be one of the biggest threats to the achievement of sustainability. When talking about the achievement of sustainability researchers and practitioners often refer to three dimensions that need to be taken into account: society, economy and the natural environment (Peattie, 2001). The developments of these three dimensions are interlinked. As humanity started to explore and exploit the uses of different natural resources economic growth was established, which in turn allowed for societal development such as improvements in health care and education. of course societal developments such as higher levels of education help to stimulate economic development, which combined allow for innovation that can be used to prevent environmental damage. However, as societies and economies across the world are developing at a fast pace, the burden that is placed on the natural environment is growing. Many natural resources are used at a speed that will ensure that they are gone within a century while the global climate is being threatened by the increasing levels of consumption (UNEP, 2012). Predictions are that current levels of innovation will not be able to compensate for these effects and that the depletion of natural resources and changes in climate will cause more inequality between groups of people around the globe as a result of local shortages of resources and natural catastrophes (UNEP, 2012). Next to these societal effects economic development is likely to be hampered. Current consumption levels are not sustainable, so if we want to allow future generations to be able to meet their needs, we need to be more careful in how we try to meet our needs in the present.

Since marketing as a practice and science is focused on meeting people's needs and largely impacts consumption levels, we pose that marketing is the field of research that can make a difference in the achievement of sustainability goals. Famous marketing scholars such as Michael Porter and Philip Kotler have made a start by emphasizing the importance of adapting marketing practices and research to match environmental developments (e.g., Kotler, 2011; Porter \& Kramer, 2006). Both stress the need to stop pitting business objectives against environmental protection, and instead focus on opportunities that benefit business and the envi- 
ronment alike. Although these renown marketing scholars spread their message more marketing research is needed that identifies opportunities to stimulate environmental responsibility among consumers and companies, and helps to change the belief that environmental protection necessarily coincides with economic costs. In this dissertation we present two studies that try to contribute to this cause.

In our first study, we demonstrate that retailers can stimulate their employees to take more responsibility for achieving environmental goals and that this can simultaneously result in environmental benefits (in the shape of sales of green products) as well as economic benefits (in the shape of higher margins). While previous research on green retailing mainly focused on greening internal and supply side processes such as procurement, product and store design, transportation and internal energy use (Lai, Cheng, \& Tang, 2010), our research takes a customer oriented perspective and adds value by examining the role of sales associates in the achievement of environmental goals. Although limiting the environmental impact of internal and supply side retail processes is important, we pose that retailers should focus more of their pro-environmental initiatives on influencing consumer choice as the environmental impact of many retailers mainly resides in the "use phase" of products sold (Prindle, 2010). It is therefore relevant to better understand how a sales associate can be motivated to promote products with a lower environmental impact to consumers, especially for products such as household appliances that account for the vast majority of consumer electricity use and have a long-term environmental impact (Mills \& Schleich, 2010). Our first study provides valuable insights on this topic.

In our second study we focus on stimulating environmental responsibility among consumers. More specifically, we examine how marketing communication messages that aim to increase the relevance of environmental protection can be used to stimulate consumers' sense of environmental responsibility and in turn their pro-environmental behavior. Whereas previous research showed that increasing the relevance of environmental protection through the stimulation of an affinity with future generations can trigger people to make more environmentally friendly choices (Wade-Benzoni, 2008), our research shows that this will only work under certain conditions. If consumers believe that they have no or little influence on the state of the environment through their own behavior (perceived consumer efficacy is low), stimulating affinity can backfire and result in lower levels of environmental responsibility. Our study adds value by showing the limitations of previously suggested approaches to stimulate environmental responsibility, so that they can be optimized. Additionally, our study introduces a stimulus to raise consumer's affinity with future generations by making them think of their own children/grandchildren, that can be used in marketing communications. Our stimulus is shown to work among members of the general public, making it more useful compared to stimuli only tested in student samples. 


\section{Optimization of pro-environmental activities and processes}

In this paragraph we make some concrete suggestions for activities and processes that can be implemented to help optimize the effectiveness and efficiency of proenvironmental initiatives. We discuss activities and processes that can increase pro-environmental behaviors that are relevant for non-academic audiences such as (inter)governmental, commercial and non-profit organizations.

Our findings presented in chapter 2 mainly hold implications for marketing practice and especially for retailers. However, our findings also have value for (inter)governmental organizations (e.g., the European Commission), that want to optimize the impact of subsidies or regulations they implement to support environmental initiatives and performance by retailers. Given the finding that store managers play a central role in improving a retailer's environmental performance, we propose that retailers should emphasize their importance by assigning the role of environmental champions to store managers and making them responsible for the dissemination of environmental practices among sales associates. To make sure that store managers can successfully fulfill this role, retailers should instigate environmental awareness and training programs that are tailored to store managers' specific needs. Since our findings show that store managers serve as role models they need to walk the talk and do so consistently. Therefore, tailor-made programs should be developed that do not only provide information about relevant environmental practices, but additionally help them to understand and change their own action patterns. Our script-based approach, that is available in Appendix $\mathrm{B}$, can be altered to serve as a customized training module that helps store managers to identify discrepancies between their actual and desired behaviors, and thereby optimize a retailer's environmental performance. Retailers could further support such an approach by using environmentally successful store managers as trainers of their colleagues. Alternatively, the described education programs for store managers could also be used to transfer knowledge to channel partners or within non-retail organizations that want to foster environmental responsibility. Governmental organizations could support such initiatives by providing subsidies or training materials.

The findings presented in chapter 3 can be used to optimize the efficiency and effectiveness of marketing communications aimed to increase consumers' proenvironmental behaviors. The presented tactics can be useful for (inter)governmental and non-profit organizations that want to promote pro-environmental consumer behaviors in general or for commercial and non-profit organizations that want to promote specific pro-environmental offerings to consumers. Our findings show that consumers' affinity with future generations, which can be stimulated (at least for a short while) through marketing communications that make consumers think of their own children or grandchildren, can help to raise their levels of environmental stewardship and indirectly pro-environmental behaviors. This 
works best if consumers simultaneously perceive they can have a positive impact on the environment (high efficacy). We present this finding with a warning caveat because a message that stimulates affinity can backfire if consumers show lower levels of efficacy. In such situations raising affinity can actually reduce consumers' environmental responsibility. These results demonstrate that the effectiveness of current marketing communications aimed at increasing affinity, such as the use of the slogan "geef de aarde door" by the Dutch branch of the WWF are affected by consumers' levels of efficacy. In general we suggest that organizations that use or want to use affinity oriented communications to promote pro-environmental behaviors or products should 1) not target consumer groups that are known to show lower levels of PCE, 2) should only use them in surroundings where they are unlikely to be accompanied by messages that stimulate low levels of efficacy (e.g., not use them on channels that report news about environmental issues in business), or 3 ) best of all should integrate an efficacy raising stimulus in their marketing communications. Whereas we asked consumers to write a story about their own (grand)children to stimulate affinity, some practical examples to raise affinity have been developed and used in the meantime by companies like IKEA and Unilever (IKEA, 2013; Unilever, 2013). We propose that organizations that want to use affinity oriented marketing communications look at both examples since they have the ingredients to be very effective. Both companies have created commercials that simultaneously trigger your affinity with future generations and show how the company provides you with the opportunity to make a difference, so raising your efficacy. When developing their own affinity oriented commercials, organizations can use the scale that we developed to test and optimize their effectiveness.

In this valorization addendum we have provided a brief overview of some activities and processes that can help to optimize the effectiveness and efficiency of pro-environmental initiatives by (inter)governmental, commercial and non-profit organizations. For the interested reader more detailed information about the practical and managerial implications of our research is available in paragraphs 2.6.2, 3.8.1 and 4.5 of this dissertation. Furthermore, we strive to share our findings with marketing practitioners through outlets such as the Dutch Center for Information Based Decision Making \& Marketing Research (MOA). 



\section{Summary}

Making Sense of Environmental Responsibility

Investigating Environmental Stewardship

among Retail Employees and Consumers 
In the past decades environmental problems such as pollution, resource depletion and global warming have become a major concern across the globe. One of the key causes of these problems is the fact that humanity consumes more resources than the earth's regenerative capacity can handle. Therefore current consumption patterns will have to change. This is not easy as pro-environmental behavior often come at a cost of immediate self-interests, whereas associated benefits mainly serve long-term collective interests. Marketing research can play a valuable role by exploring effective ways to help people overcome such barriers and promote environmental responsibility. In this dissertation we contribute through two studies in which we examine how the stimulation of a personal sense of responsibility for the environment and its beneficiaries (i.e., environmental stewardship), can be used to encourage pro-environmental action among retail personnel and consumers.

The results of our first study show how retailers can stimulate a stronger sense of environmental responsibility among their sales associates, which in turn motivates them to promote products with a lower environmental impact to consumers. Our research shows that store managers who prioritize pro-environmental goals over competing goals and those who use transformational leadership practices, create higher levels of environmental stewardship among their sales associates. For sales associates who have longer working relationships with their store managers this effect is even stronger. However, environmental stewardship is lower among sales associates who are lead by store managers who vary in their prioritization of environmental and other goals over different situations. Those sales associates who experience higher levels of environmental stewardship achieve higher margins and sell more green products, but sell less regular products. Overall, our findings show that retailers can effectively support the environmental cause by instigating environmental initiatives aimed at operational managers as they in turn inspire frontline employees to work towards environmental goals.

In our second study we show how marketing communication messages that aim to increase the relevance of environmental protection can be used to stimulate consumers' environmental responsibility and in turn their pro-environmental behavior. Whereas previous research showed that increasing the relevance of environmental protection through the stimulation of an affinity with future generations can trigger people to make more pro-environmental choices, our research shows that this will only work under certain conditions. If consumers believe that they have no or little influence on the state of the environment through their own behavior (perceived consumer efficacy is low), stimulating affinity can backfire and result in lower levels of environmental stewardship. This has negative effects as consumers with lower levels of environmental stewardship are less likely to act in pro-environmental ways. Overall, our findings show that marketing communications aimed at stimulating an affinity with future generations can effectively support the environmental cause as long as it simultaneously raises consumers' feelings of efficacy. 
Concluding, our empirical studies show that stimulating a sense of responsibility for the environment and its beneficiaries (i.e., environmental stewardship), in a retail and a consumer context, can help to achieve more environmentally friendly consumption patterns. 



\section{Samenvatting}

Verantwoordelijkheid voor het Milieu Begrijpelijk Maken

Onderzoek naar Milieurentmeesterschap onder

Retailpersoneel en Consumenten 
In de afgelopen decennia zijn de zorgen over milieuproblemen zoals vervuiling, de uitputting van natuurlijke bronnen en de opwarming van de aarde drastisch toegenomen. Een van de belangrijkste achterliggende oorzaken is dat de mensheid momenteel meer consumeert dan de aarde aankan. Huidige consumptiepatronen zullen daarom aangepast moeten worden. Dit is niet eenvoudig aangezien er aan milieuvriendelijk gedrag op de korte termijn vaak persoonlijke nadelen kleven, terwijl de voordelen vooral ten goede komen aan het collectief op de lange termijn. Onderzoek op het gebied van marketing kan een belangrijke rol spelen bij het vinden van effectieve manieren om mensen te helpen dergelijke obstakels te overwinnen en de verantwoordelijkheid voor het milieu te vergroten. In dit proefschrift leveren we een bijdrage door in twee studies uit te zoeken hoe het stimuleren van een persoonlijk gevoel van verantwoordelijkheid voor het milieu en degenen die er afhankelijk van zijn (i.e. milieurentmeesterschap), gebruikt kan worden om milieuvriendelijk gedrag te bevorderen onder retailpersoneel en consumenten.

De resultaten van onze eerste studie tonen hoe retailers onder hun verkopers een sterker verantwoordelijkheidsgevoel voor het milieu kunnen creëren en hoe dat hen motiveert om o.a. milieuvriendelijkere producten aan klanten aan te bevelen. Het onderzoek laat zien dat filiaalmanagers die een hogere prioriteit geven aan milieudoelen ten opzichte van concurrerende doelen en managers die transformationele leiderschapspraktijken gebruiken, een hogere mate van milieurentmeesterschap onder hun verkopers creëren. Voor verkopers die langer met hun manager samenwerken is dit effect zelfs sterker. Daar staat tegenover dat milieurentmeesterschap lager is onder verkopers die aangestuurd worden door filiaalmanagers die tussen verschillende situaties een sterke variatie laten zien in hun prioriteit voor milieu- ten opzichte van concurrerende doelen. Verkopers die een hogere mate van milieurentmeesterschap ervaren, behalen hogere marges en verkopen meer milieuvriendelijke producten, maar ze verkopen minder reguliere producten. Retailers kunnen effectief bijdragen aan een beter milieu door milieu-initiatieven te richten op filiaalmanagers aangezien zij verkopers stimuleren om op hun beurt aan milieudoelen te werken.

In onze tweede studie tonen we hoe marketingcommunicatie, gericht op het vergroten van de relevantie van milieubescherming, gebruikt kan worden om milieurentmeesterschap en daarmee indirect ook milieuvriendelijk gedrag onder consumenten te stimuleren. Waar eerder onderzoek heeft aangetoond dat het vergroten van de relevantie van milieubescherming, door middel van het stimuleren van een gevoel van affiniteit met toekomstige generaties, mensen aan kan zetten om milieuvriendelijke keuzes te maken, laat ons onderzoek zien dat dit alleen werkt onder bepaalde omstandigheden. Als consumenten het idee hebben dat ze via hun eigen gedrag geen of weinig invloed op de staat van het milieu kunnen uitoefenen, kan het stimuleren van affiniteit averechts werken en resulteren in een lagere mate van milieurentmeesterschap. Dit heeft negatieve consequenties aangezien mensen die een lagere mate van milieurentmeesterschap ervaren minder geneigd 
zijn om milieuvriendelijk te handelen. Onze bevindingen tonen dat marketing communicatie die gericht is op het vergroten van de affiniteit met toekomstige generaties effectief kan bijdragen aan milieuvriendelijker gedrag zolang de boodschap ook bijdraagt aan het gevoel dat een individuele consument een verschil kan maken.

Concluderend tonen onze empirische studies dat het stimuleren van een sterker verantwoordelijkheidsgevoel met betrekking tot het milieu en degenen die er afhankelijk van zijn (een hogere mate van milieurentmeesterschap), zowel in een retail- als consumentencontext, bij kan dragen aan milieuvriendelijkere consumptiepatronen. 

Dankwoord 
Toen ik begon met het schrijven van dit proefschrift dacht ik dat het vooral een reis zou worden op zoek naar meer kennis. Nu het proefschrift af is, zie ik een nog grotere winst in de ervaringen en vaardigheden die ik in deze periode heb opgedaan. Ik wil dan ook iedereen bedanken die hieraan heeft bijgedragen.

Allereerst wil ik mijn promotoren Prof. dr. Ko de Ruyter en Prof. dr. Martin Wetzels bedanken voor het in mij gestelde vertrouwen en de mogelijkheid om te promoveren op een voor mij belangrijk en interessant onderwerp. Ko, ik wil je bedanken voor je begeleiding en je eindeloze stroom aan ideeën om ons onderzoek te verbeteren. Je hebt mij wegwijs gemaakt in de kunst van het academisch schrijven en veel geleerd over het positioneren van papers en duidelijk uitdrukken van standpunten. Je commentaar en inzichten hebben enorm geholpen mijn stukken en schrijfstijl te verbeteren. Martin, met jou als begeleider van mijn scriptie is het eigenlijk allemaal begonnen. Bij jou kon ik altijd terecht met mijn vragen over het verbeteren van onze onderzoeksmethodiek en statistische analyses. Je hebt mij telkens gemotiveerd om nieuwe en betere analysemethoden uit te proberen en mij geholpen deze onder de knie te krijgen. Daar pluk ik ook in mijn huidige baan nog steeds de vruchten van.

Additionally, I would like to express my gratitude to dr. Debbie Keeling. Debbie, it has been a pleasure working with you. From the moment you stepped in, your positive energy and can-do attitude have been a great help to overcome hurdles on the road and your feedback has largely contributed to improve our papers and this dissertation. Our cooperation has taught me that commitment and success do not require people to meet in person frequently, but can prosper based on skype and email conversations.

Verder wil ik Prof. dr. Ad de Jong bedanken voor de samenwerking. Ad, ik heb veel geleerd tijdens onze gesprekken over de theorie en methodes met betrekking tot multilevel analyse. Daarnaast hebben onze werksessies in Eindhoven en je snelle reacties op mijn vragen een grote bijdrage geleverd aan ons eerste paper, bedankt daarvoor.

I would also like to thank Prof. dr. Jos Lemmink, Prof. dr. Siggi Gudergan, Prof. dr. Paul Matthyssens en Prof. dr. Janjaap Semeijn for their willingness to be part of the assessment committee, taking the time to read and evaluate my dissertation and for their valuable comments.

Natuurlijk wil ik ook alle oud-collega's van het departement Marketing \& Supply Chain Management bedanken voor hun hulp bij vragen maar ook voor de gezellige tripjes en de Sinterklaasmiddagen. Lisa, Els, Gaby, Piet, Caroline, Kelly, Vera, Bram, Kathleen, Lieven, Simon, Evelyne en Dominik bedankt dat ik altijd bij jullie binnen kon lopen voor advies en voor de mogelijkheid mijn experimenten in jullie vakken te integreren. Verder heb ik veel geleerd van de sessies die jullie gegeven hebben binnen de PhD vakken en de samenwerking met jullie als blokcoördinatoren waarin ik als tutor actief was. Pascalle, Eefje en Nicole bedankt voor jullie ad- 
ministratieve hulp, bestellingen en het oplossen van tal van problemen, maar vooral voor jullie betrokkenheid en humor.

Mijn eerste kamergenoten, Marjolein, Anto en Mirjam, ik wil jullie bedanken voor het warme welkom en het delen van ervaringen en adviezen over hoe dingen het beste aan te pakken. Later kwamen Iraz, Anne en Katja daarvoor in de plaats. We hebben gedurende onze tijd als promovendi zoveel samen gedeeld, intense vreugde, frustraties, verdrietige momenten en heel veel lol, zowel op als buiten het werk. We zijn heel goede vrienden geworden en ook al zien we elkaar niet zo heel vaak, ik weet dat jullie er zijn als het nodig is. Anne en Katja, bedankt dat jullie mijn paranimfen wilden zijn. Liz you were the last to join the office while I was there and I admire you for your optimism and positive energy, thanks for lending me some, when I was in need of it.

Naast mijn kamergenoten waren er natuurlijk ook nog al die andere promovendi binnen ons departement en daarbuiten om even mee te sparren, vakken te volgen, $\mathrm{PhD}$ tripjes mee te maken en experimenten uit te voeren. Bedankt voor de mooie tijd samen. Jacqueline, ik heb altijd erg genoten van onze gezamenlijke treinreizen en je adviezen hebben me heel erg geholpen.

Ik wil mijn huidige collega's bij Epiphany ook heel erg bedanken voor hun betrokkenheid. Het is niet eenvoudig een proefschrift af te schrijven naast een veeleisende baan, maar jullie hebben mij ondersteund om dat doel toch te bereiken. Jan en Rachel, jullie wil ik speciaal bedanken voor het in mij gestelde vertrouwen en jullie hulp om (beter) te leren plannen, dingen af te maken, te accepteren dat het nooit perfect zal worden en te relativeren. Mede dankzij jullie hulp is dit boek nu echt af.

Verder wil ik ook mijn familie en vrienden bedanken voor hun steun, aanmoedigingen en geduld. Ik heb me de afgelopen jaren heel vaak beroepen op het excuus, "sorry, ik kan niet afspreken want ik moet aan mijn proefschrift werken, het is bijna af". Dat het daadwerkelijk zo ver is gekomen heb ik mede aan jullie te danken, ik ben heel erg dankbaar dat ik zo'n loyale en betrokken familie en vriendengroep om me heen heb. Jullie zijn de "stewards" in mijn leven, degenen die altijd klaar staan en offers maken om mij te helpen mijn doelen te bereiken. Ik ga ervan uit dat ik jullie de komende tijd weer meer ga zien en kijk daar al heel erg naar uit.

Tom, Tom en Tom, jullie wil ik persoonlijk bedanken voor jullie bijdrage aan dit proefschrift. Naast jullie steun hebben jullie me ieder op een eigen manier geholpen. Tom als vriend en collega was je er altijd om even binnen te lopen en te sparren over mijn papers en experimenten, bedankt voor je advies. Tom, met je kennis over computers en software heb je mede gezorgd dat ik de dataverzameling voor mijn eerste paper efficiënt uit kon voeren. En Tom, jij was altijd beschikbaar als ik iets perfect wilde hebben in de Engelse taal.

Mamma, dankjewel voor je steun als ik het even niet zag zitten. Je "nog even volhouden, het is bijna klaar" heeft me erg geholpen, zoals je me altijd geholpen hebt om te geloven in mezelf. Jij en pappa hebben me altijd voorgehouden dat een 


\section{DANKWOORD}

goede opleiding belangrijk is, zonder me te pushen of te sturen richting altijd maar hoger en beter en meer. Toch ben ik daar naar blijven streven en ik ben bang dat dat niet meer weg gaat. Oma bedankt voor alle goede zorgen, de kaarsjes en het voorbeeld dat doorzetten loont. Simone, bedankt voor je steun, je relativeringsvermogen heeft me erg geholpen vol te blijven houden. Monika en Enghard, bedankt voor jullie betrokkenheid en interesse in alles wat Julia en ik doen. Daarnaast wil ik jullie ook bedanken voor jullie ideeën, hulp en flexibiliteit bij het maken van tekeningen voor de kaft.

Ten slotte wil ik jou bedanken Julia. Jij bent degene die mij als geen ander begrijpt en kan aanzetten boven mezelf uit te stijgen. Zonder jouw liefde, toewijding en geduld was het mij niet gelukt dit proefschrift tot een goed einde te brengen. Dat we met zijn tweeën gelijktijdig aan dezelfde uitdaging bezig waren heeft ons soms in de weg gezeten, vaak geholpen maar in ieder geval ook nog dichter bij elkaar gebracht. Jij bent de "Catalyst" in mijn leven en het volgende avontuur samen lonkt alweer. Ik kijk al uit naar het leven na twee proefschriften, maar nu vooral ook naar dat eerste vrije weekend samen na de verdediging. 


\section{Curriculum Vitae}

Niek Hensen was born March 24th 1983 in Maastricht, the Netherlands. From 1995 Niek attended secondary school at Stella Maris College in Meerssen, the Netherlands, where he graduated in 2001. In that same year he started his studies in Business Economics at Maastricht University. During his studies he specialized in marketing and market research and spent four months on an exchange program at Århus School of Business in Denmark. In 2006, he completed his studies with a Master of Science degree in Economics, after which he was offered a position as a $\mathrm{PhD}$ candidate at the Department of Marketing \& Supply Chain Management of Maastricht University.

In 2007, Niek started his work on this dissertation with a focus on the promotion of pro-environmental behaviors among retail employees and consumers through the stimulation of Environmental Stewardship. In his studies he made use of survey research as well as experimental designs and applied multiple statistical analyses techniques. In the meantime he taught courses at the Bachelor and Master level on various topics such as Market Research, Brand Management and Return on Marketing.

In 2012, Niek transferred to working in marketing practice and accepted a position as a consultant at Epiphany Research Based Consultancy in Amsterdam, where he is currently employed. At Epiphany RBC he has conducted multiple international market research studies with a focus on branding, concept testing and customer segmentation. 


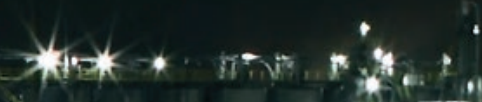

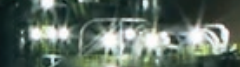

क 10.6 है

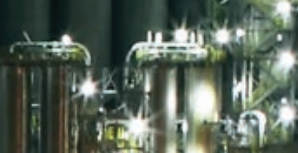

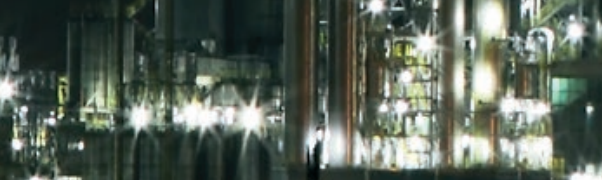

* intin

* $1, \pm$

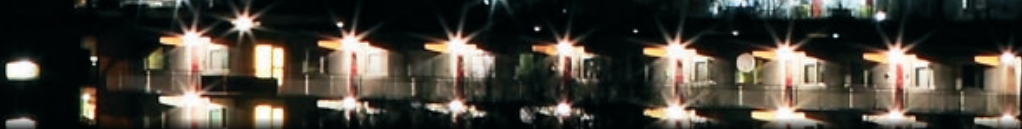

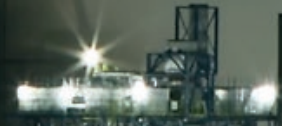

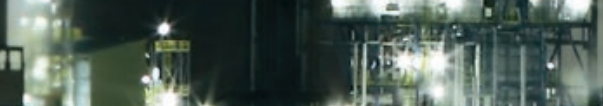

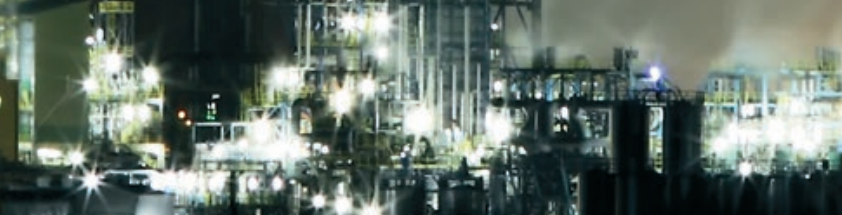

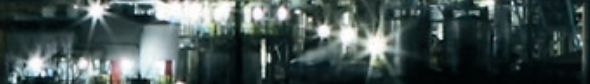

- trima mondo
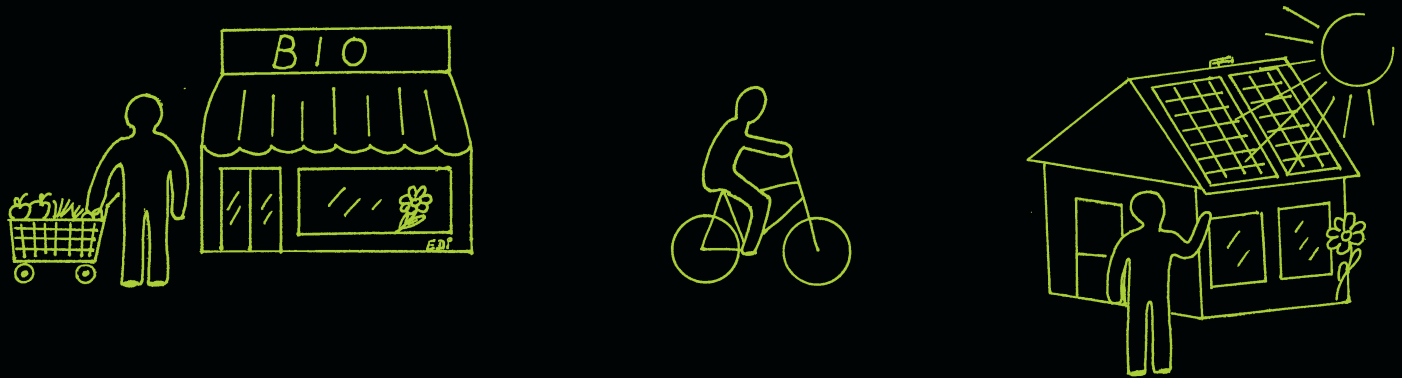